\title{
Cobalt-Catalyzed Hydrosilylation/Cyclization of 1,6-Enynes
}

Tuo Xi and Zhan Lu*

Department of Chemistry, Zhejiang University, 866 Yuhangtang Road, Hangzhou 310058, China

$\begin{array}{ll}\text { I. ORTEP representation of IP. } \mathrm{CoCl}_{2} & \text { S1 }\end{array}$

$\begin{array}{lr}\text { II. NMR Spectra } & \text { S3 }\end{array}$

I. ORTEP representation of IP' $\mathrm{CoCl}_{2}$

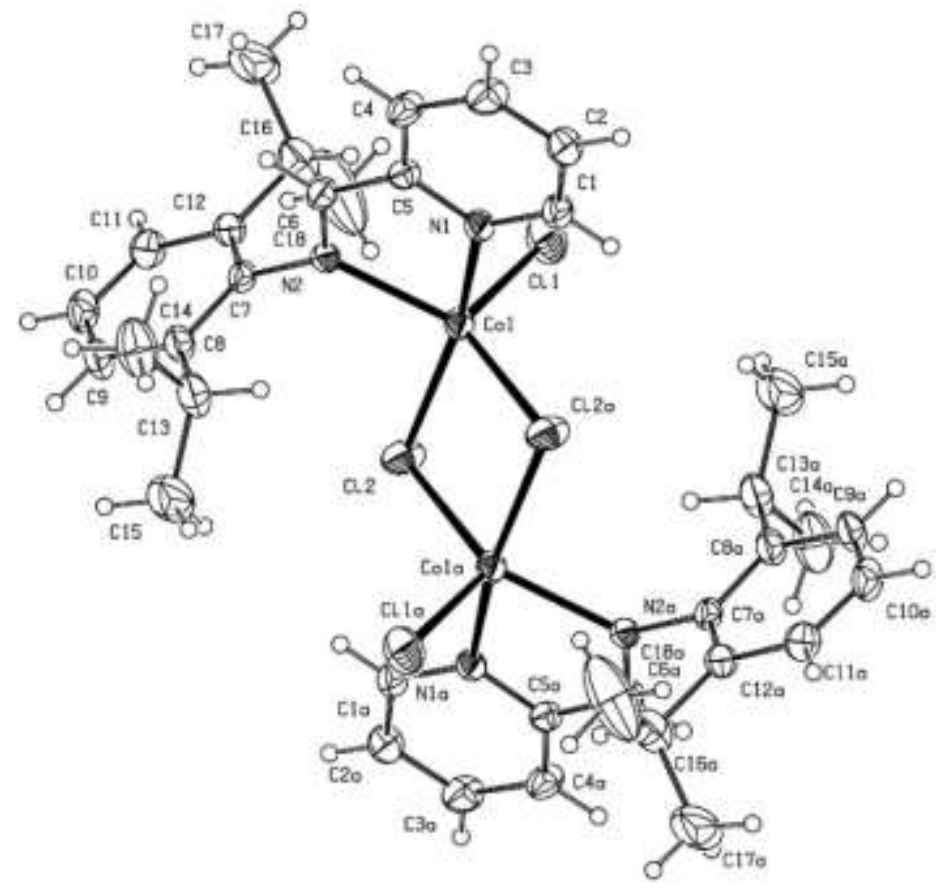

Displacement ellipsoids are drawn at the 50\% probability level.

Selected Bond Length for Complex IP-CoCl $\mathbf{2}$

\begin{tabular}{|l|l|}
\hline Selected Bond Length & Distance $(\AA)$ \\
\hline Co1-Cl1 & $2.2710(9)$ \\
\hline Co1-Cl2 & $2.4214(8)$ \\
\hline Co1-N1 & $2.109(2)$ \\
\hline Co1-N2 & $2.139(2)$ \\
\hline Co1-Cl2a & $2.3523(8)$ \\
\hline
\end{tabular}


Selected Bond Angles for Complex IP-CoCl $\mathbf{C}_{\mathbf{2}}$

\begin{tabular}{|l|l|}
\hline Selected Bond Angles & $(\mathrm{deg})$ \\
\hline Cl1-Co1-Cl2 & $107.87(4)$ \\
\hline C11-Co1-Cl2a & $114.74(4)$ \\
\hline Cl2-Co1-Cl2a & $85.27(3)$ \\
\hline N1-Co1-Cl1 & $93.04(6)$ \\
\hline N1-Co1-Cl2 & $87.07(6)$ \\
\hline N1-Co1-Cl2a & $159.05(6)$ \\
\hline N1-Co1-N2 & $76.85(8)$ \\
\hline N2-Co1-Cl1 & $107.82(6)$ \\
\hline N2-Co1-Cl2 & $95.08(6)$ \\
\hline N2-Co1-Cl2a & $135.10(6)$ \\
\hline Co1-Cl2-Co1 & $94.73(3)$ \\
\hline
\end{tabular}


II NMR Spectra
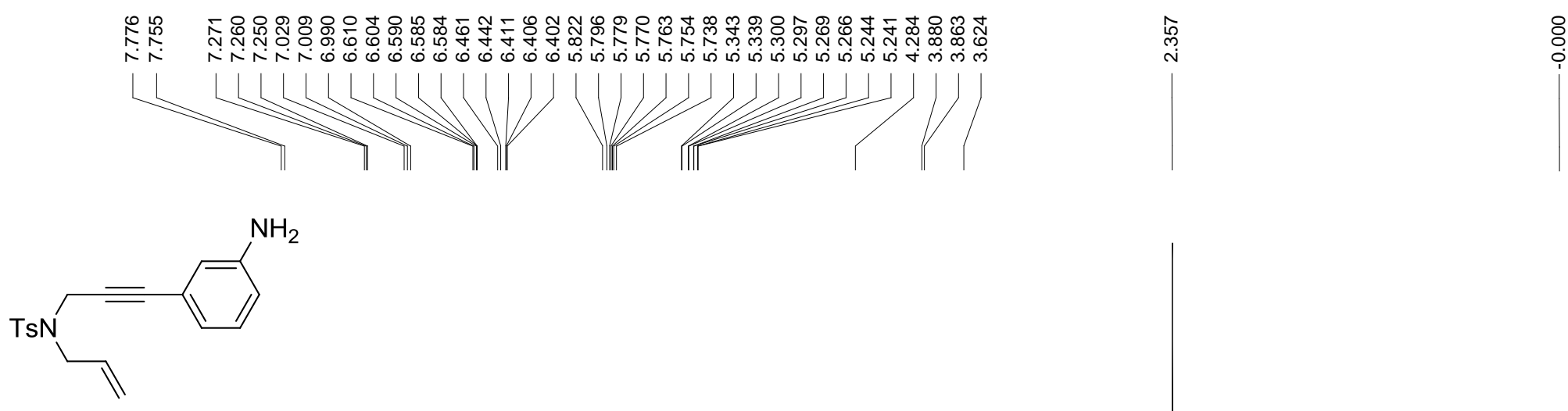

10 ${ }^{1} \mathrm{H}$ NMR $400 \mathrm{MHz}$

2.30

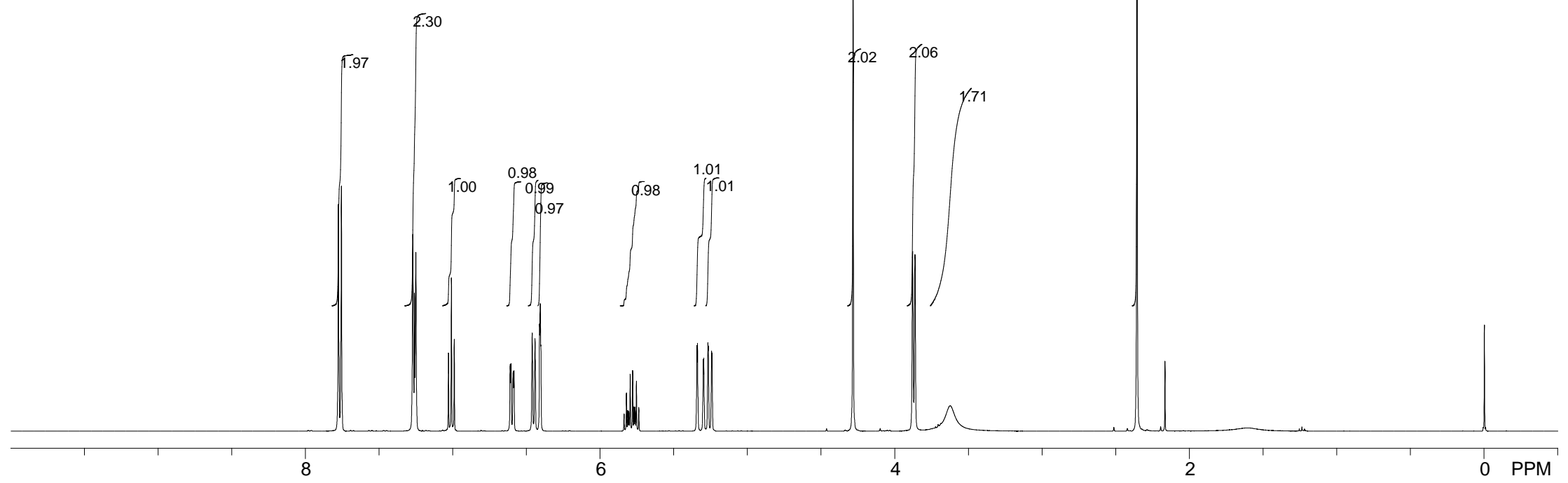




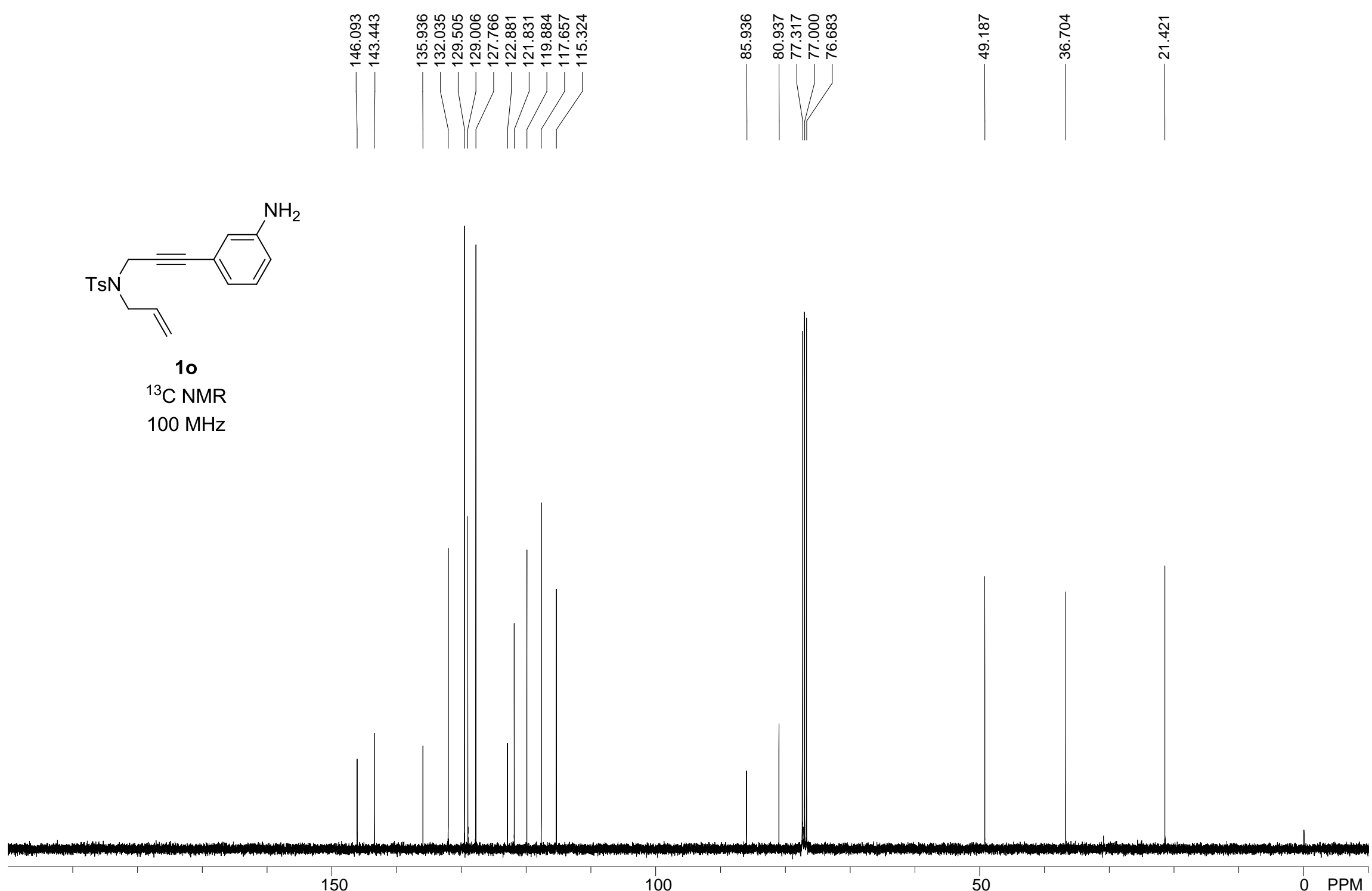




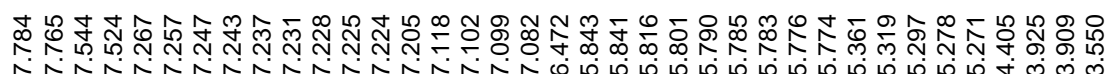

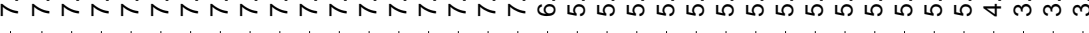

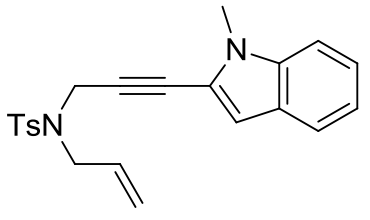

1r

${ }^{1} \mathrm{H}$ NMR

$400 \mathrm{MHz}$

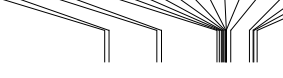

III III
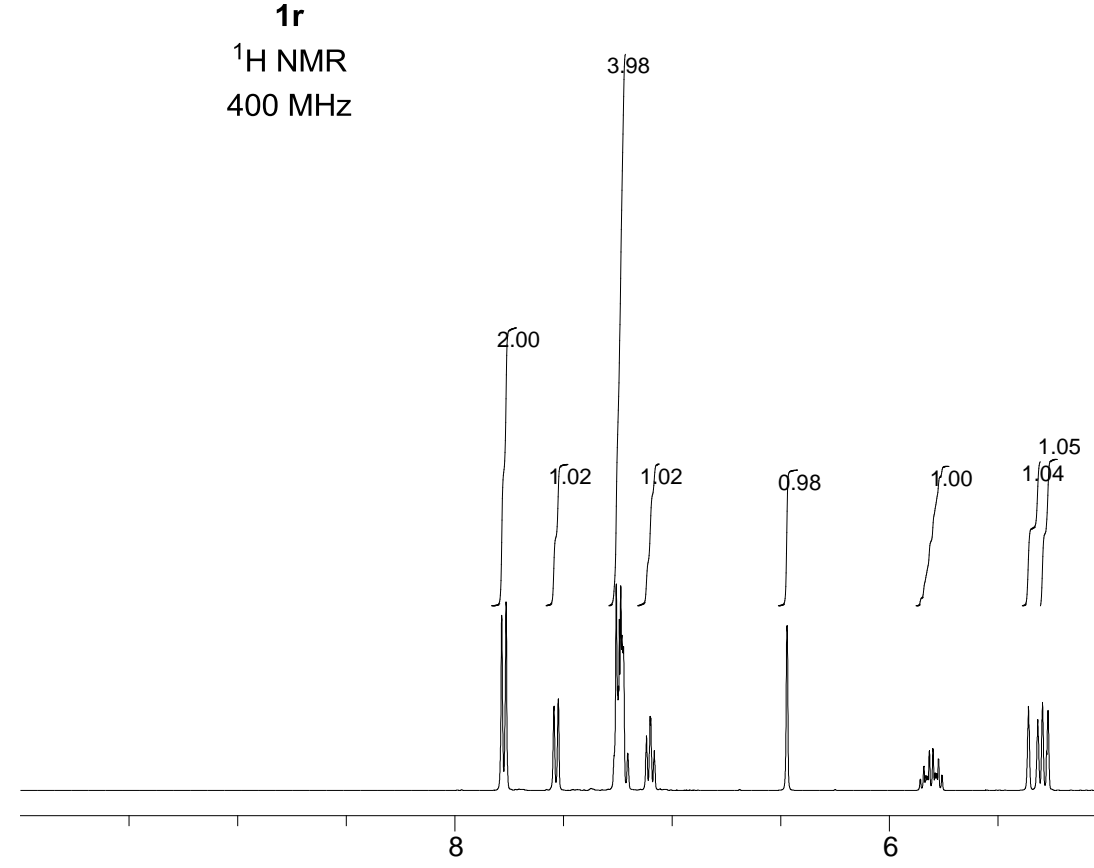

2.05

$3.03-3.05$ 

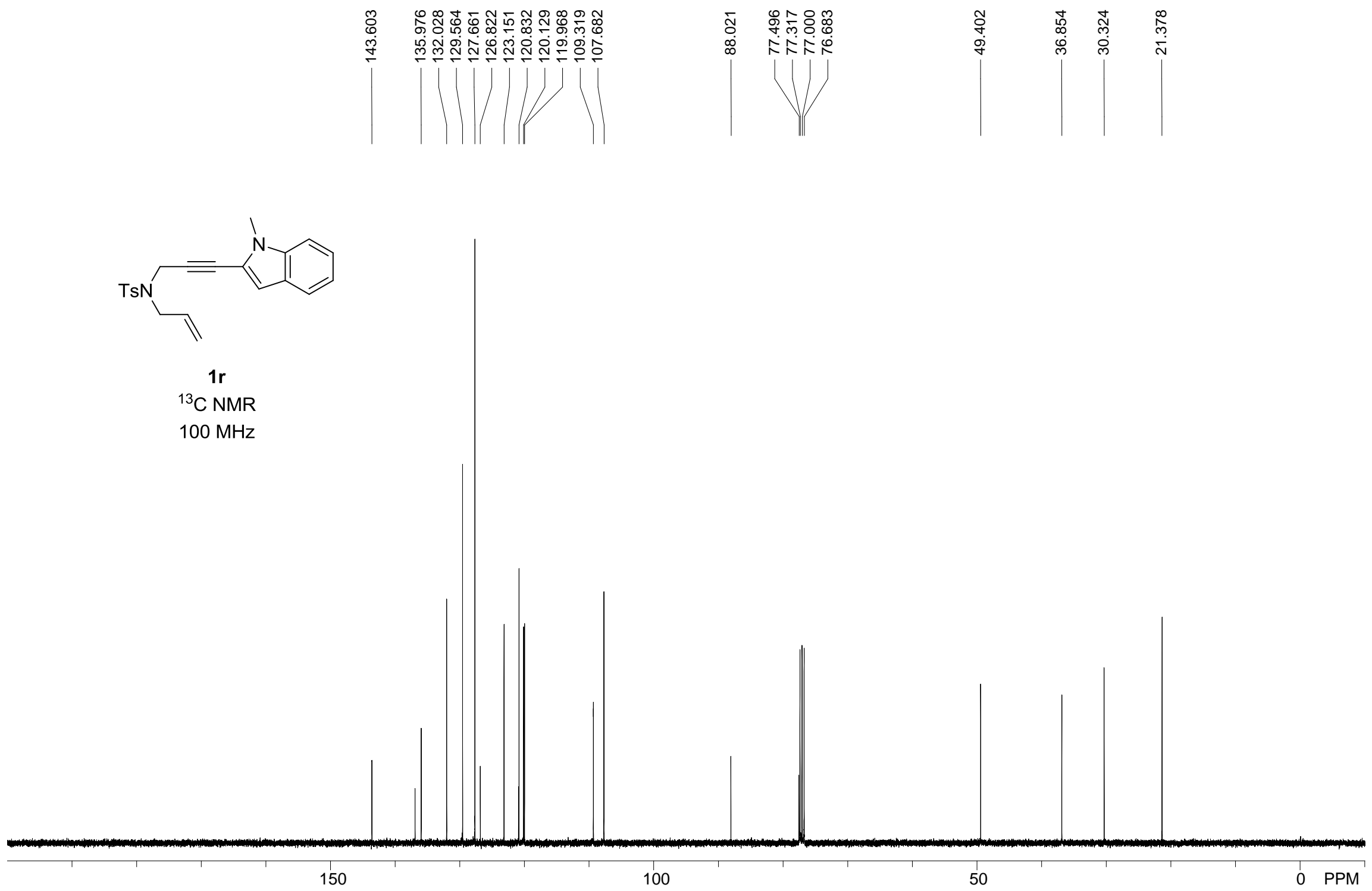

S6 


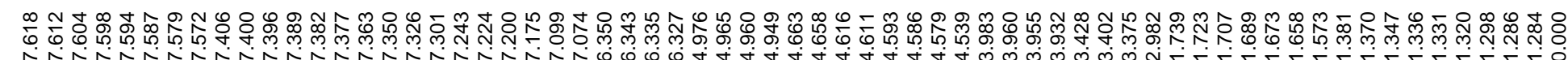

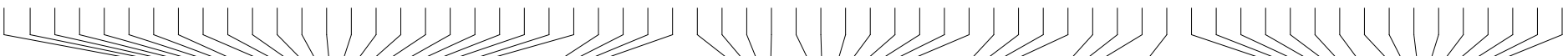
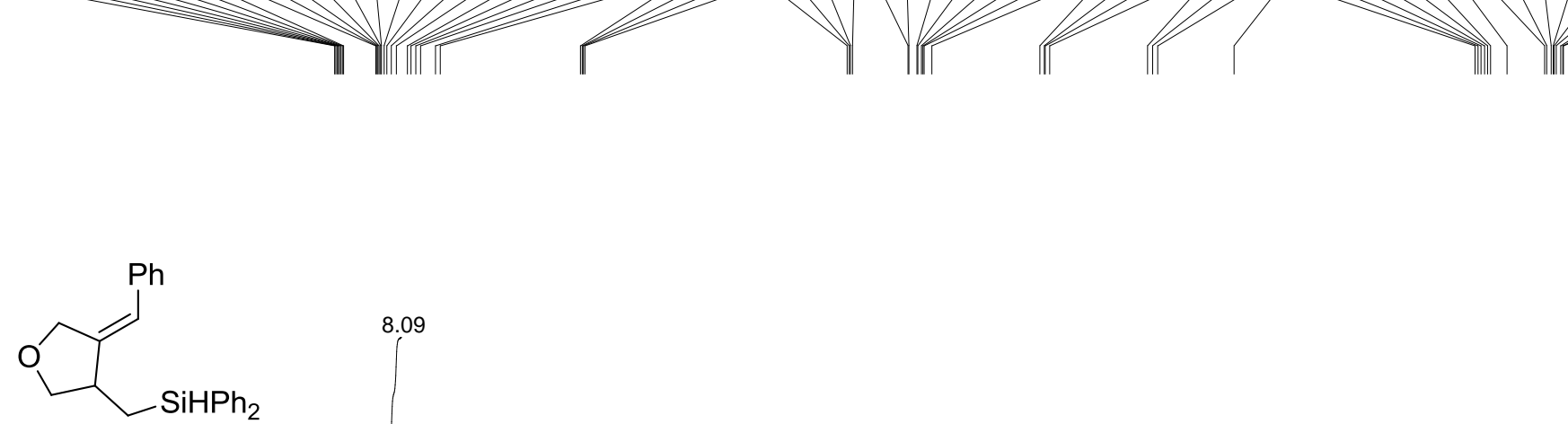

8.09

3a

${ }^{1} \mathrm{H}$ NMR

$300 \mathrm{MHz}$

2.07

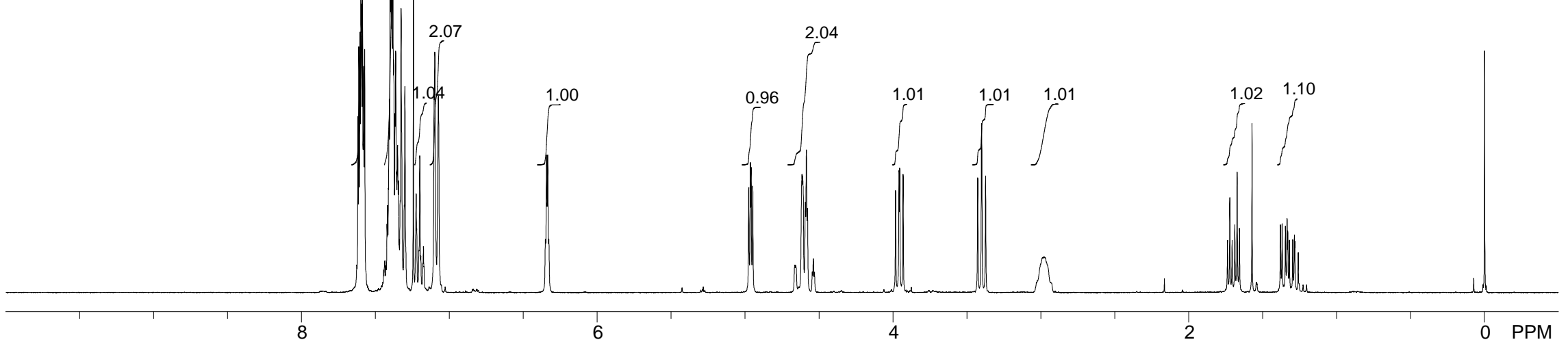




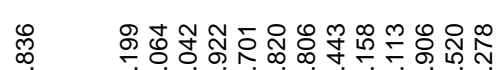

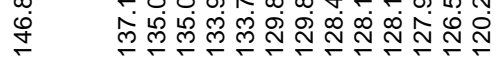

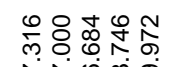

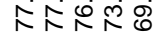

$\stackrel{8}{\circ}$

Uu

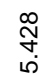

$\overbrace{\mathrm{SiHPh}_{2}}^{\mathrm{Ph}}$

$3 a$

${ }^{13} \mathrm{C}$ NMR

$100 \mathrm{MHz}$

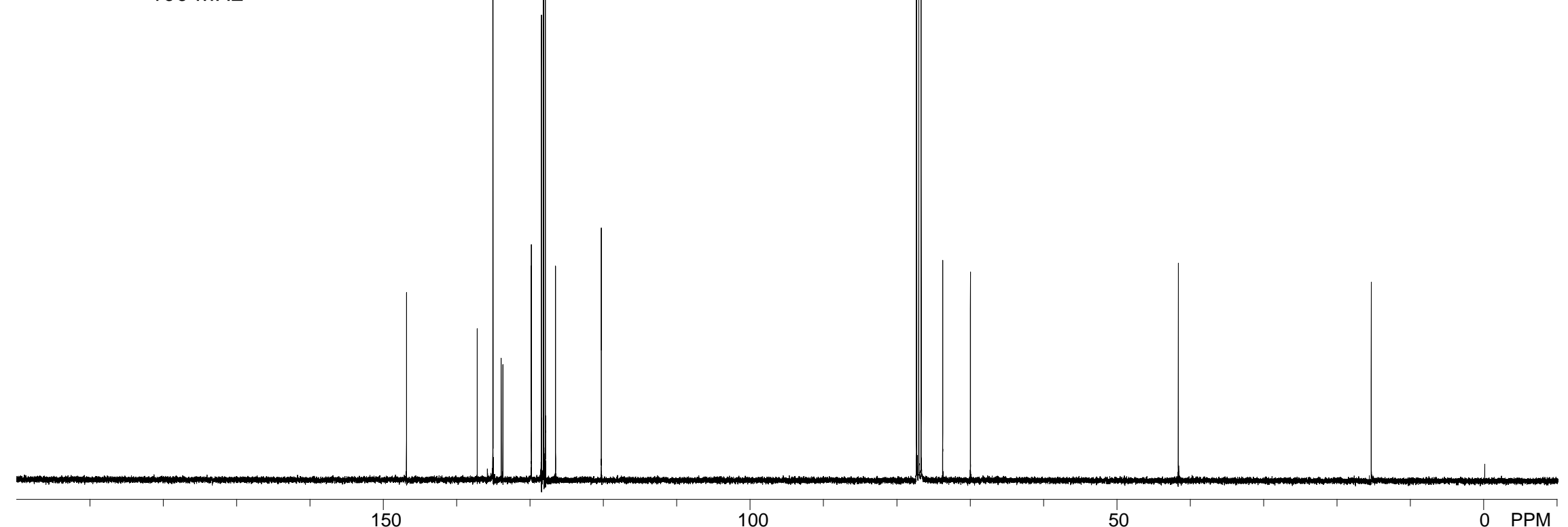




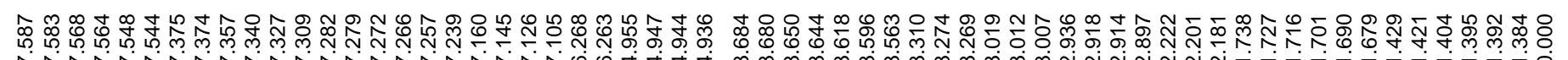
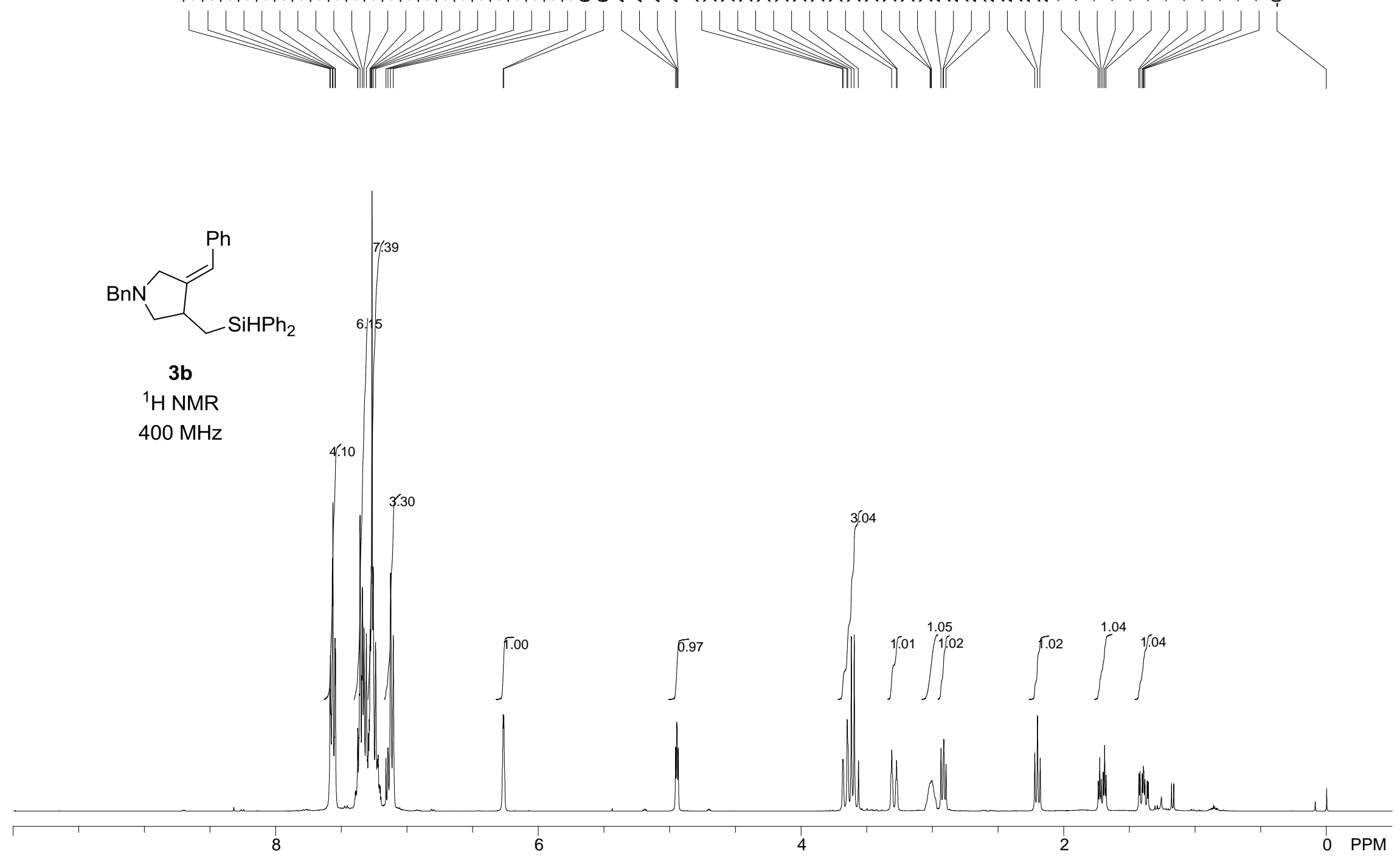

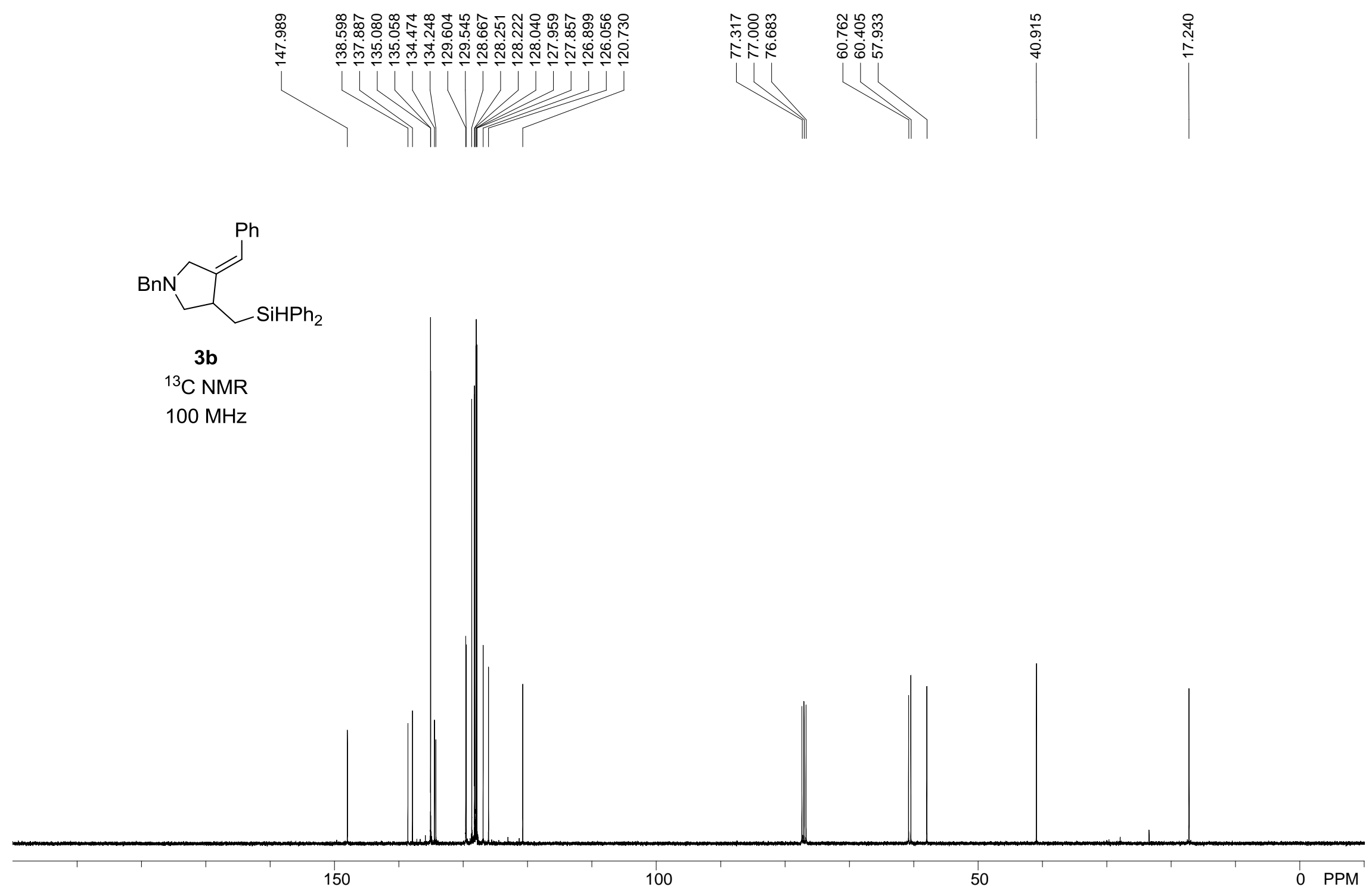


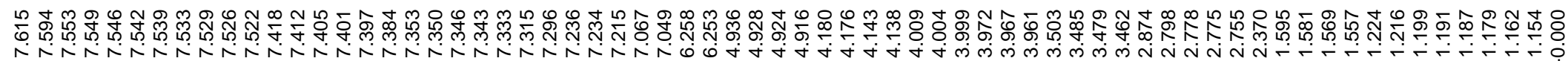

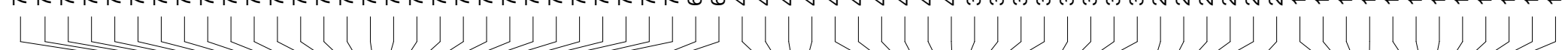
TIIIII

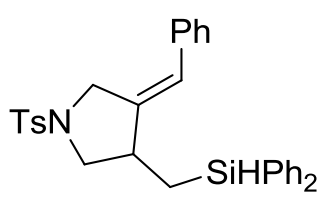

$3 c$

${ }^{1} \mathrm{H}$ NMR

$400 \mathrm{MHz}$

6.22
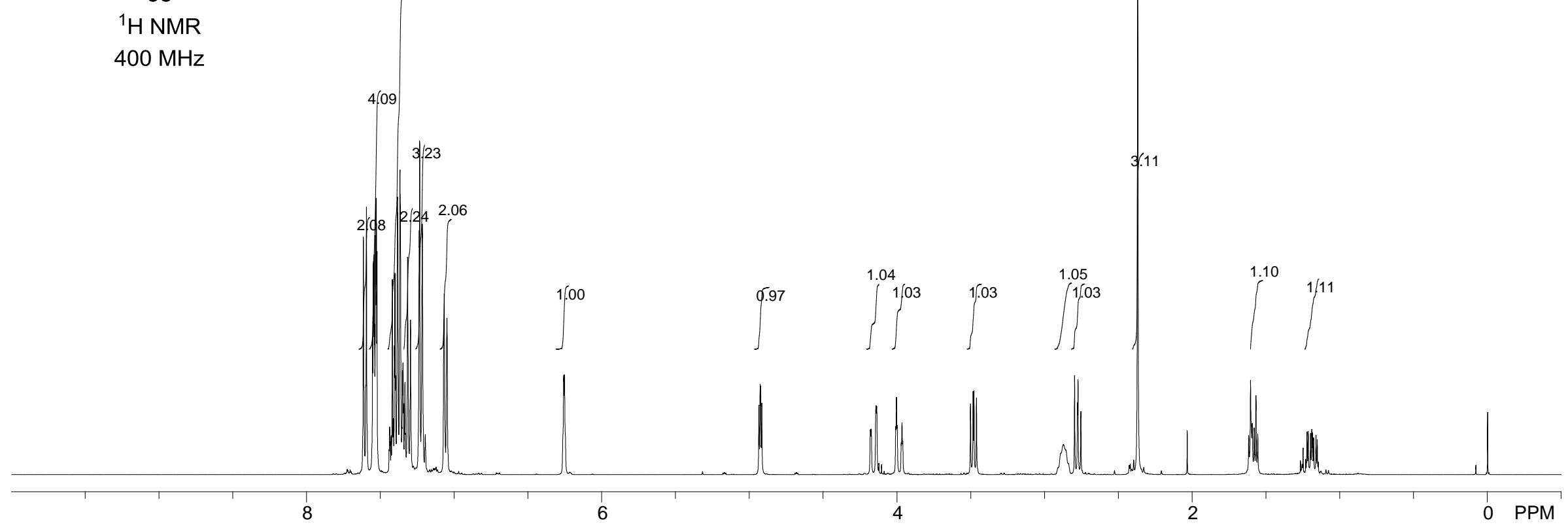


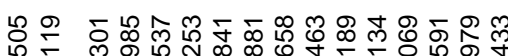

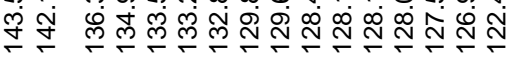

등요용

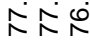

颉葛

㭥 in

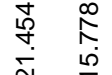

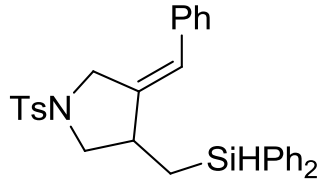

${ }^{13} \mathrm{C}$ NMR

$100 \mathrm{MHz}$ 


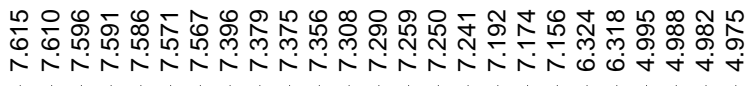

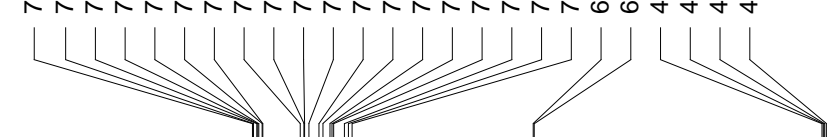

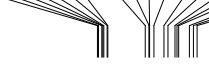

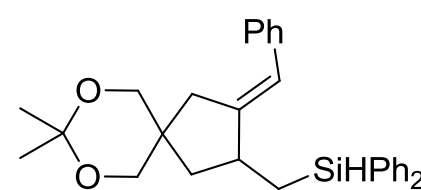

$\mathrm{O} \mathrm{SiHPh}_{2}$

3d

${ }^{1} \mathrm{H}$ NMR

$400 \mathrm{MHz}$

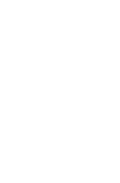

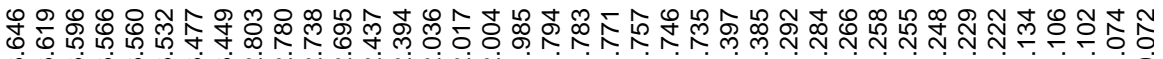
Iิ-

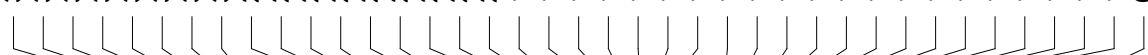

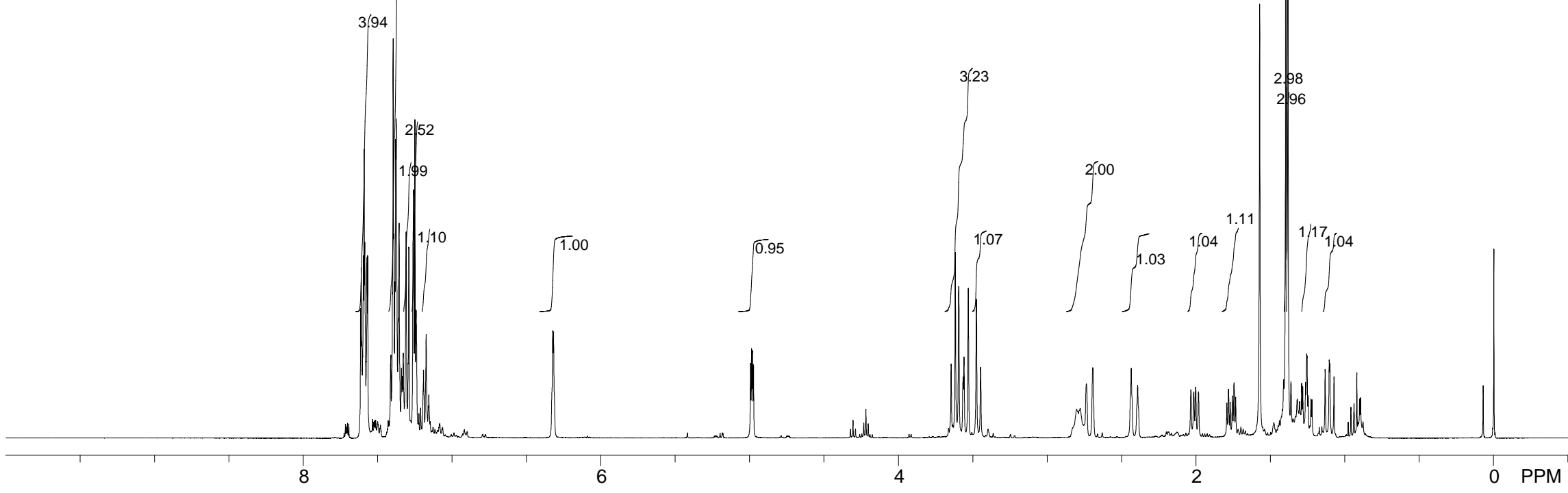

a.

1.00

0.95

3.23

2.00

1.07

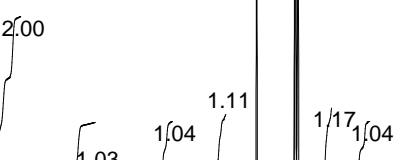




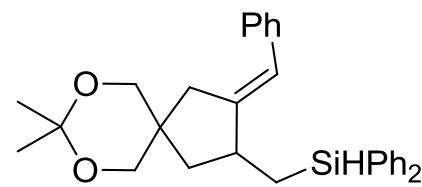

3d

${ }^{13} \mathrm{C} \mathrm{NMR}$

$100 \mathrm{MHz}$

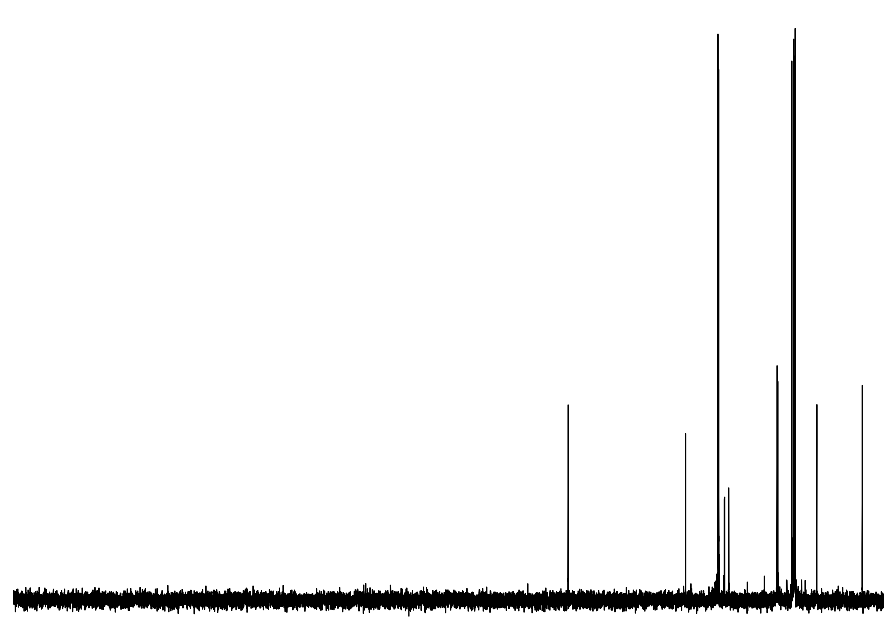




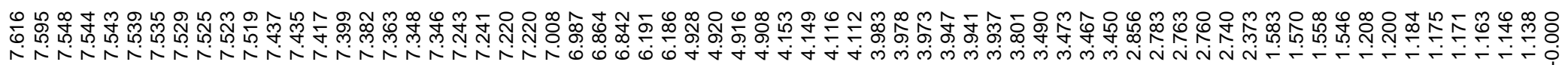
(1) Tा ili $\pi$

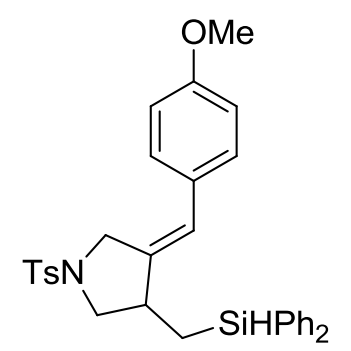

$3 e$

${ }^{1} \mathrm{H}$ NMR

$400 \mathrm{MHz}$

6.22

2.04

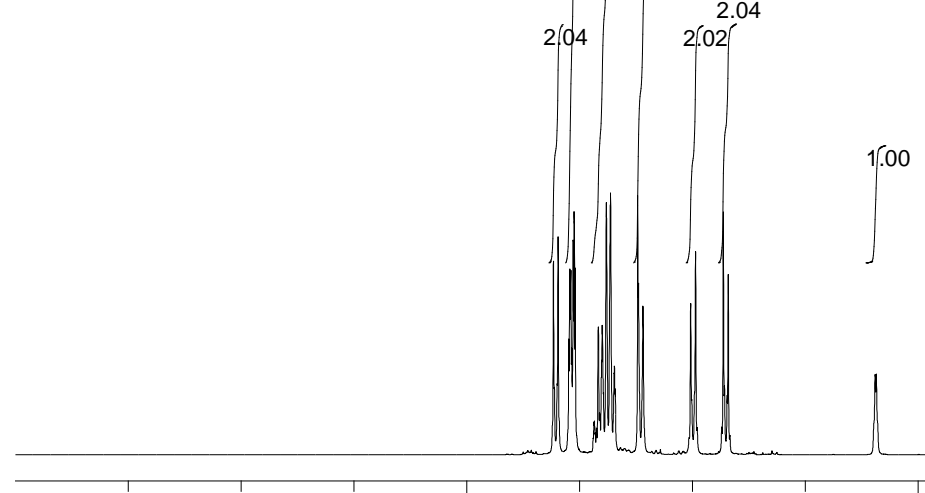

1.00

0.97

1.071 .04

1.00

2.99

8

6

0 PPM

S15 


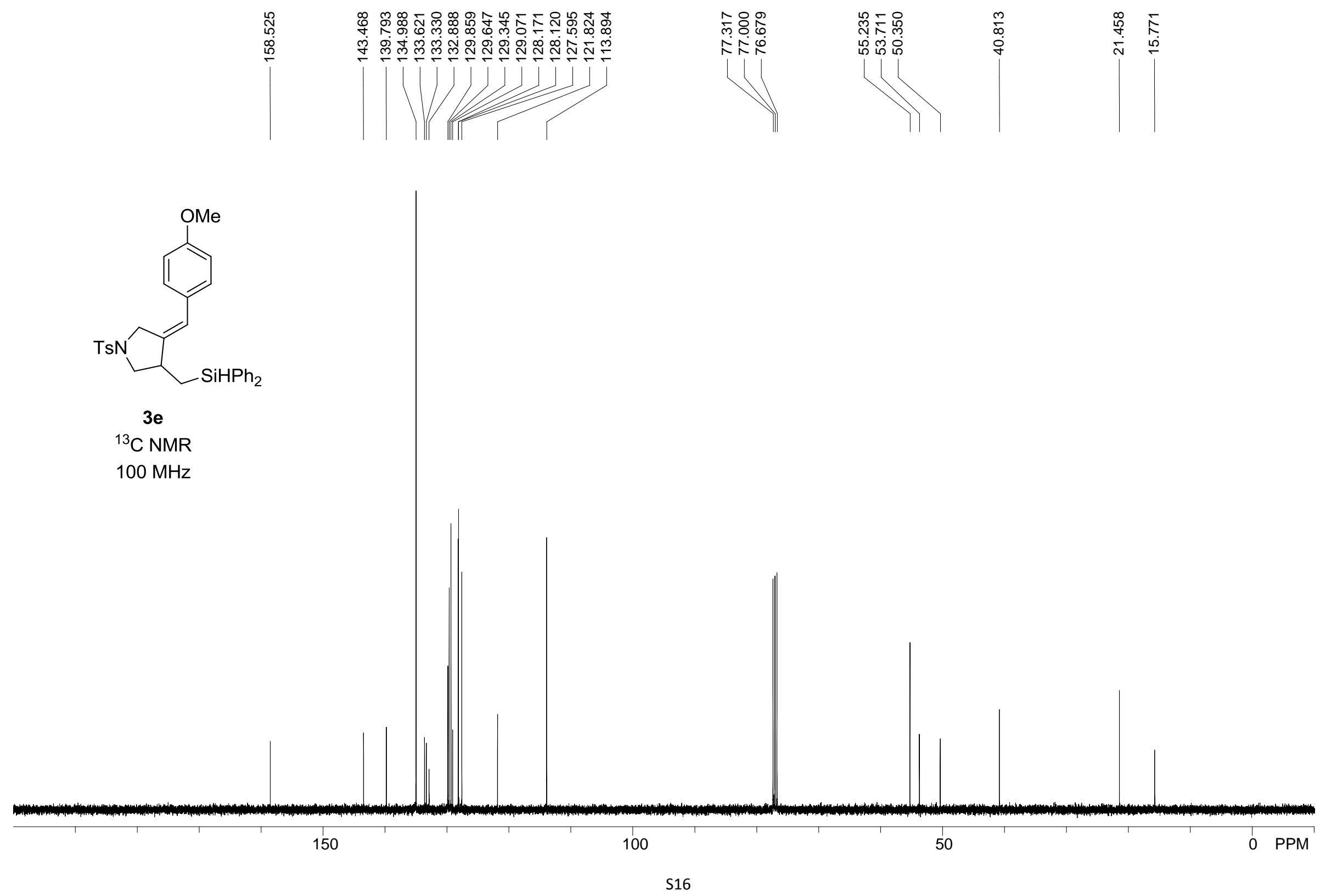




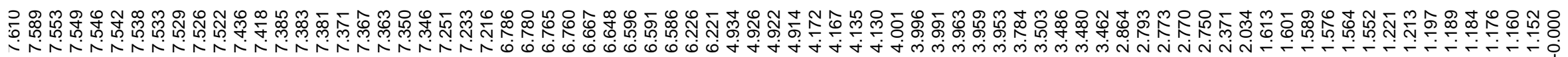

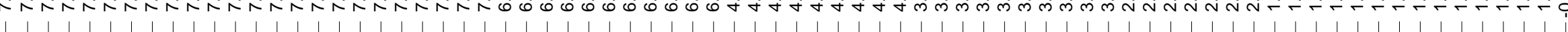

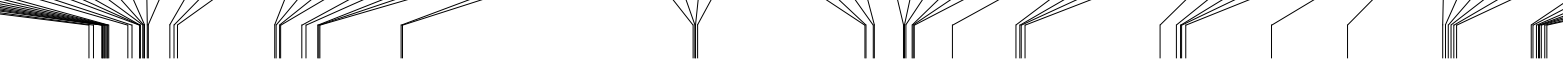

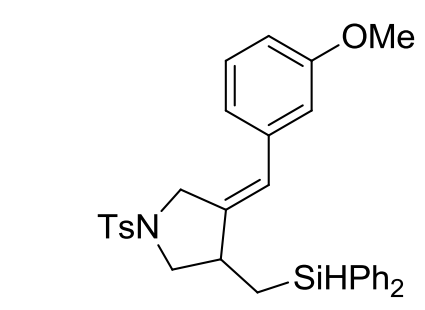

$3 \mathbf{f}$

${ }^{1} \mathrm{H}$ NMR
$400 \mathrm{MHz}$

4.05

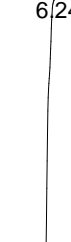

3.41

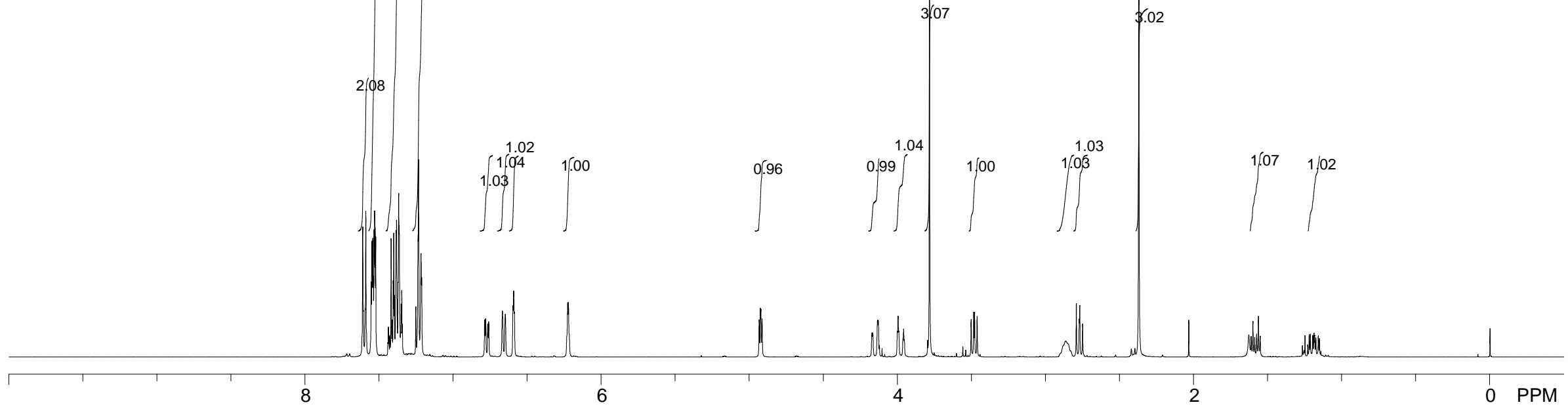

S17 


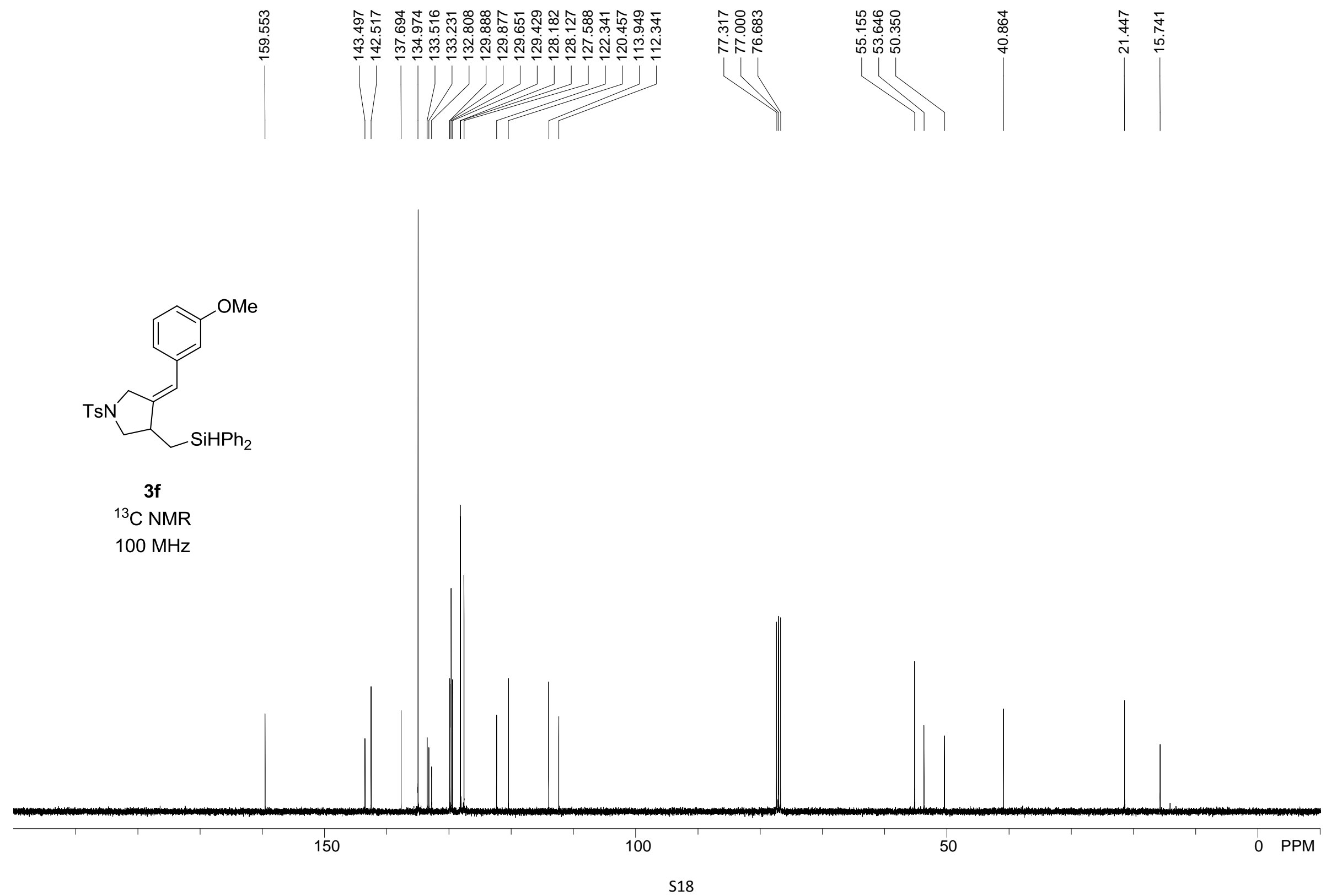




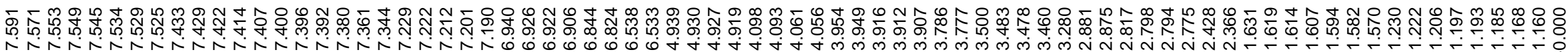

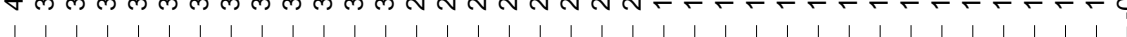

TIIIIII II III

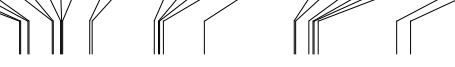

II III

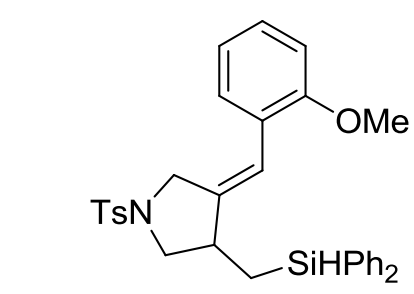

$\mathrm{OMe}$

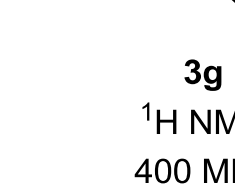

$3 g$

$\mathrm{H}$ NMR

$400 \mathrm{MHz}$

6.00

85

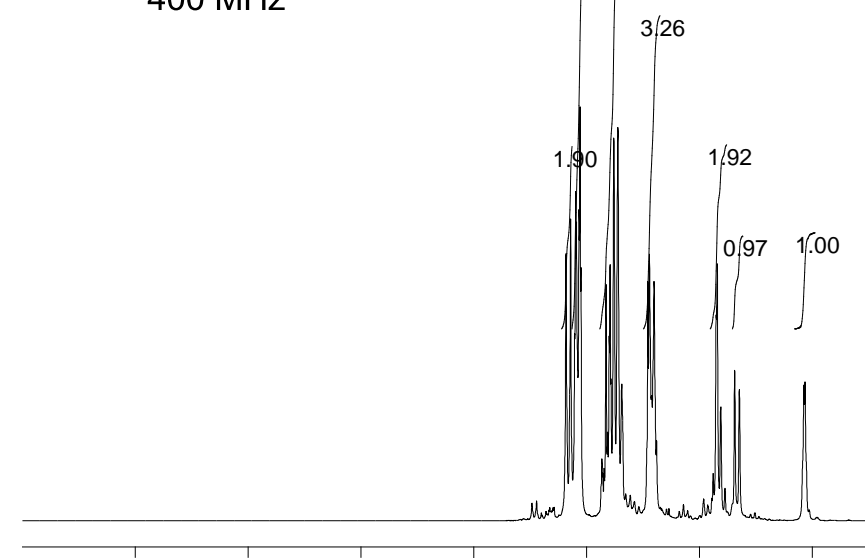

8

0.91
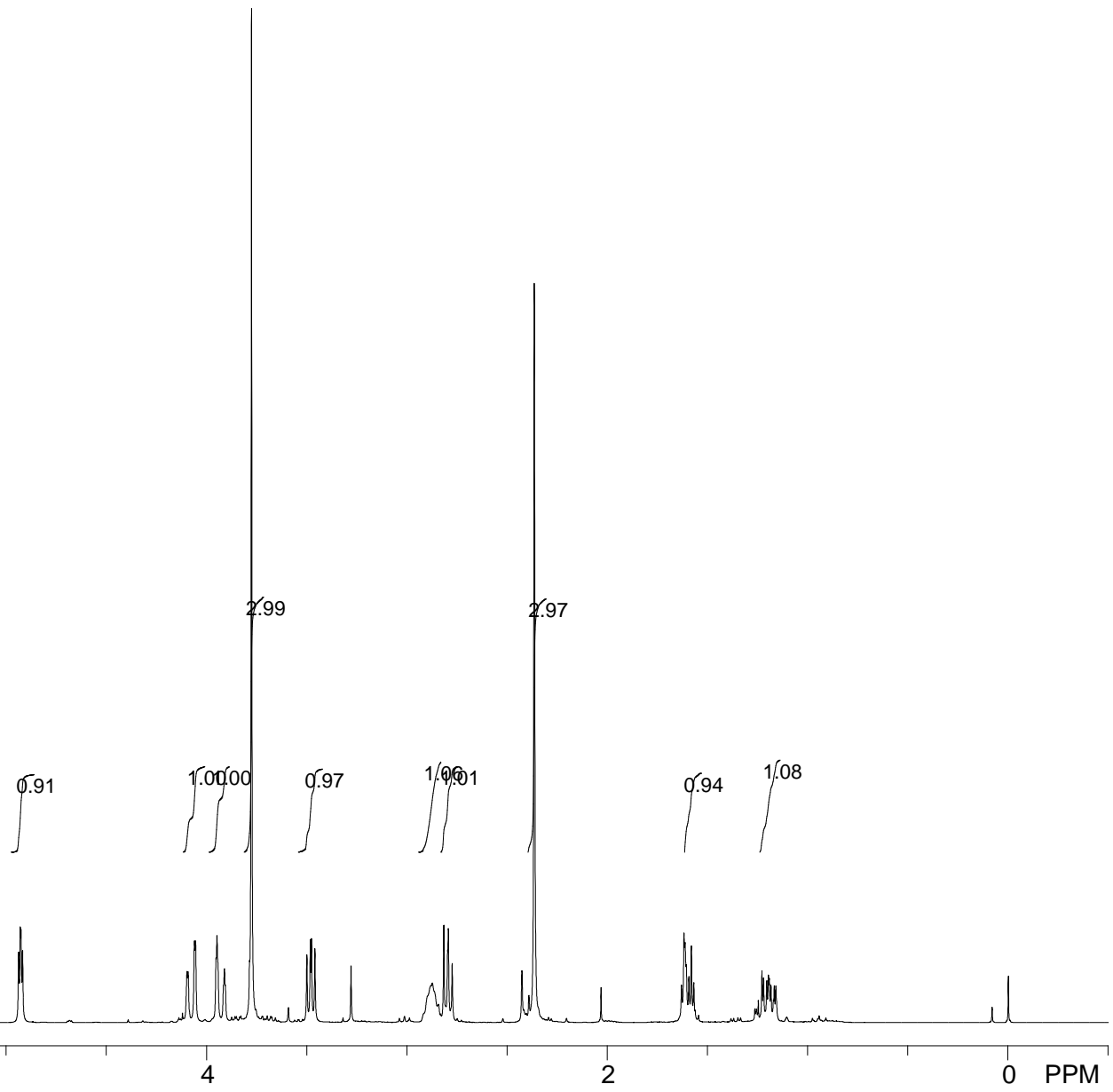

S19 


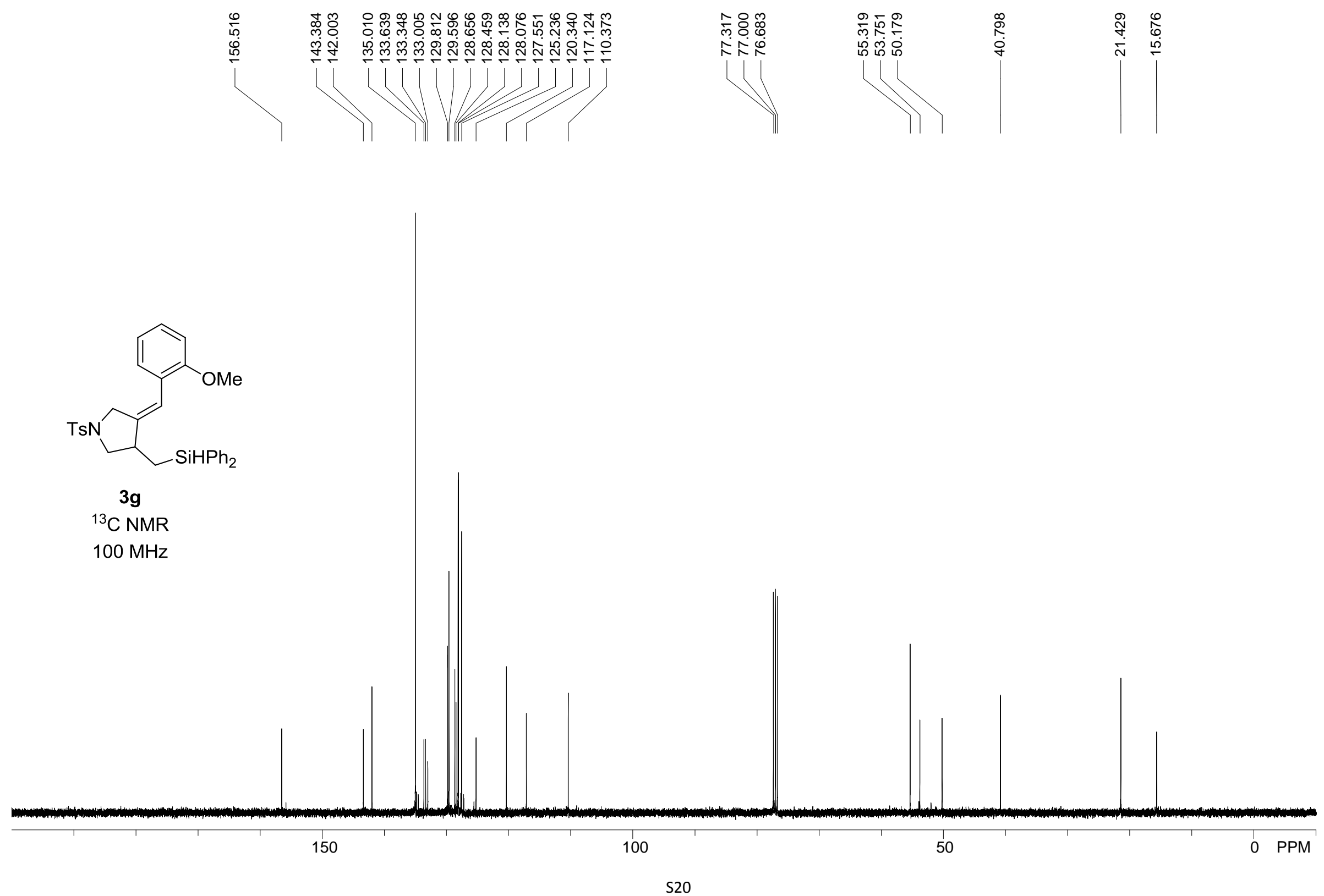




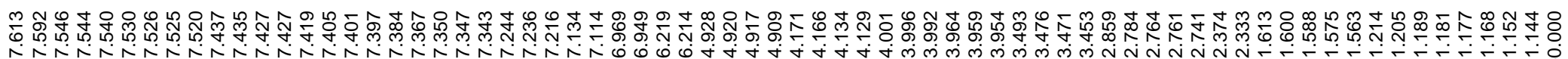

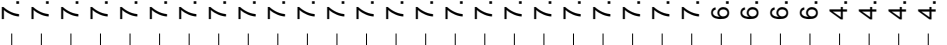

TIIIIIIII

I
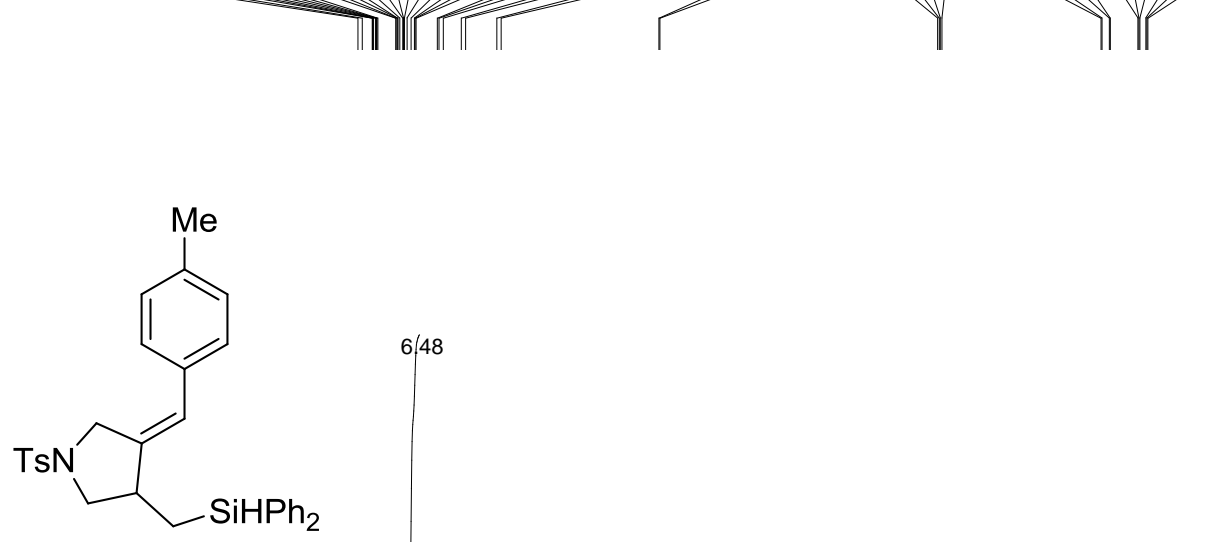

6.48

$3 h$

${ }^{1} \mathrm{H}$ NMR $400 \mathrm{MHz}$
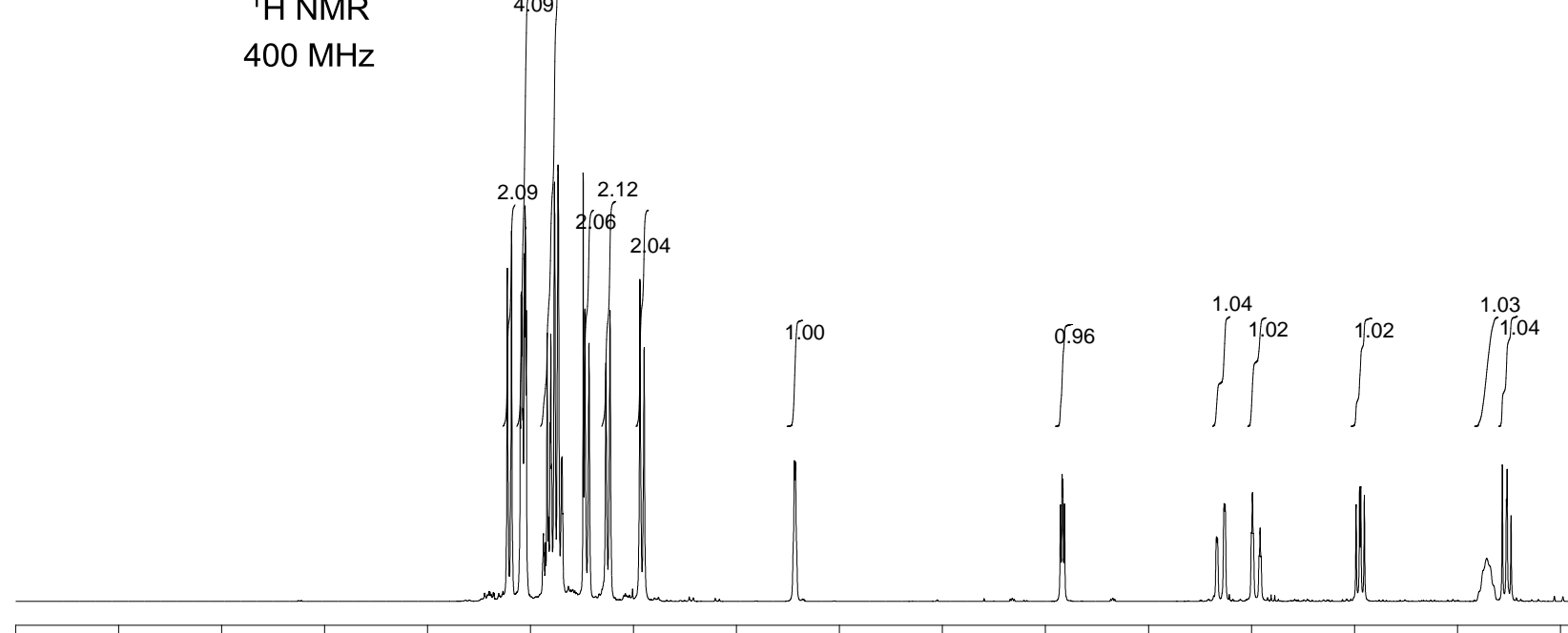

6

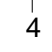




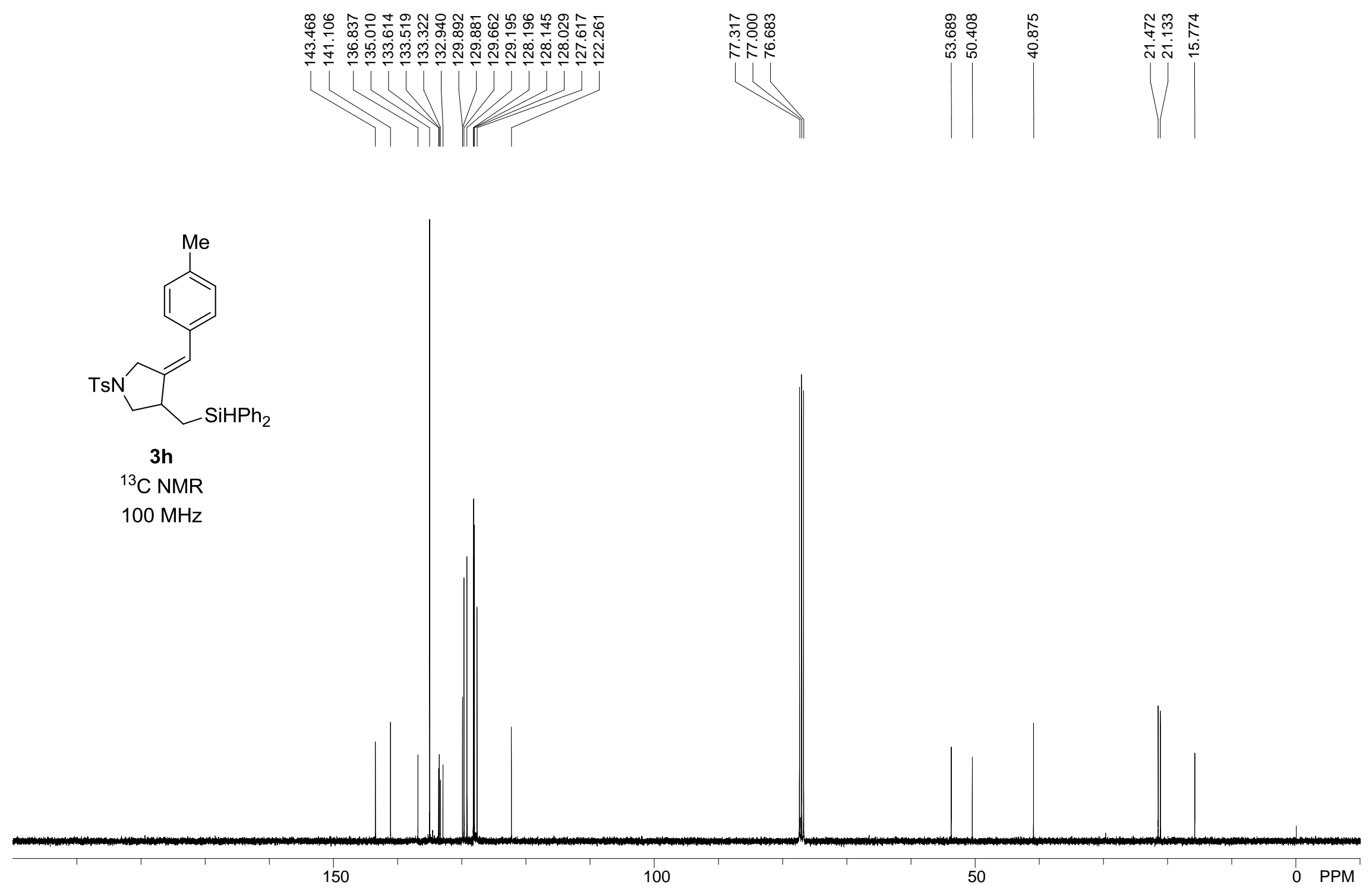




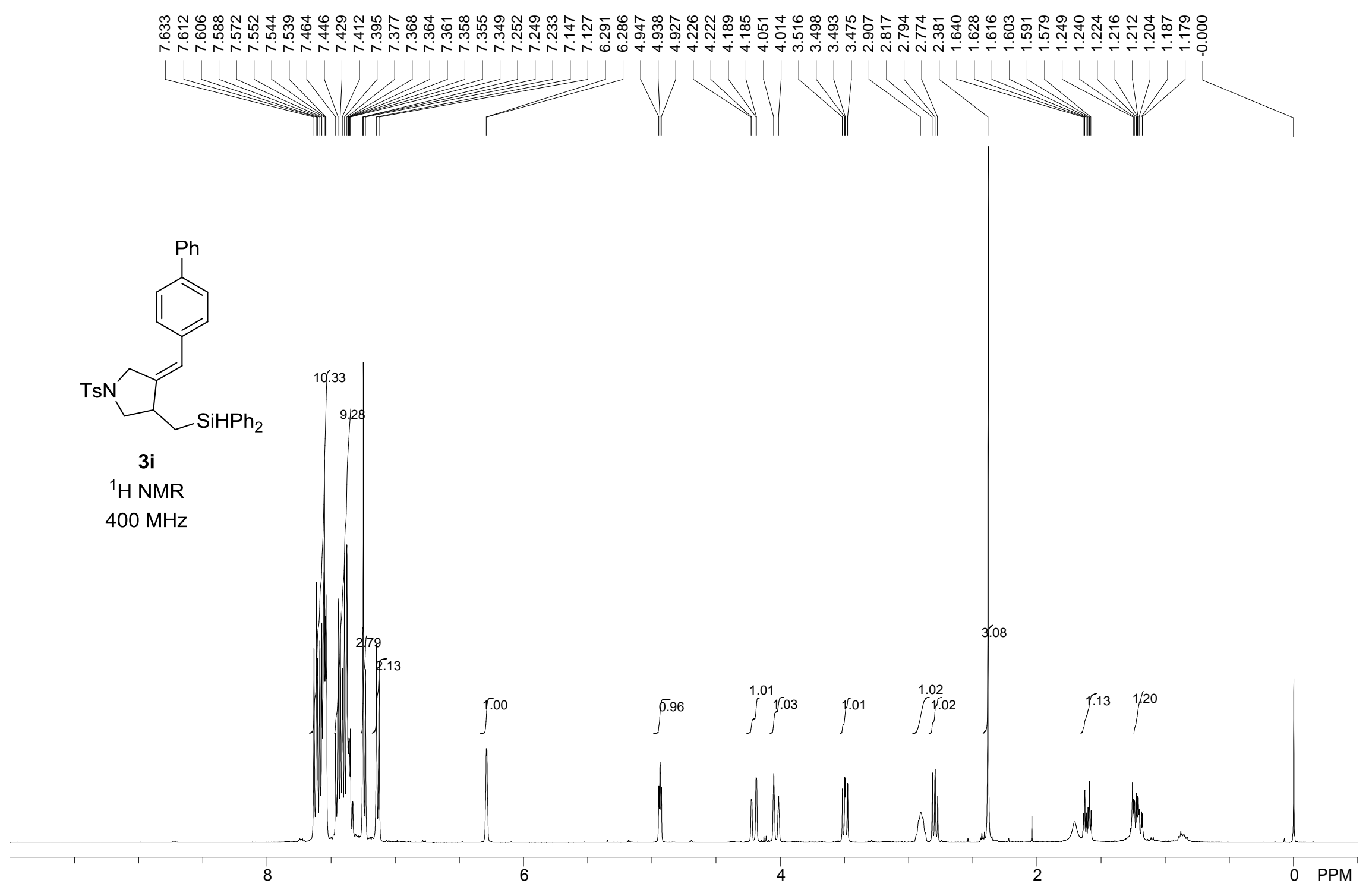




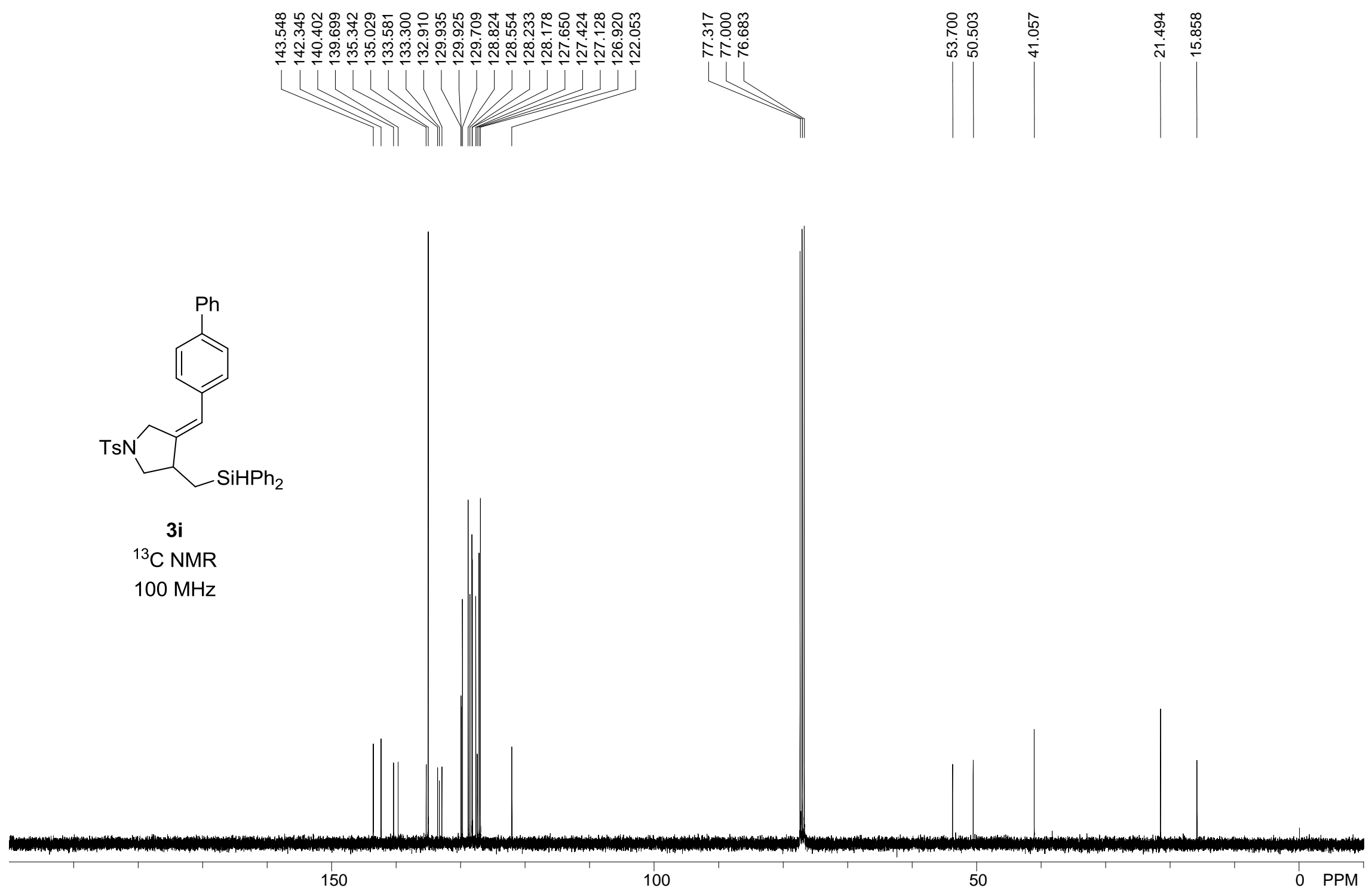




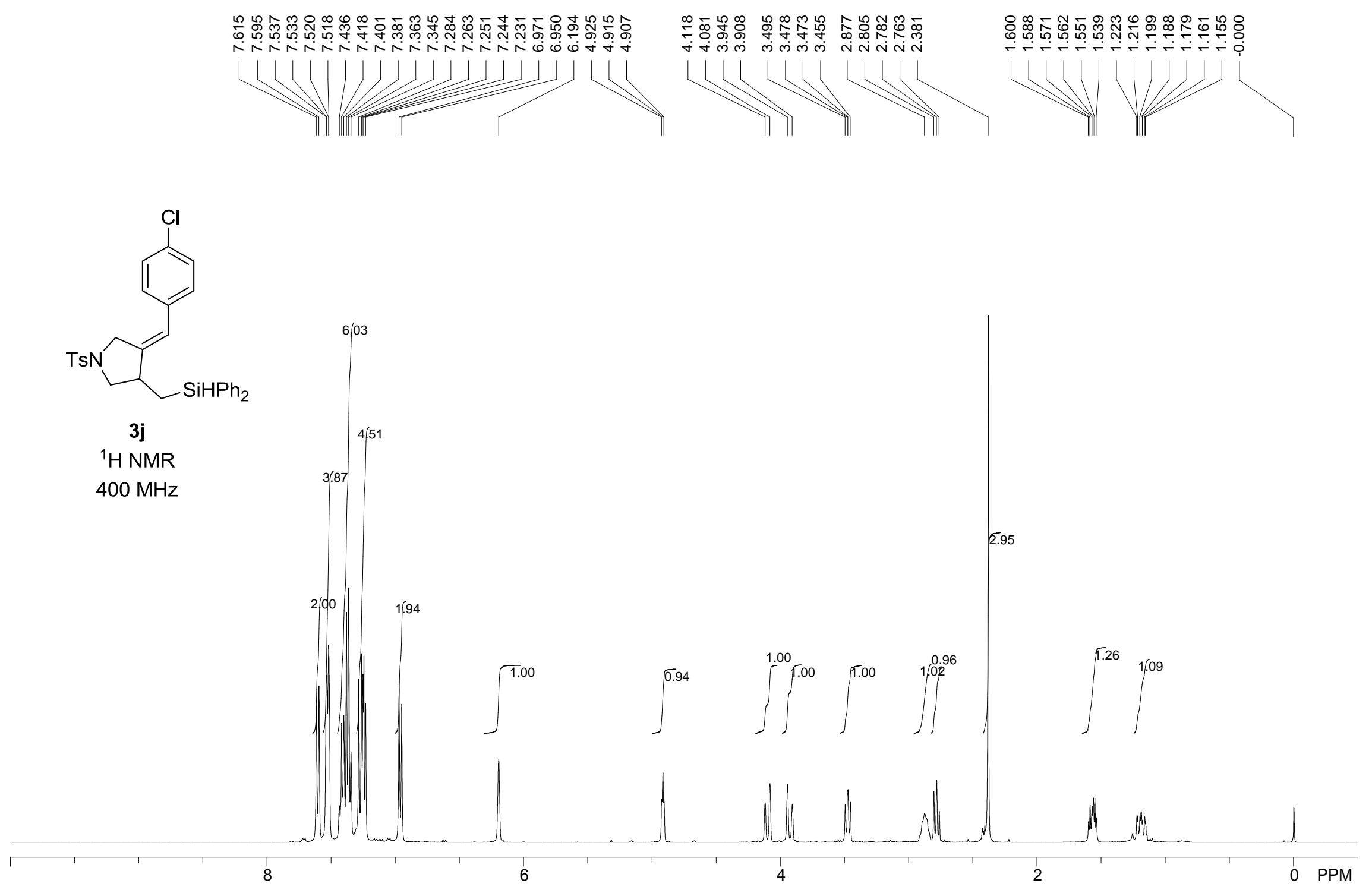

S25 


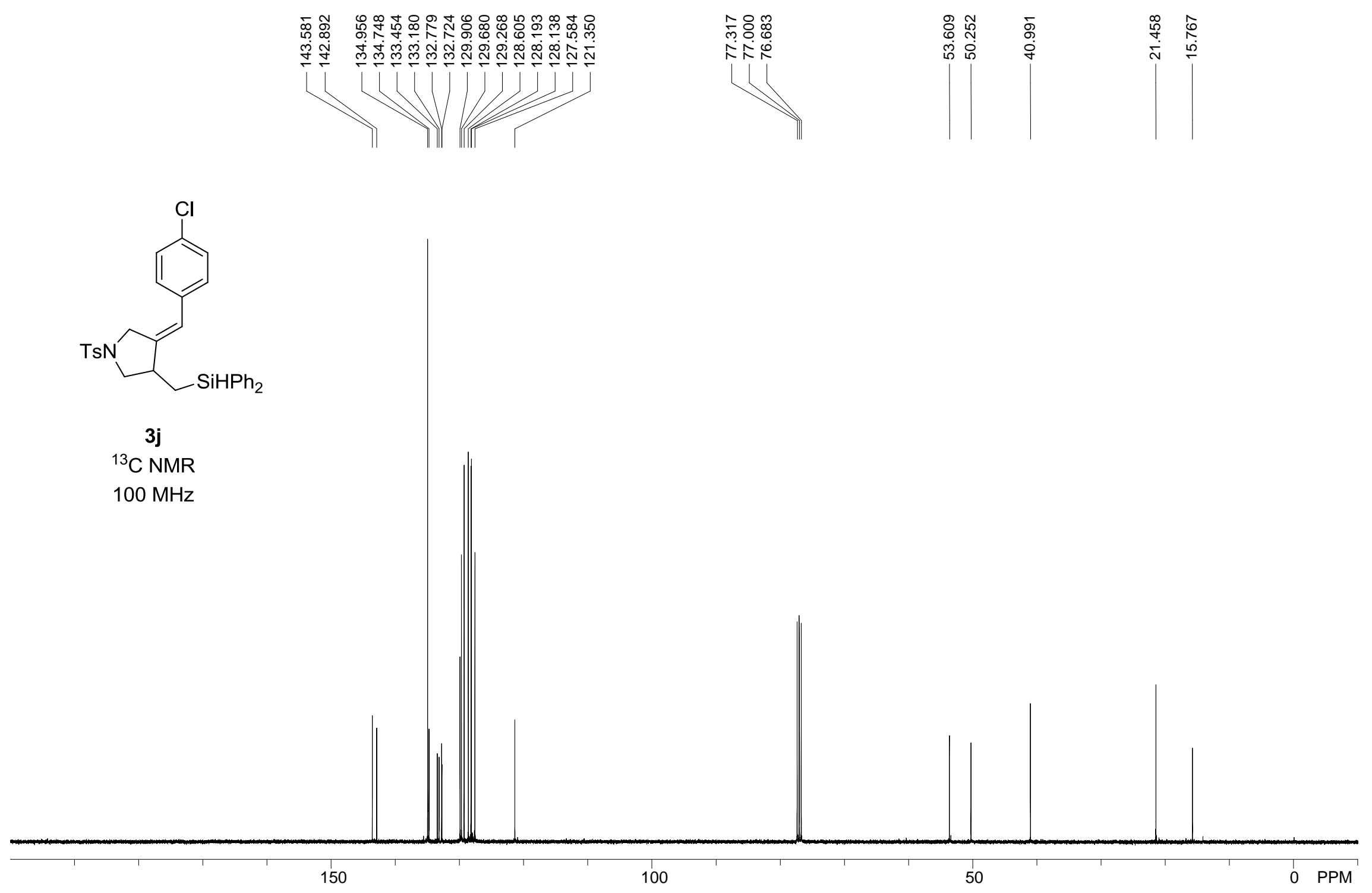




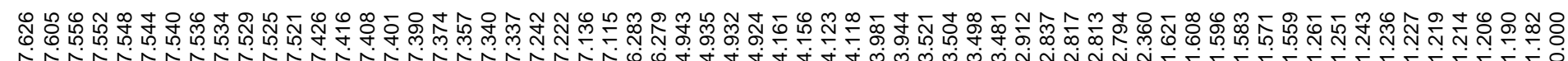

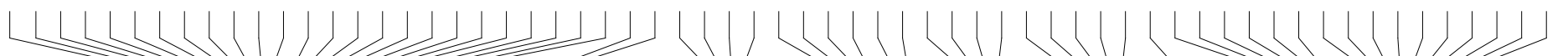
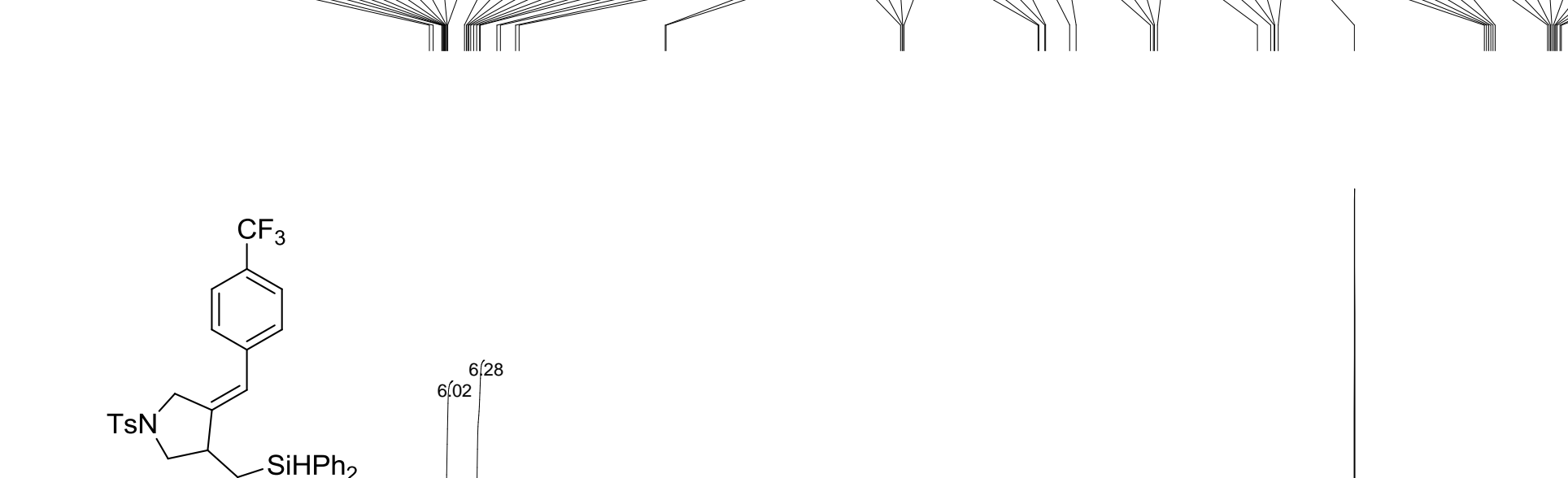

$6.02^{6.28}$

3k

${ }^{1} \mathrm{H}$ NMR $400 \mathrm{MHz}$

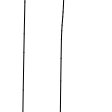

1.00

0.96

$1.011 .02 \quad 0.99$

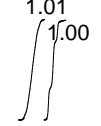

3.01

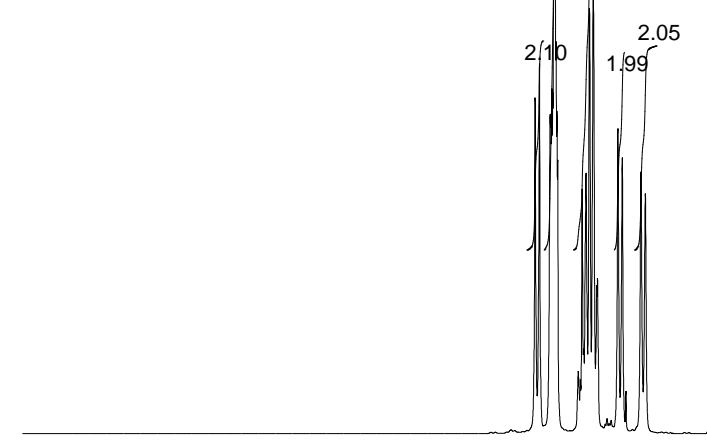




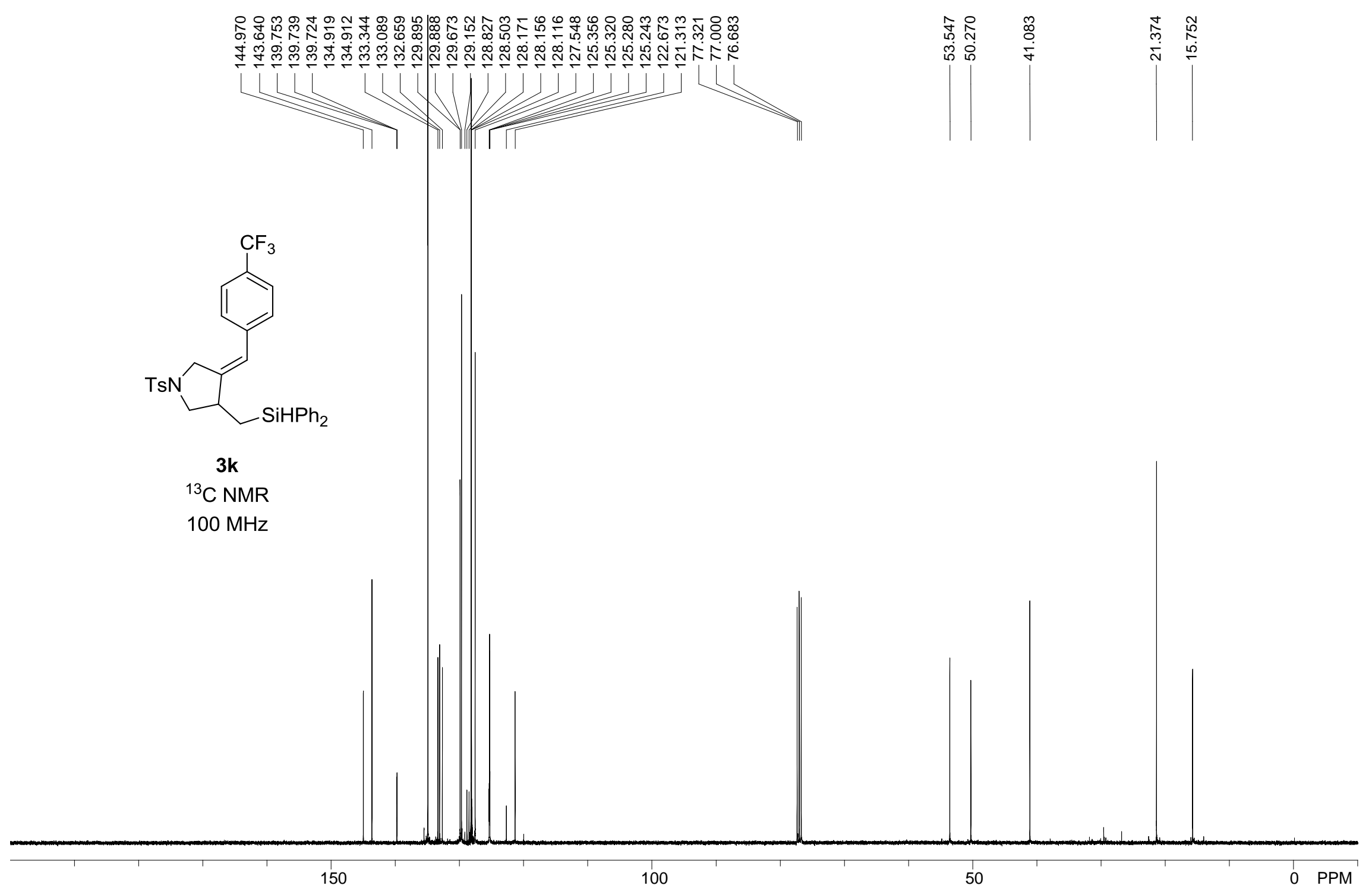




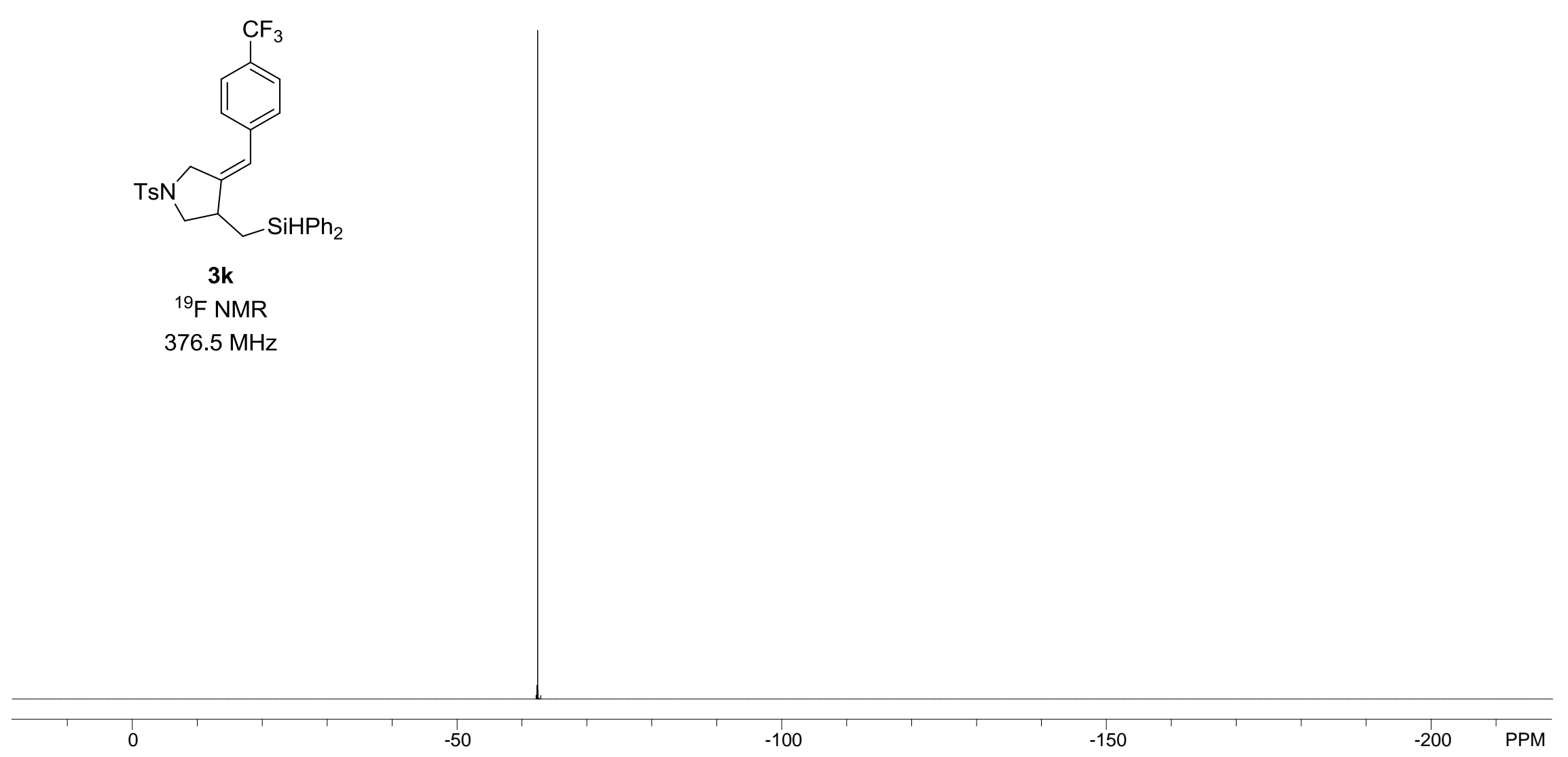




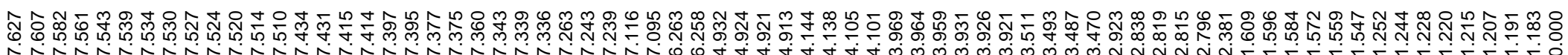

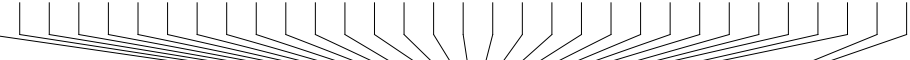

Tाiliा

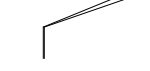

6.41

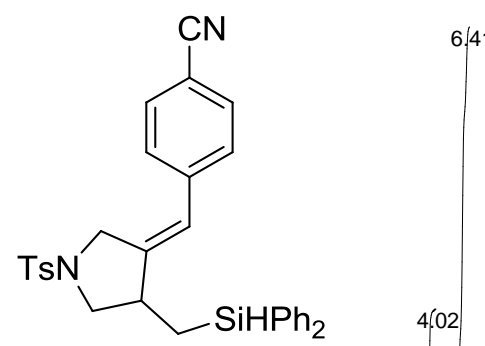

3I

${ }^{1} \mathrm{H}$ NMR

$400 \mathrm{MHz}$

402

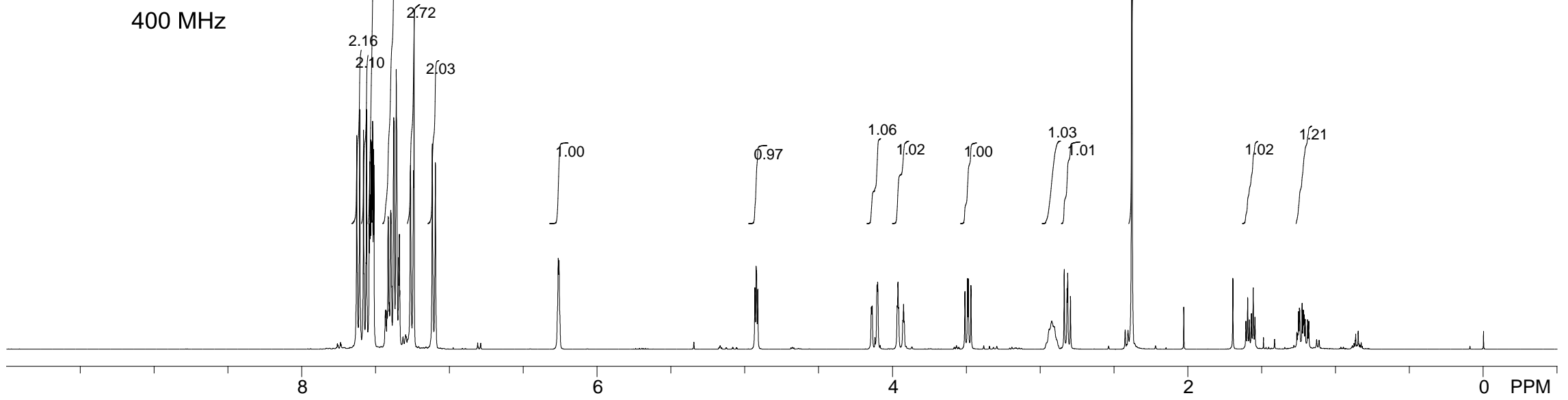

S30 


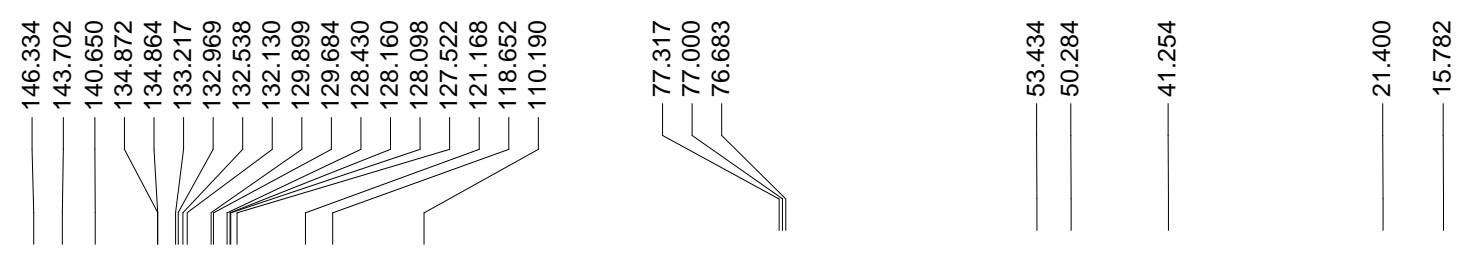

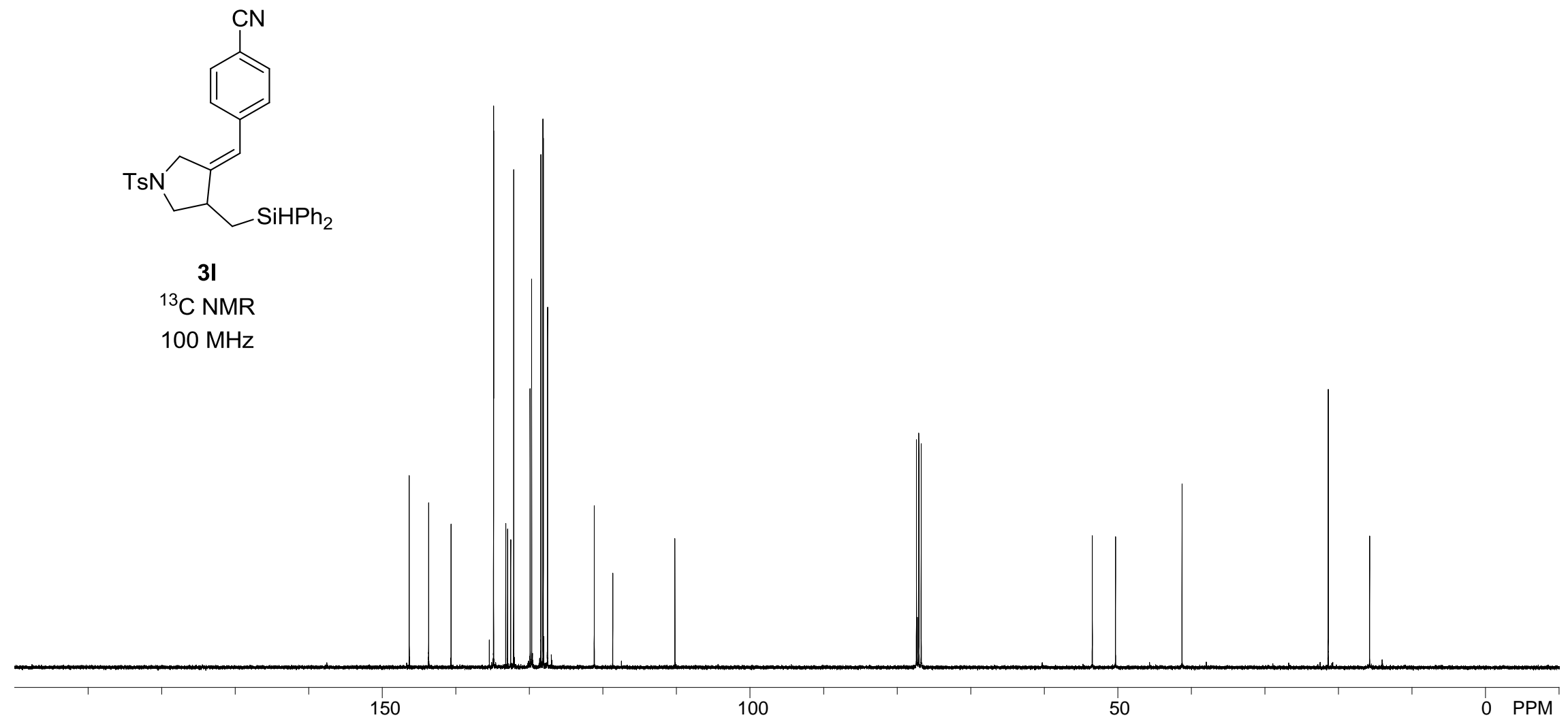




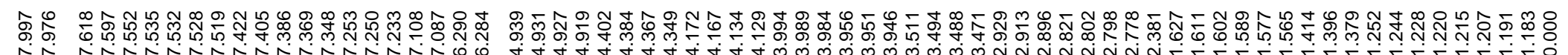

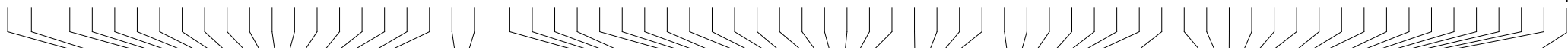
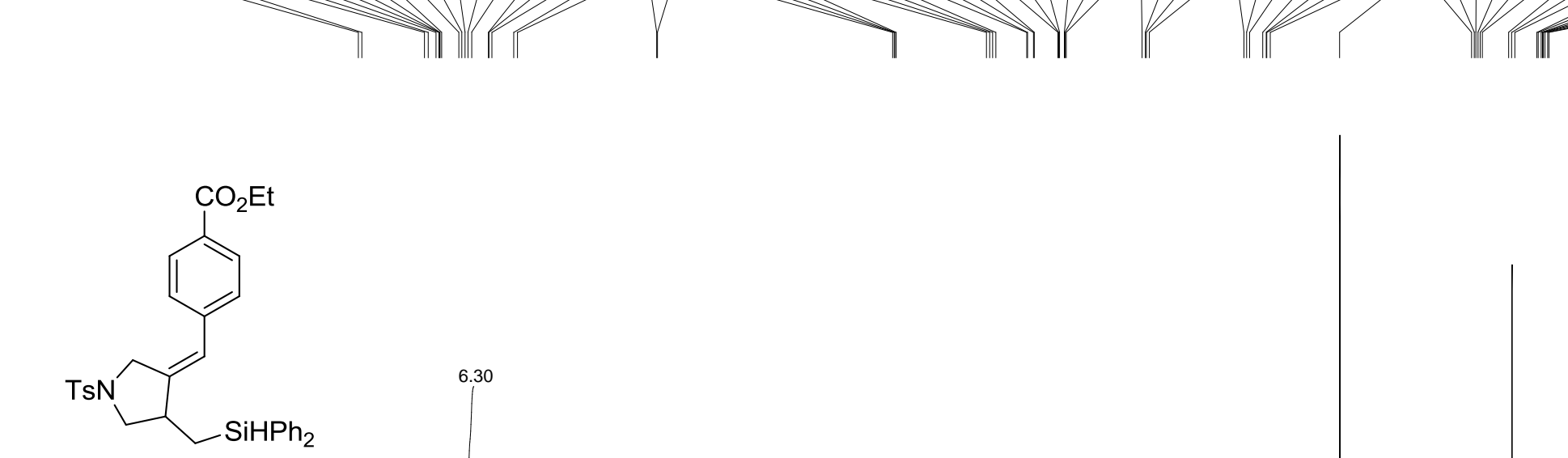

$3 m$

${ }^{1} \mathrm{H} N M R$

$400 \mathrm{MHz}$

6.30

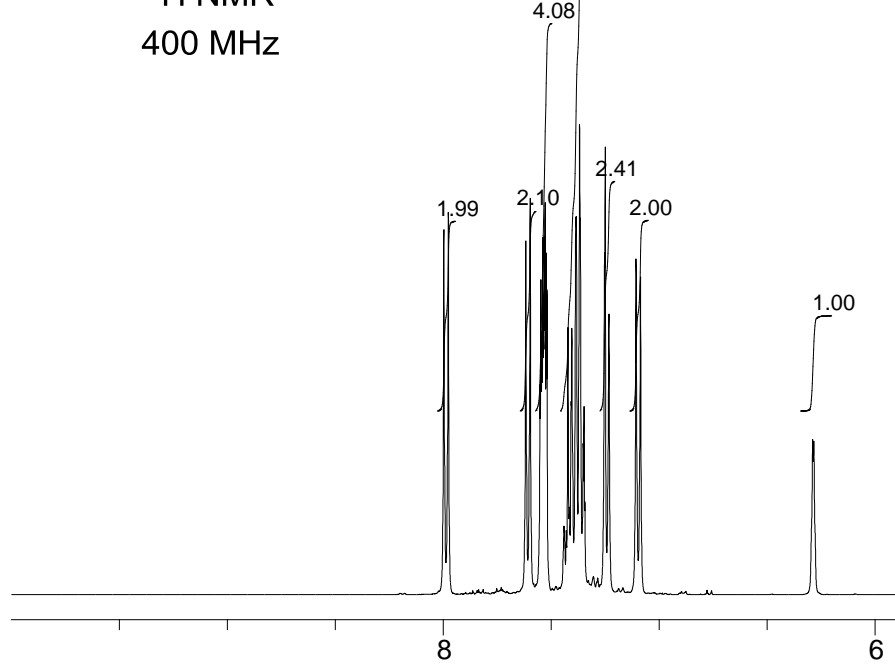

1.00 


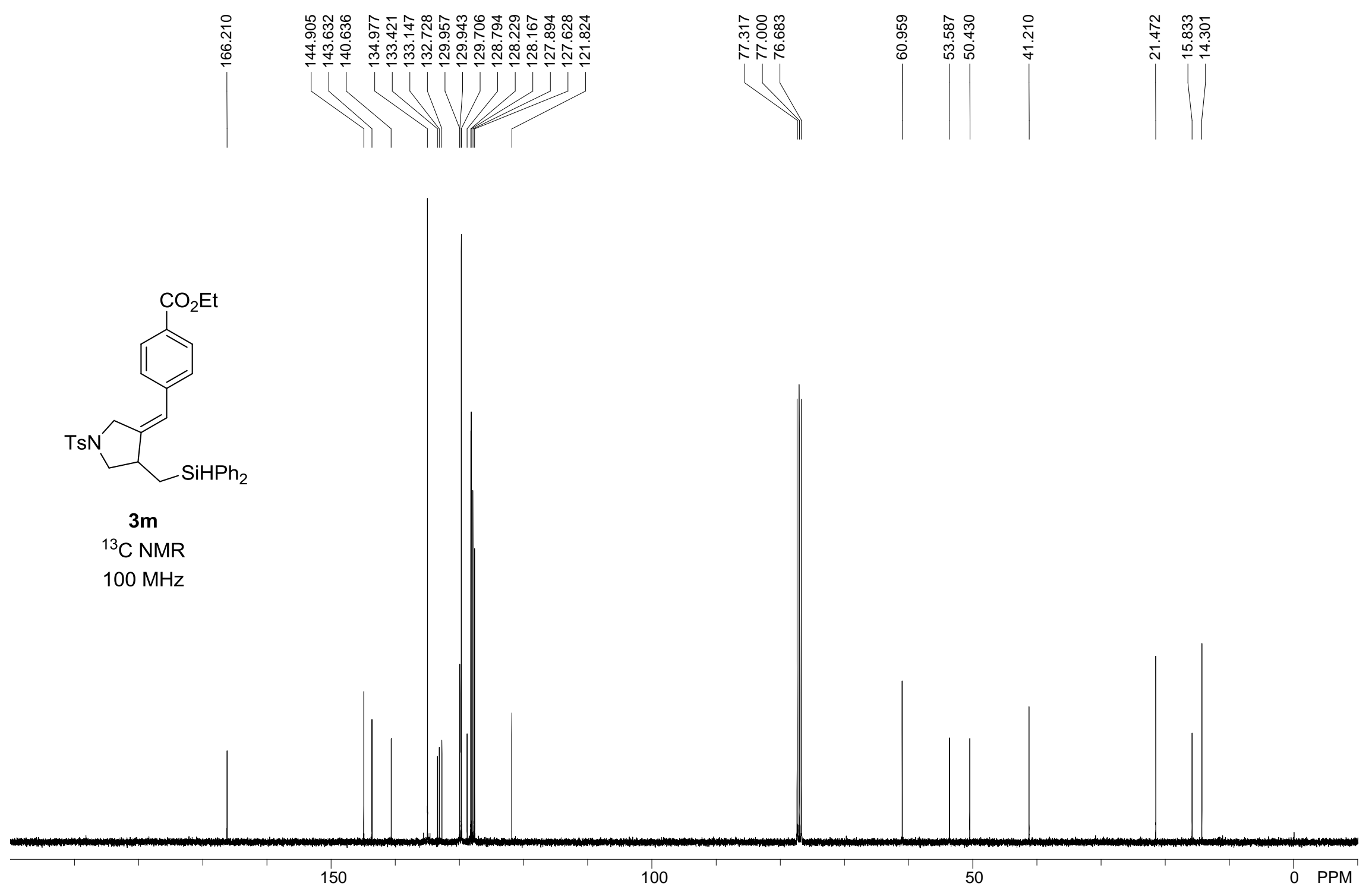




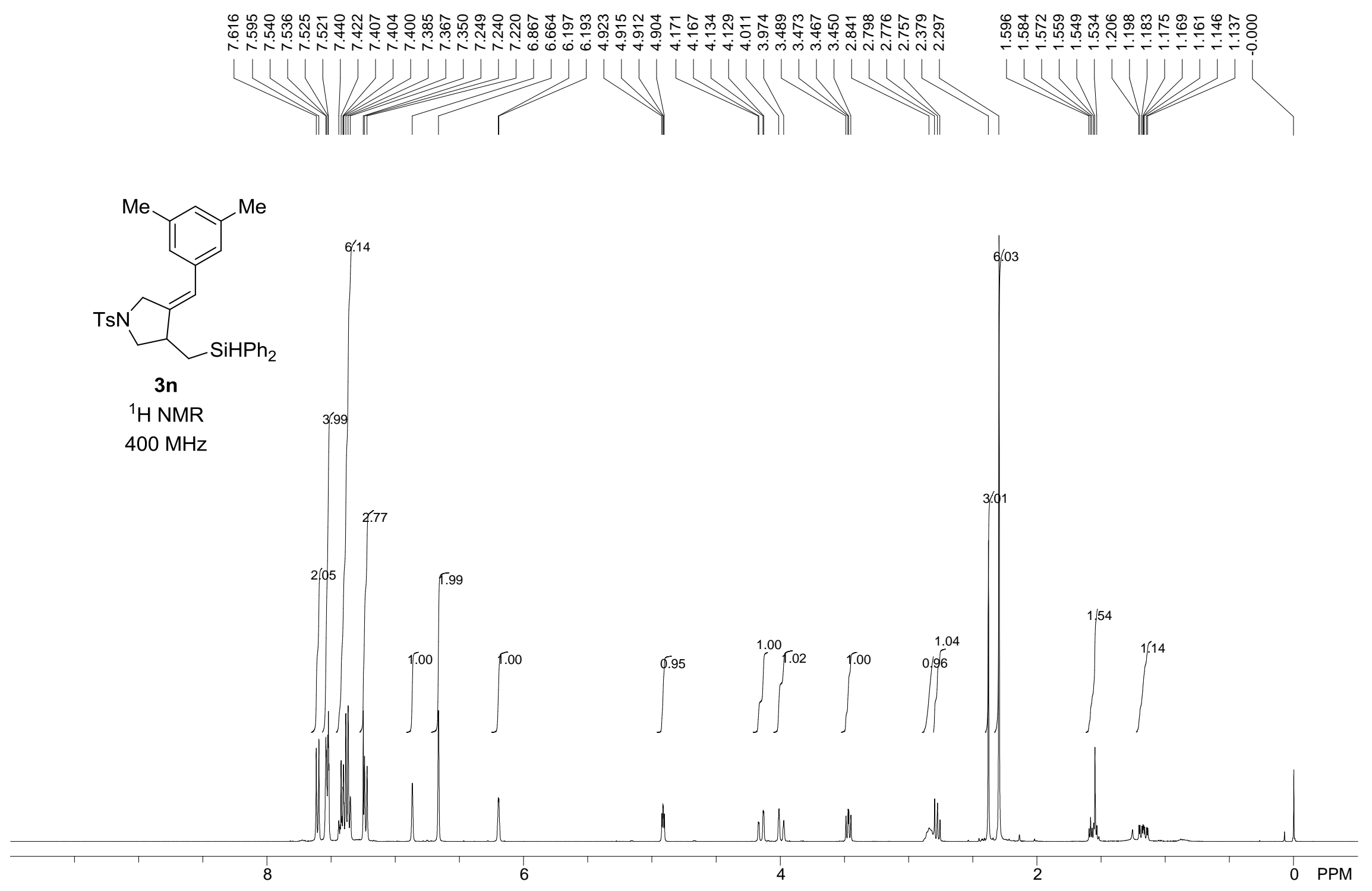




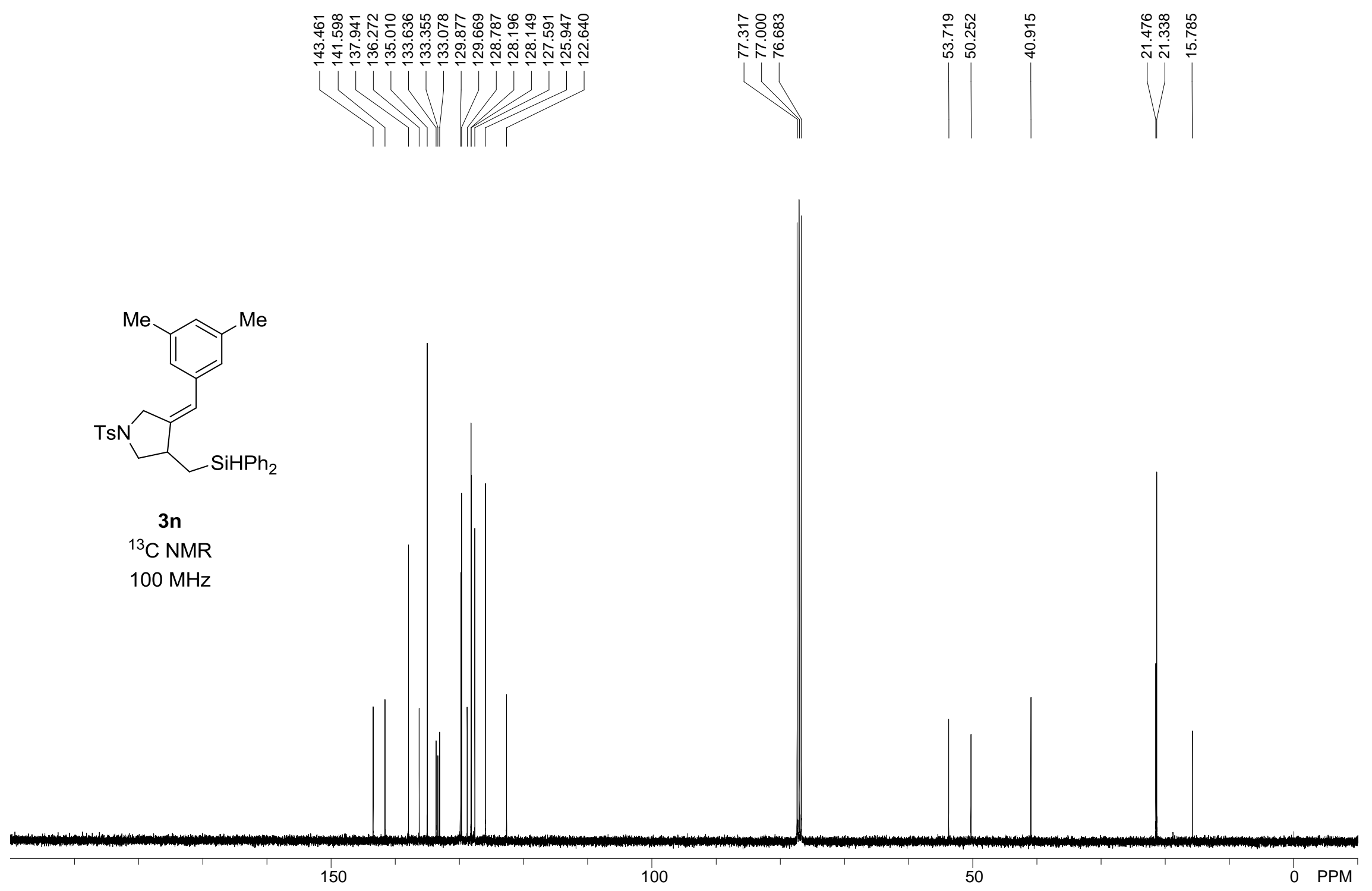




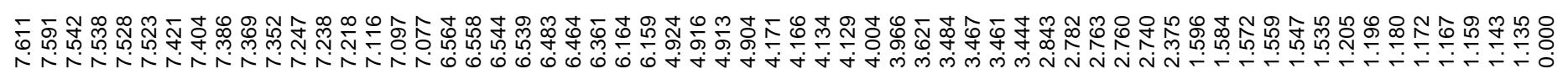

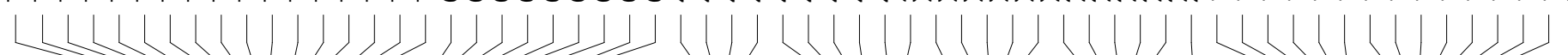

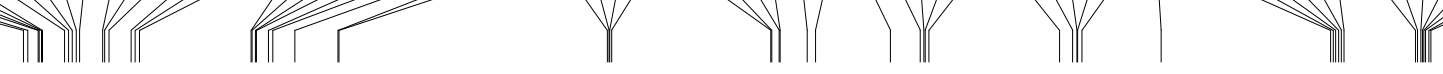

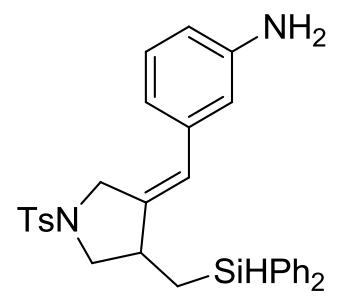

5.96

30

${ }^{1} \mathrm{H}$ NMR

$400 \mathrm{MHz}$

3.93

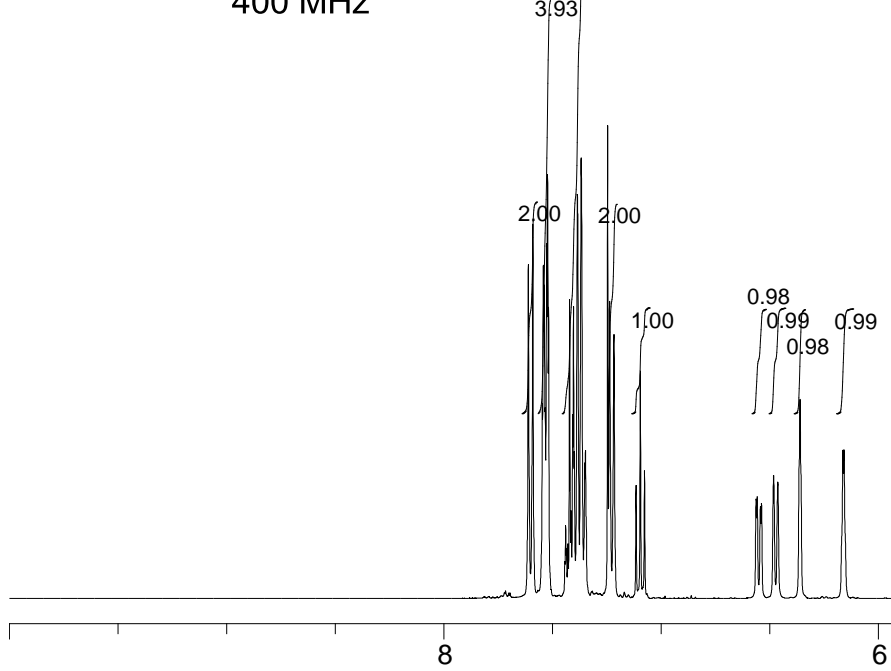

6
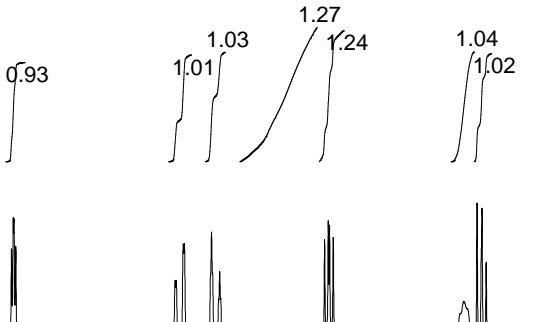

N

2

0 PPM 

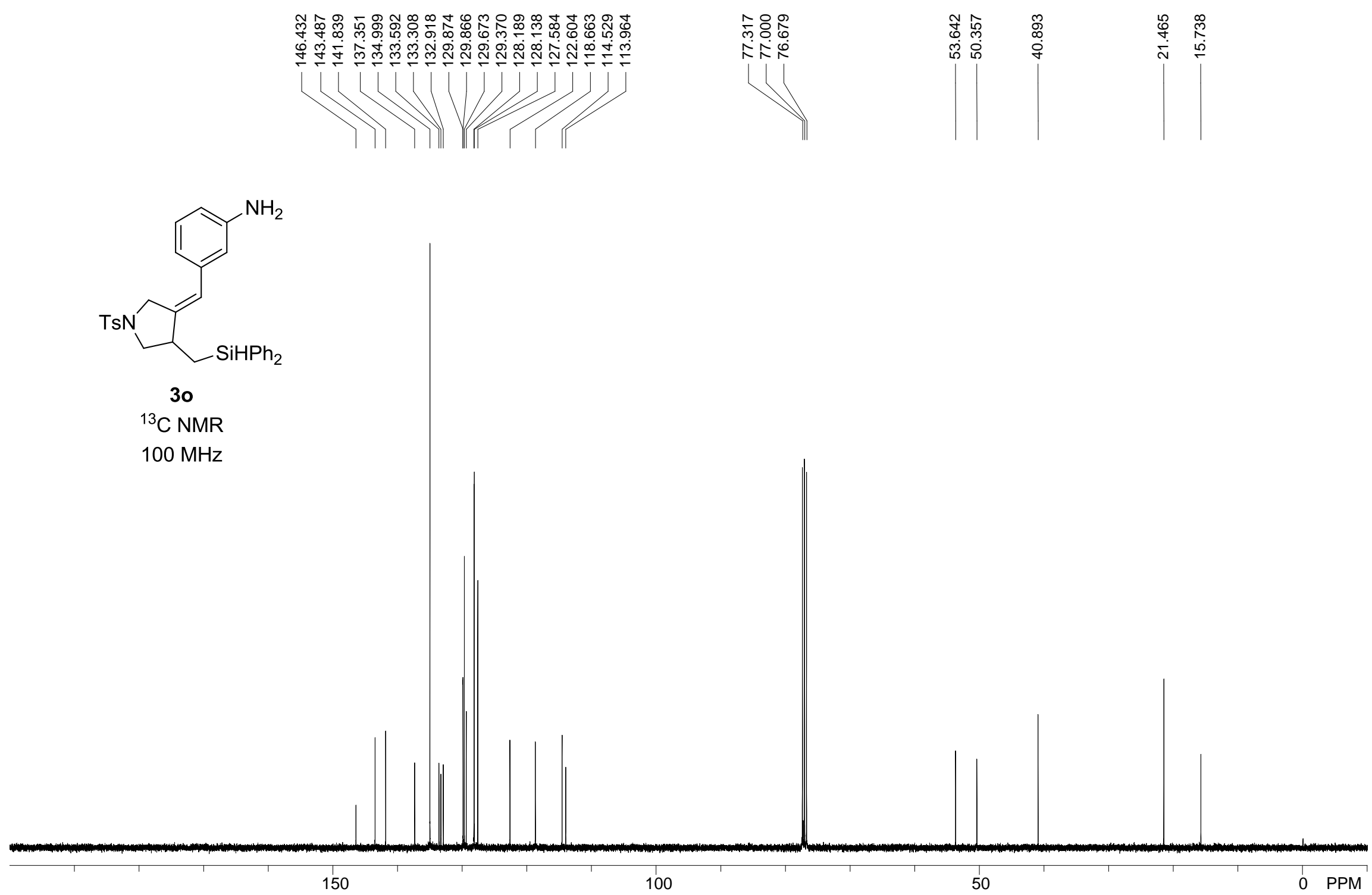


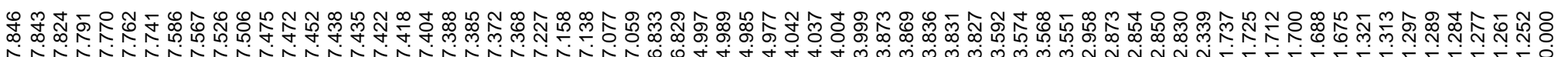

Tin $\mid$ mir

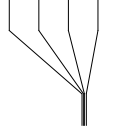

II II

VII

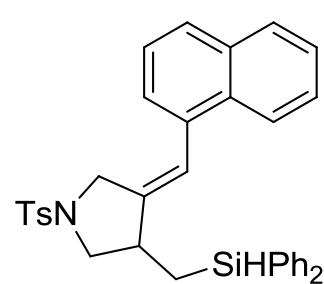

$9 \cdot 43$

$3 p$

${ }^{1} \mathrm{H} N M R$

$400 \mathrm{MHz}$

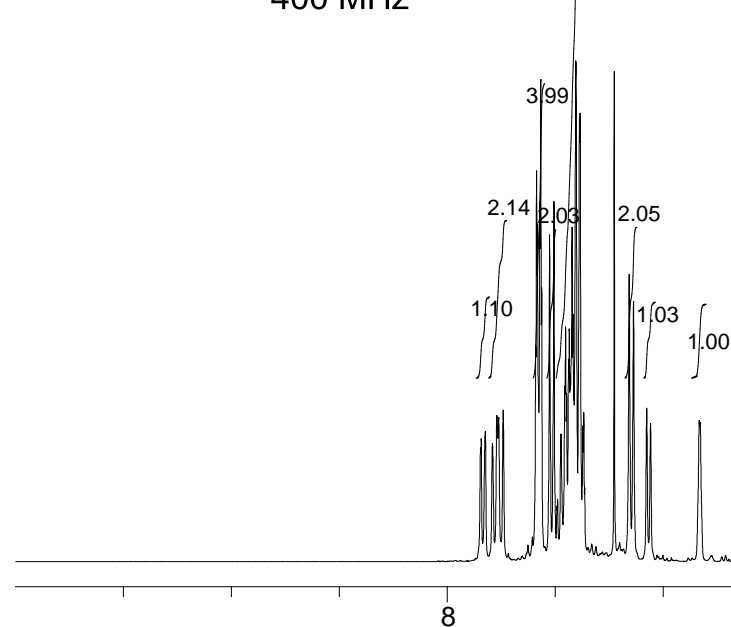

0.95

$\int^{1.03} 1.08 \quad 1.02 \quad 1.05$

1.02

1.34

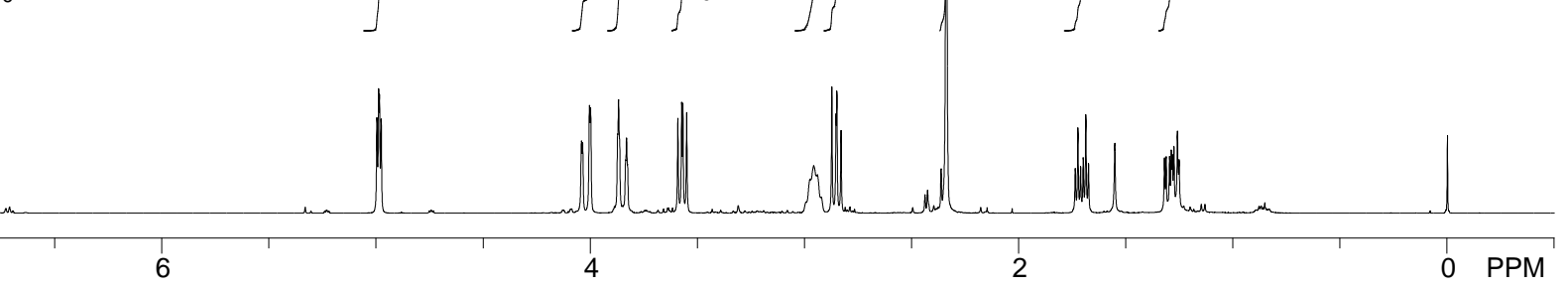




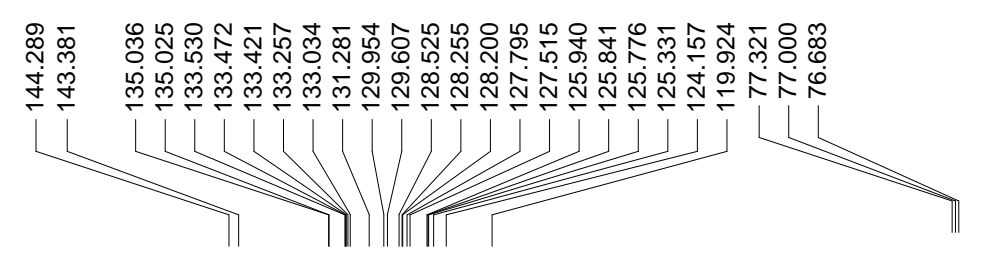

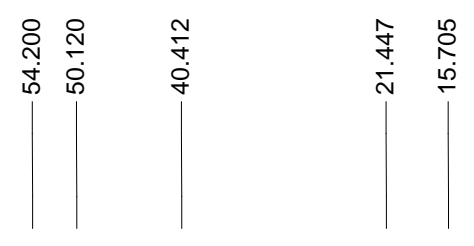

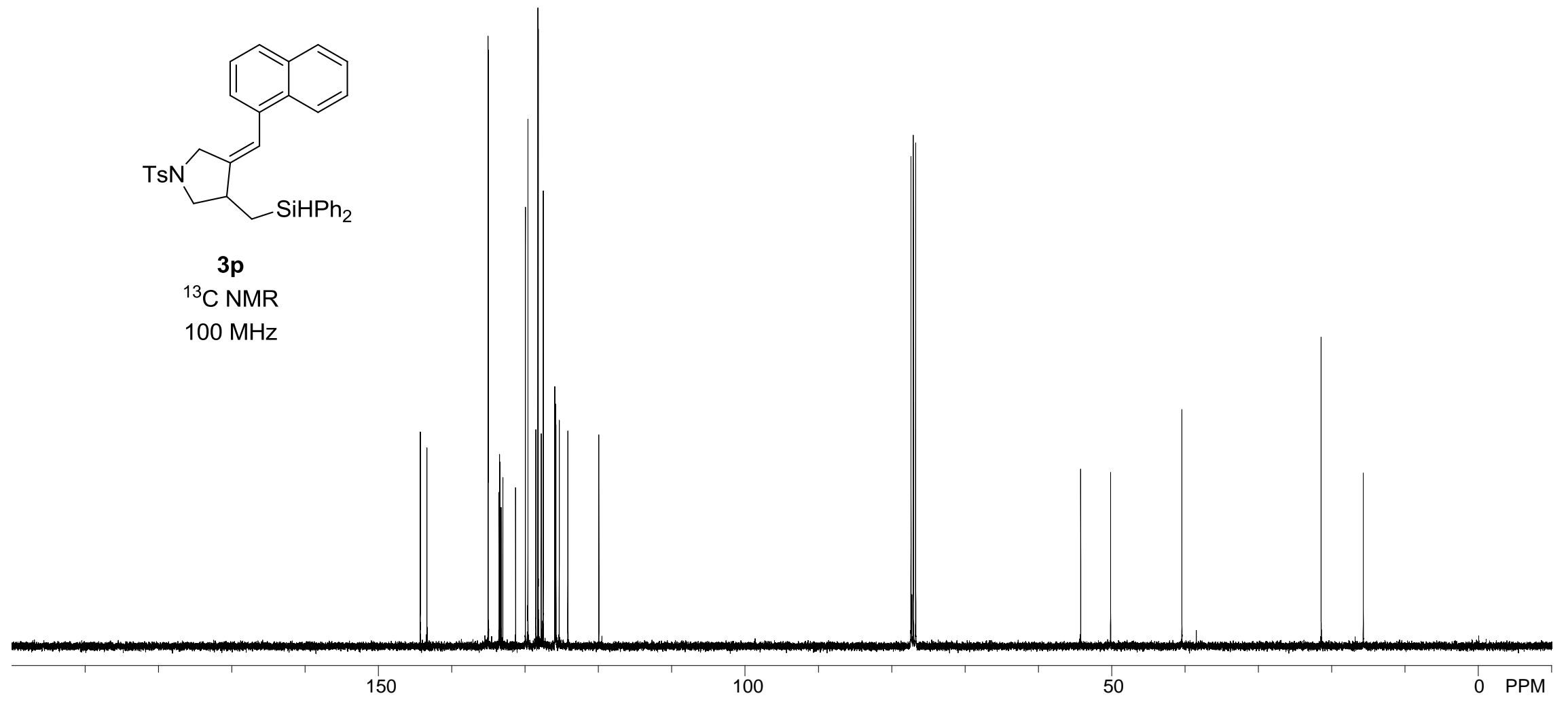




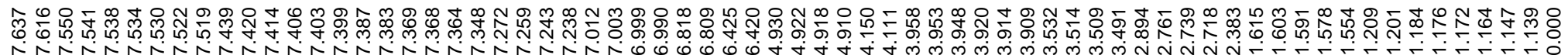

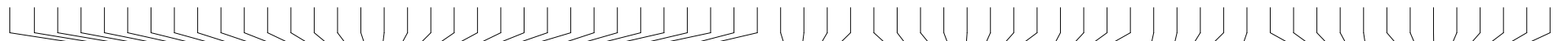
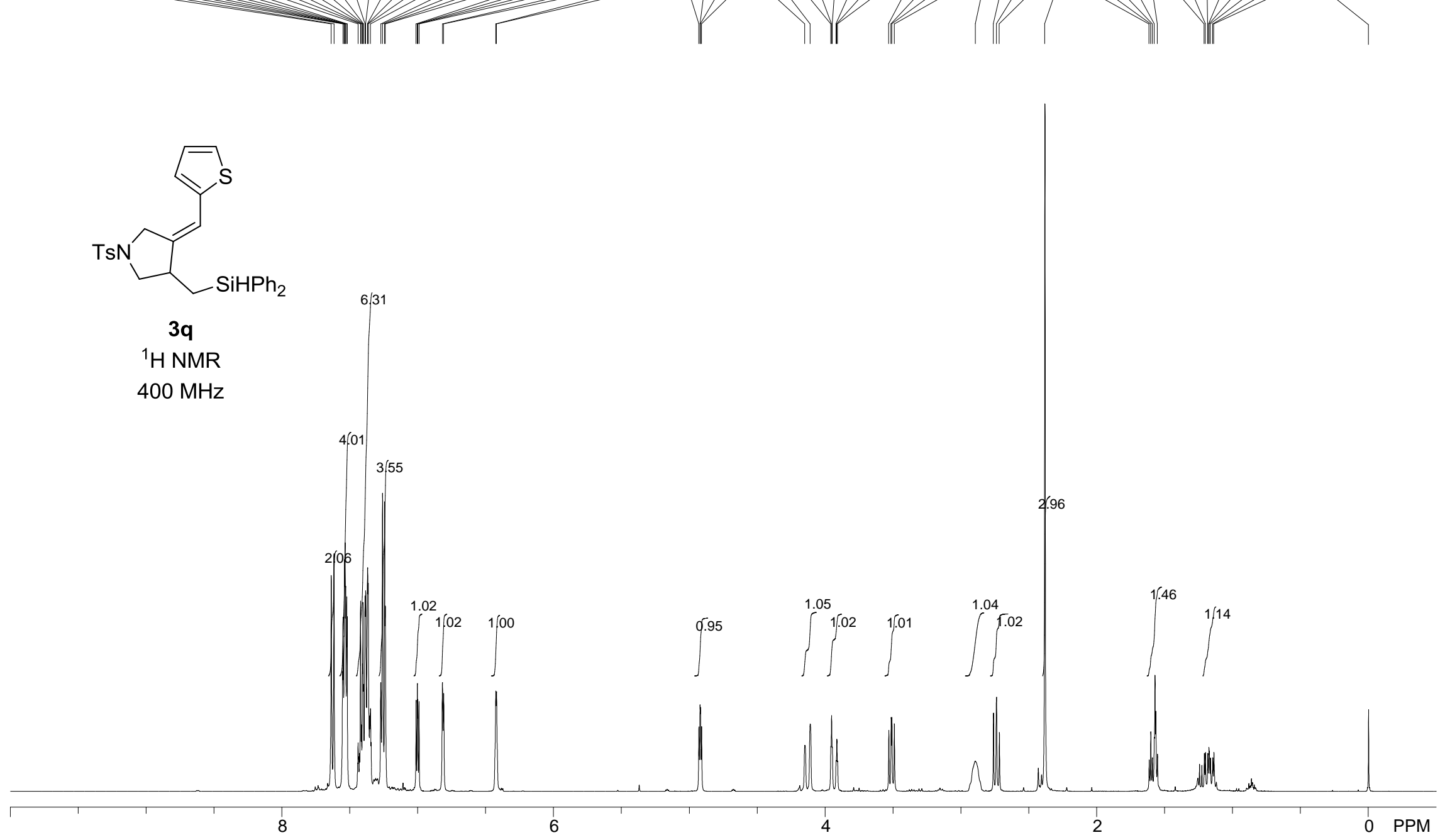


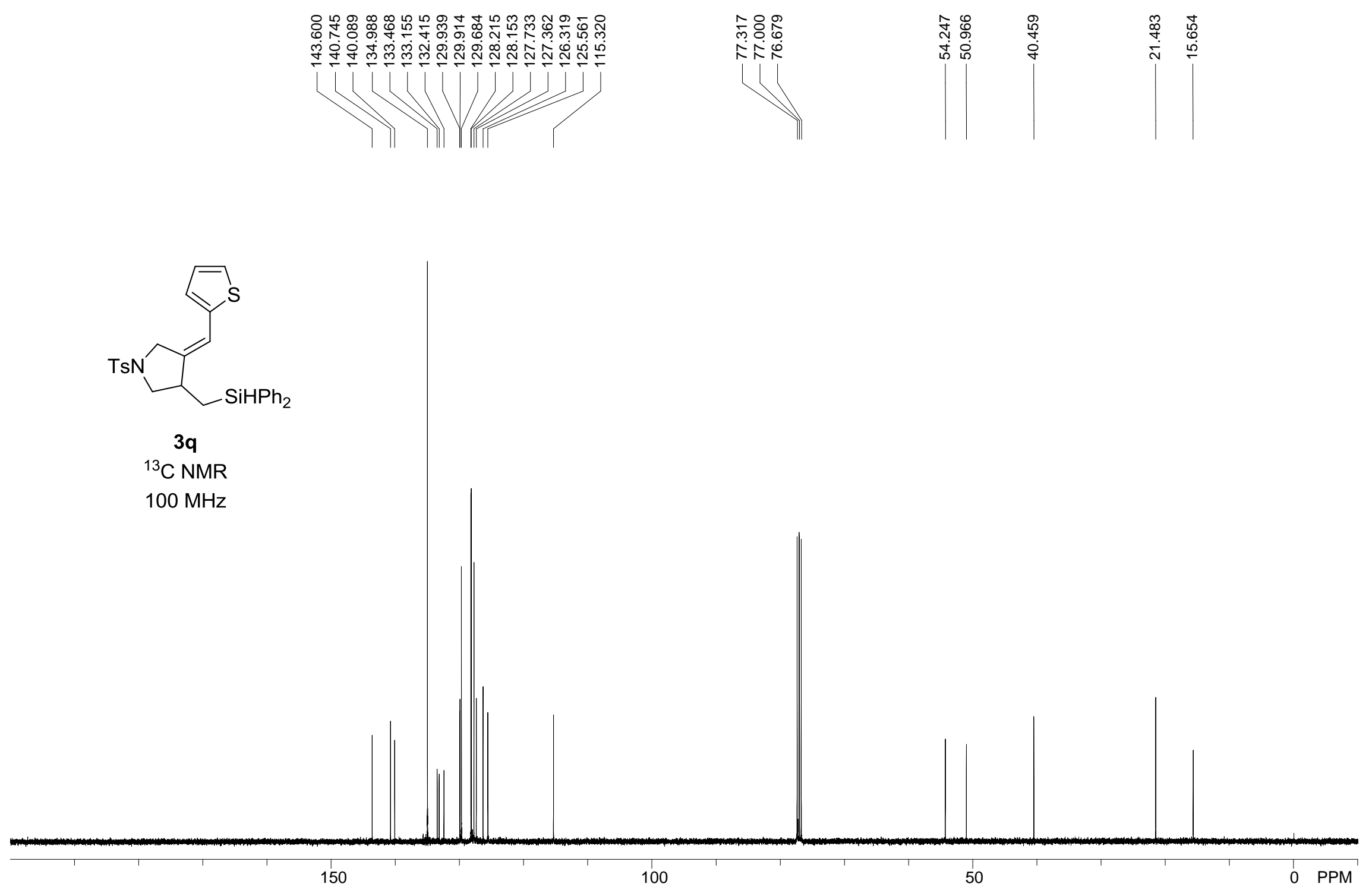

S41 


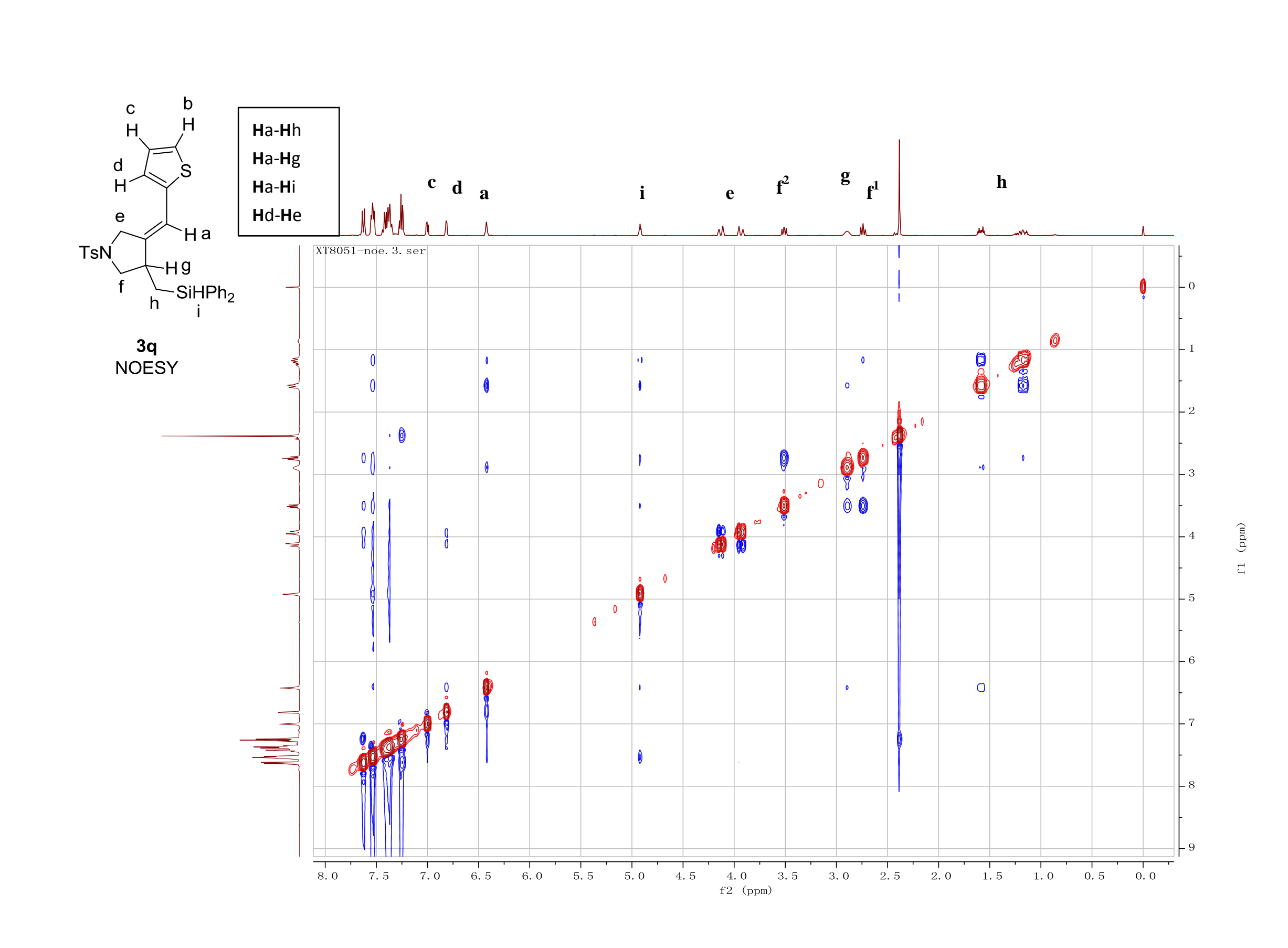




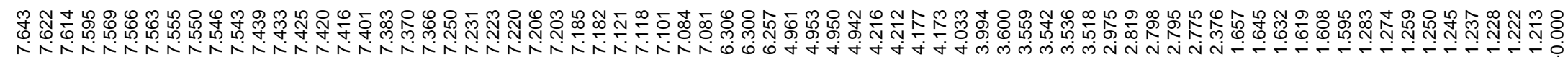

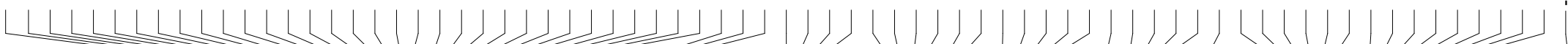

TIIIIIIII

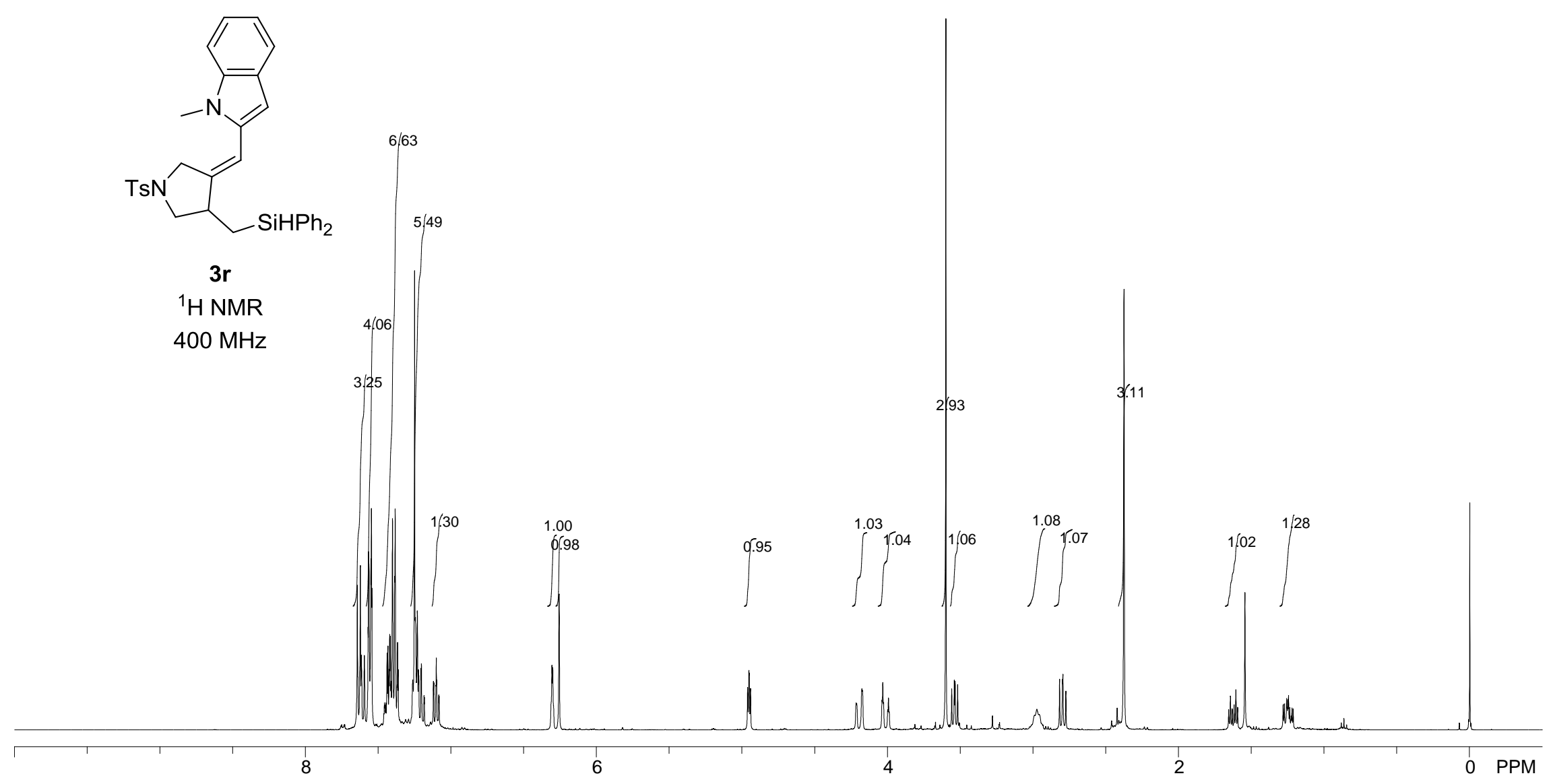

5.49

$3 r$

${ }^{1} \mathrm{H}$ NMR

$400 \mathrm{MHz}$

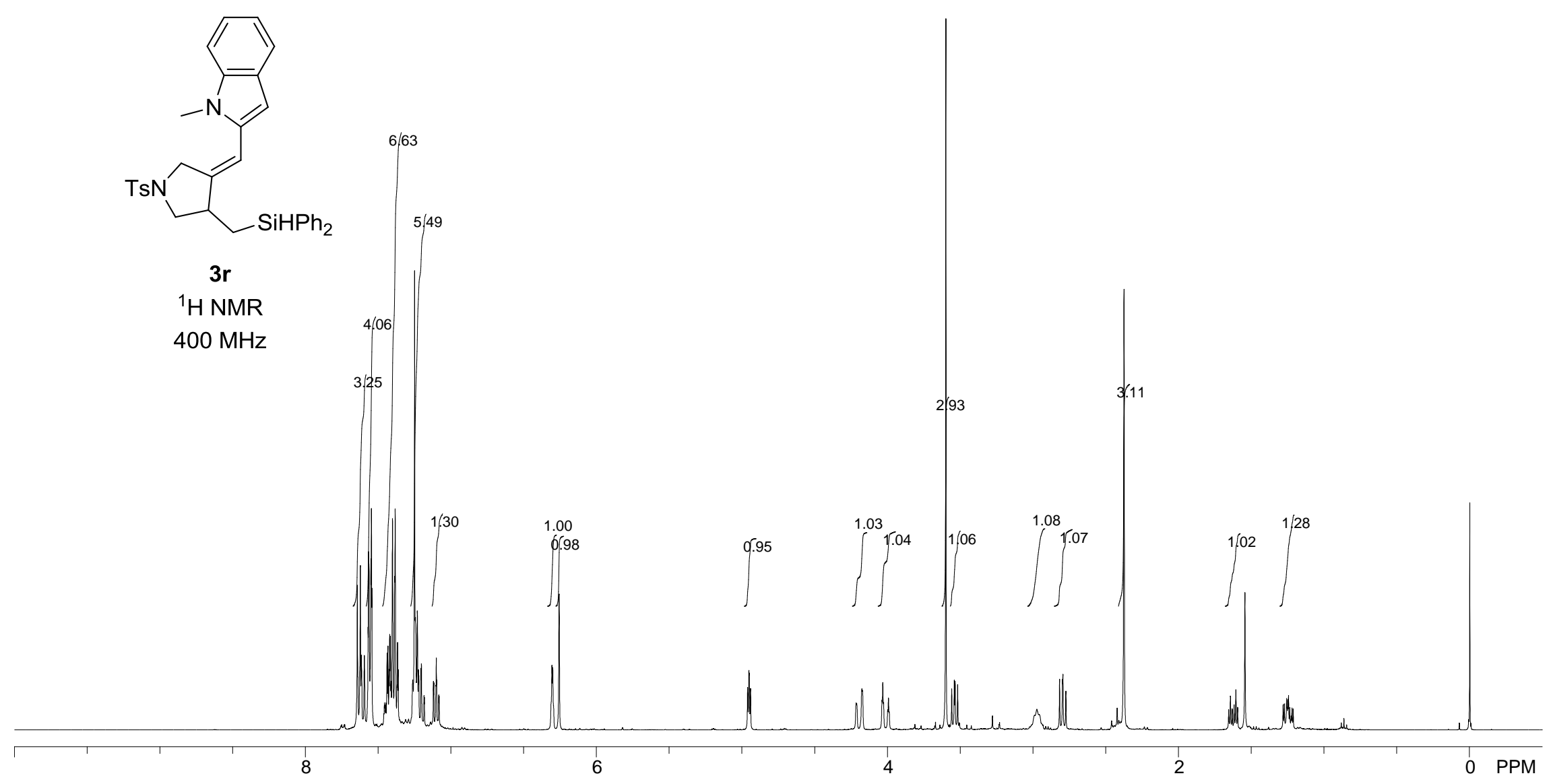



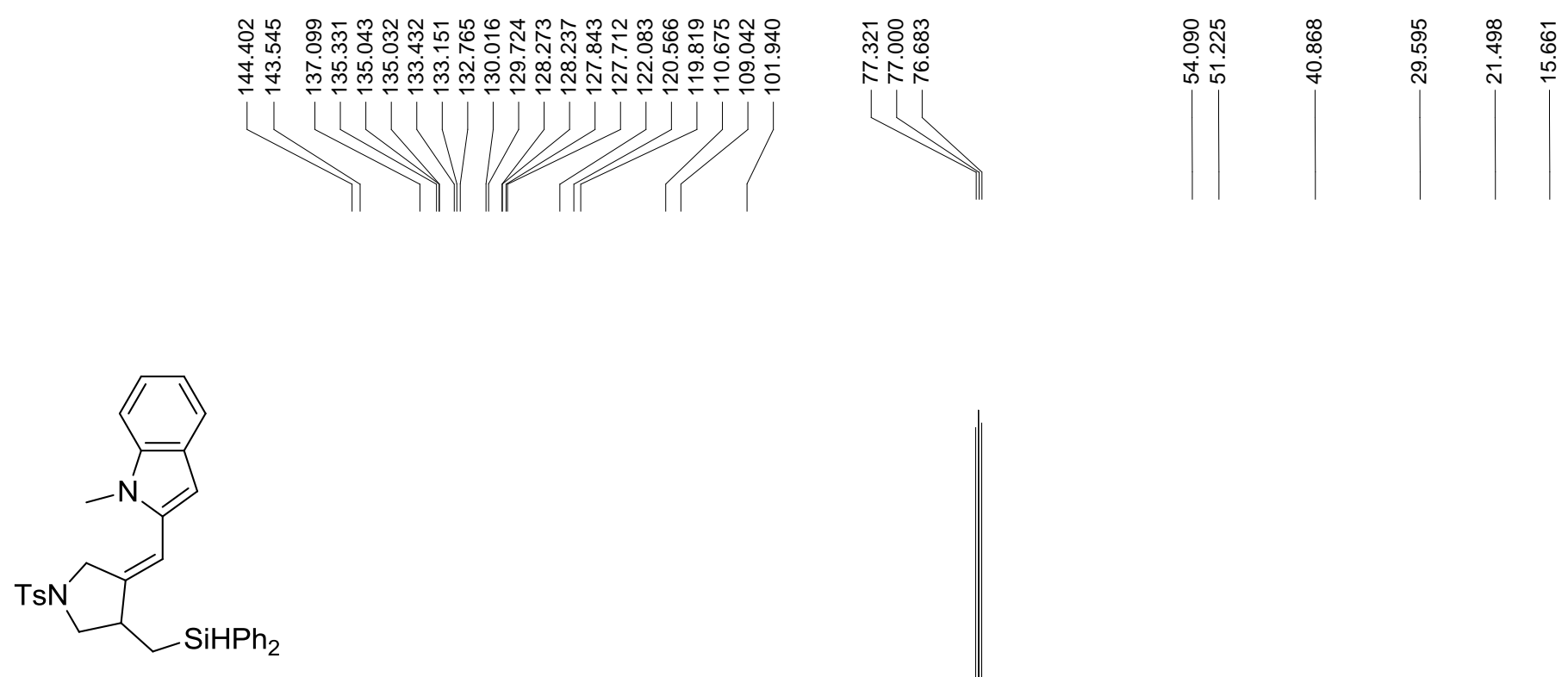

$3 \mathbf{r}$
${ }^{3} \mathrm{C} \mathrm{NMR}$
$100 \mathrm{MHz}$ 


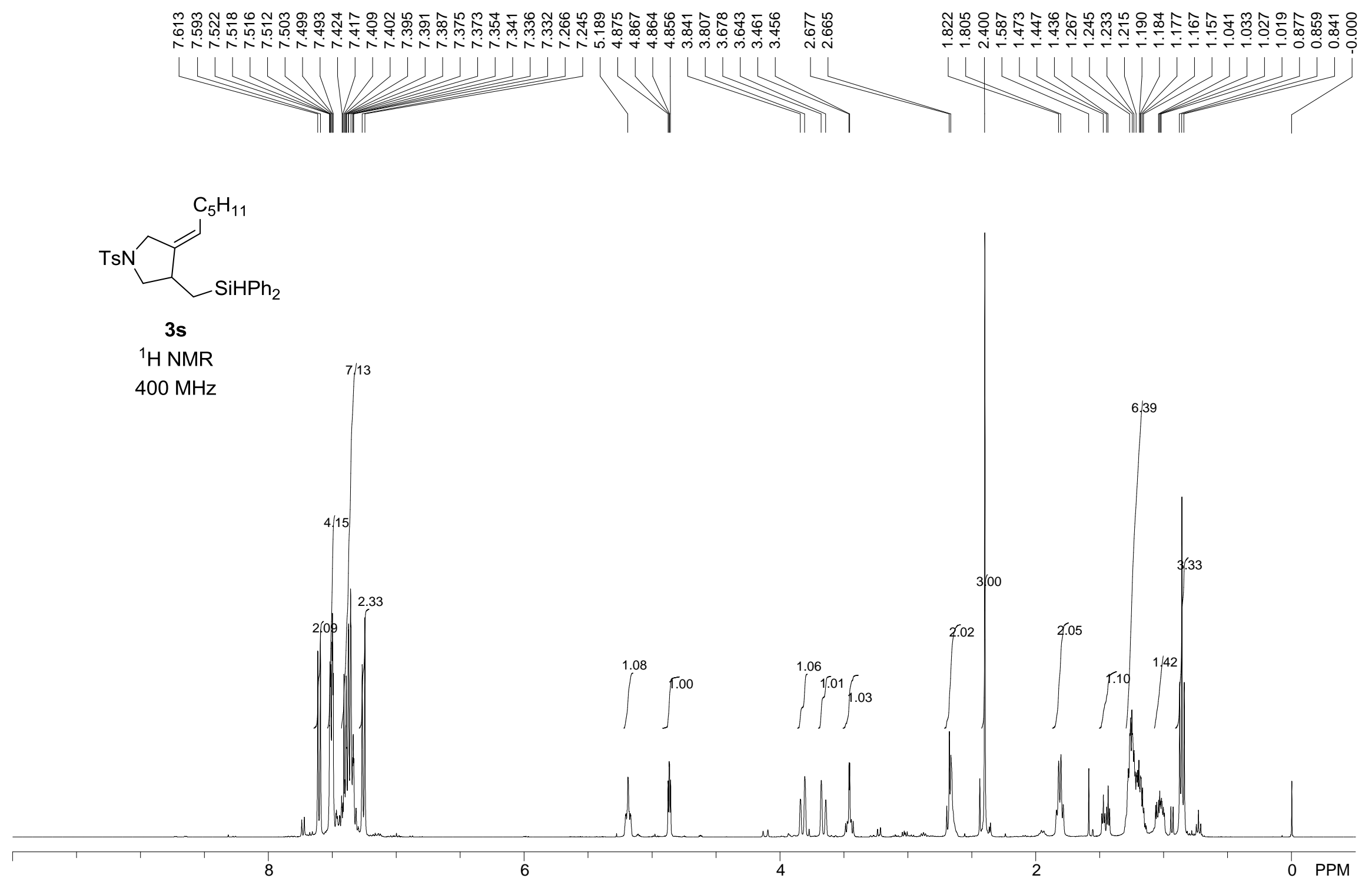

S45 


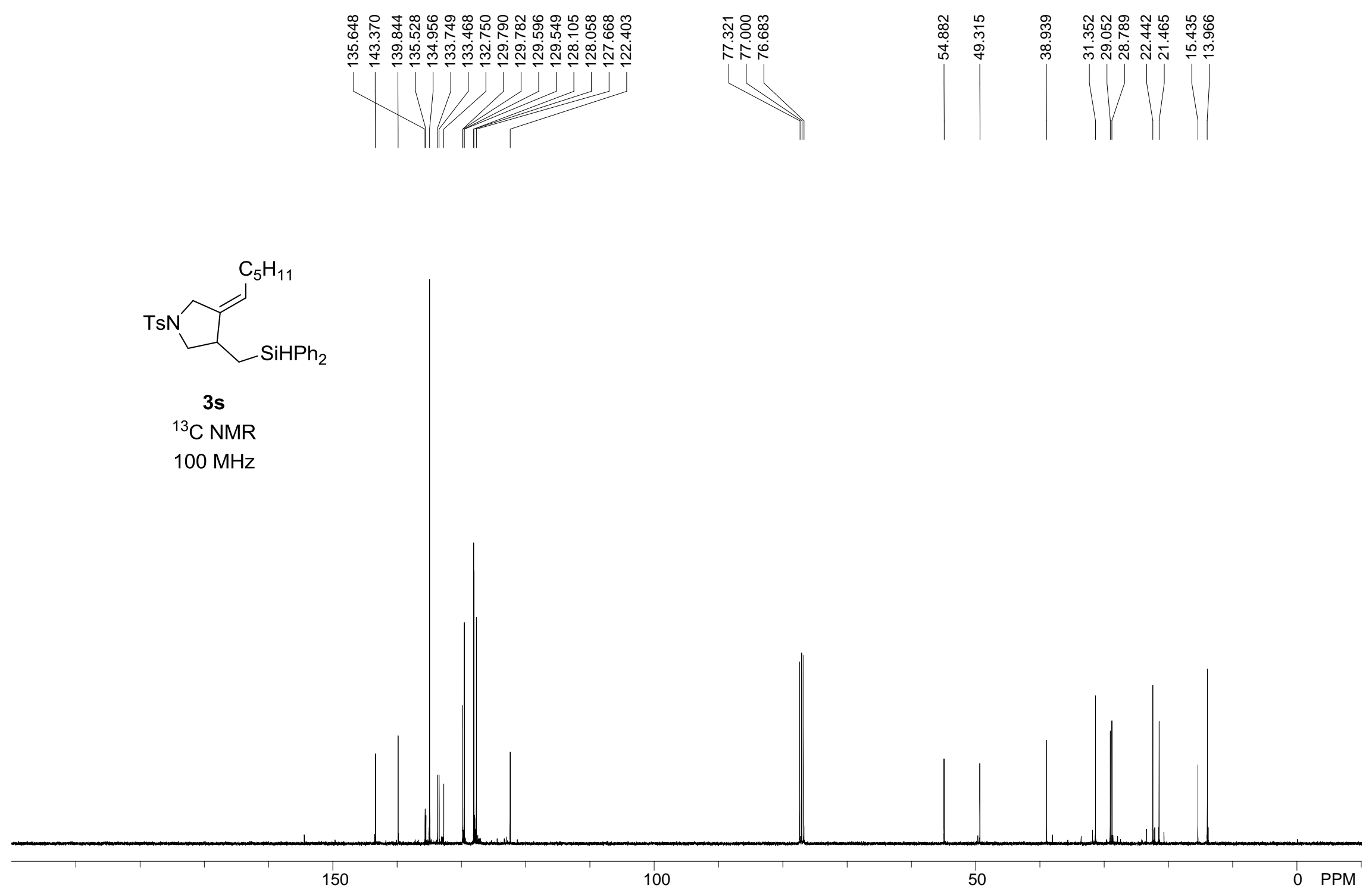




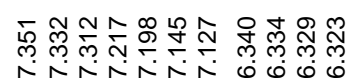

LLLLLLLLL

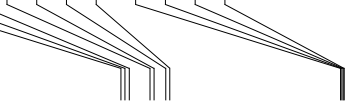

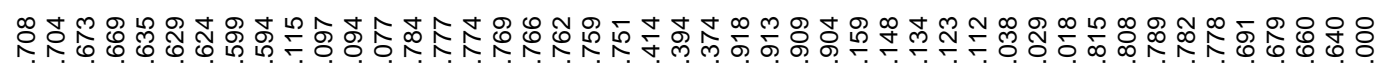

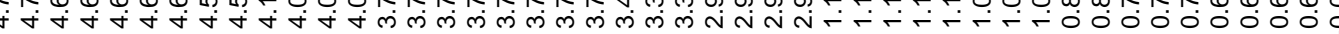

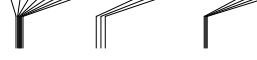

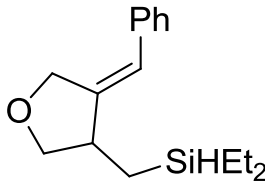

$3 a b$

${ }^{1} \mathrm{H}$ NMR

$400 \mathrm{MHz}$

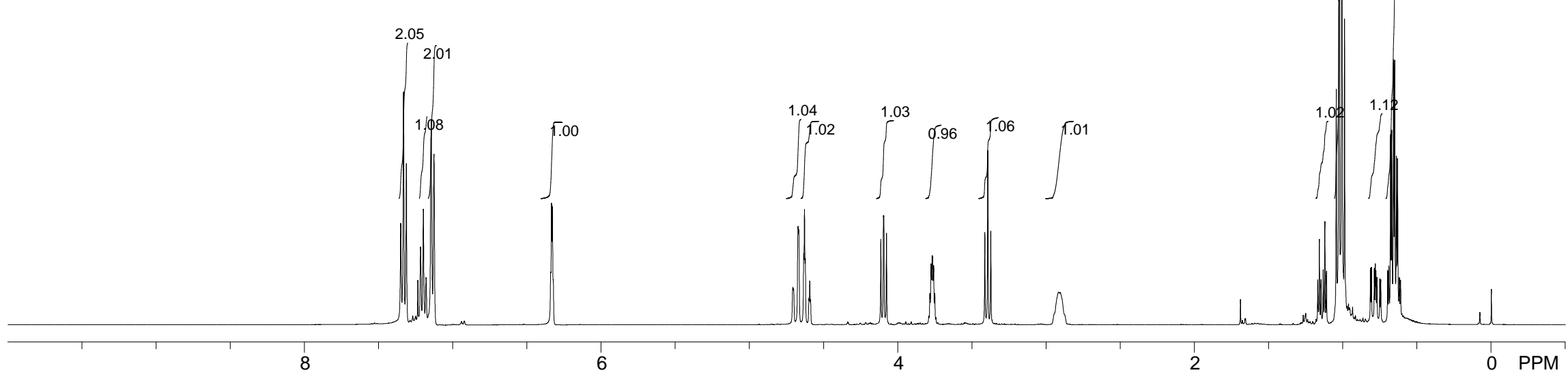




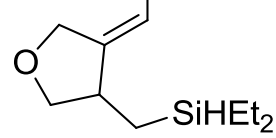

$3 a b$

${ }^{13} \mathrm{C}$ NMR

$100 \mathrm{MHz}$ 


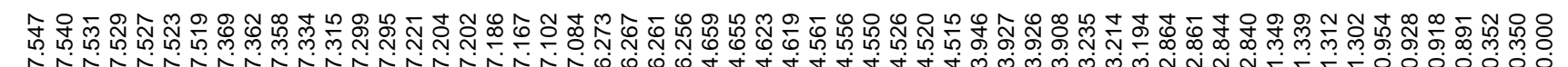
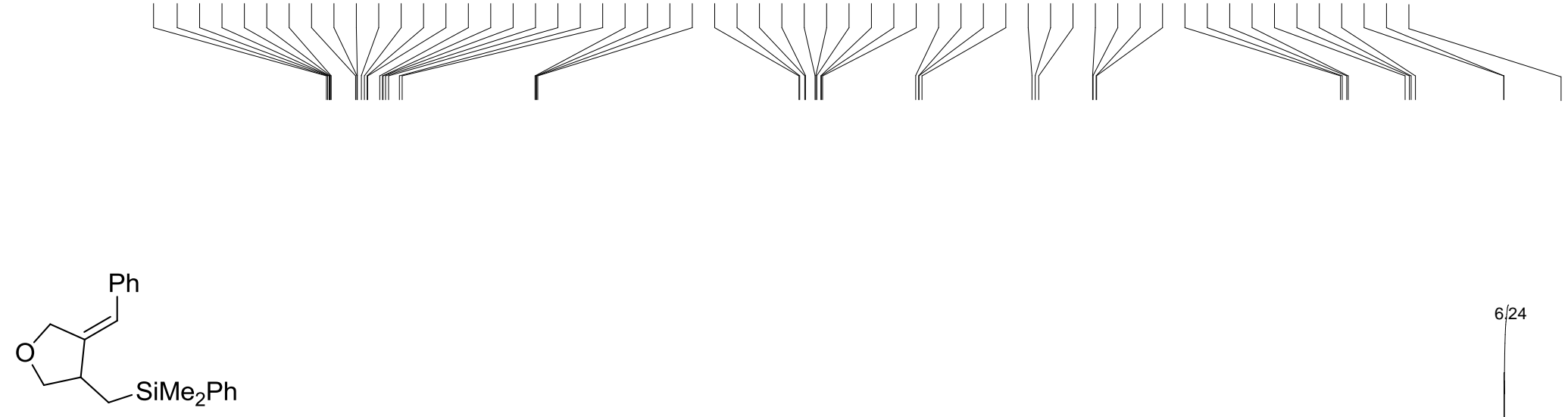

3ac

${ }^{1} \mathrm{H}$ NMR

$400 \mathrm{MHz}$

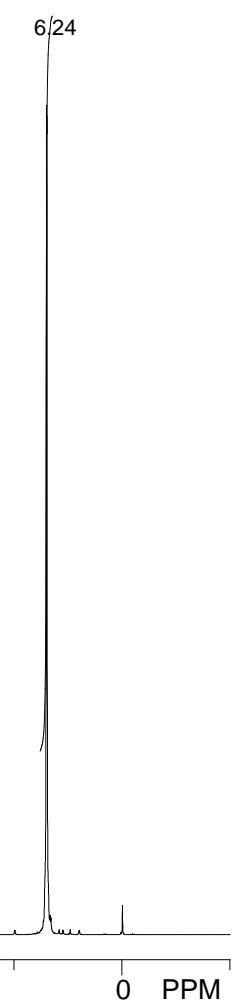



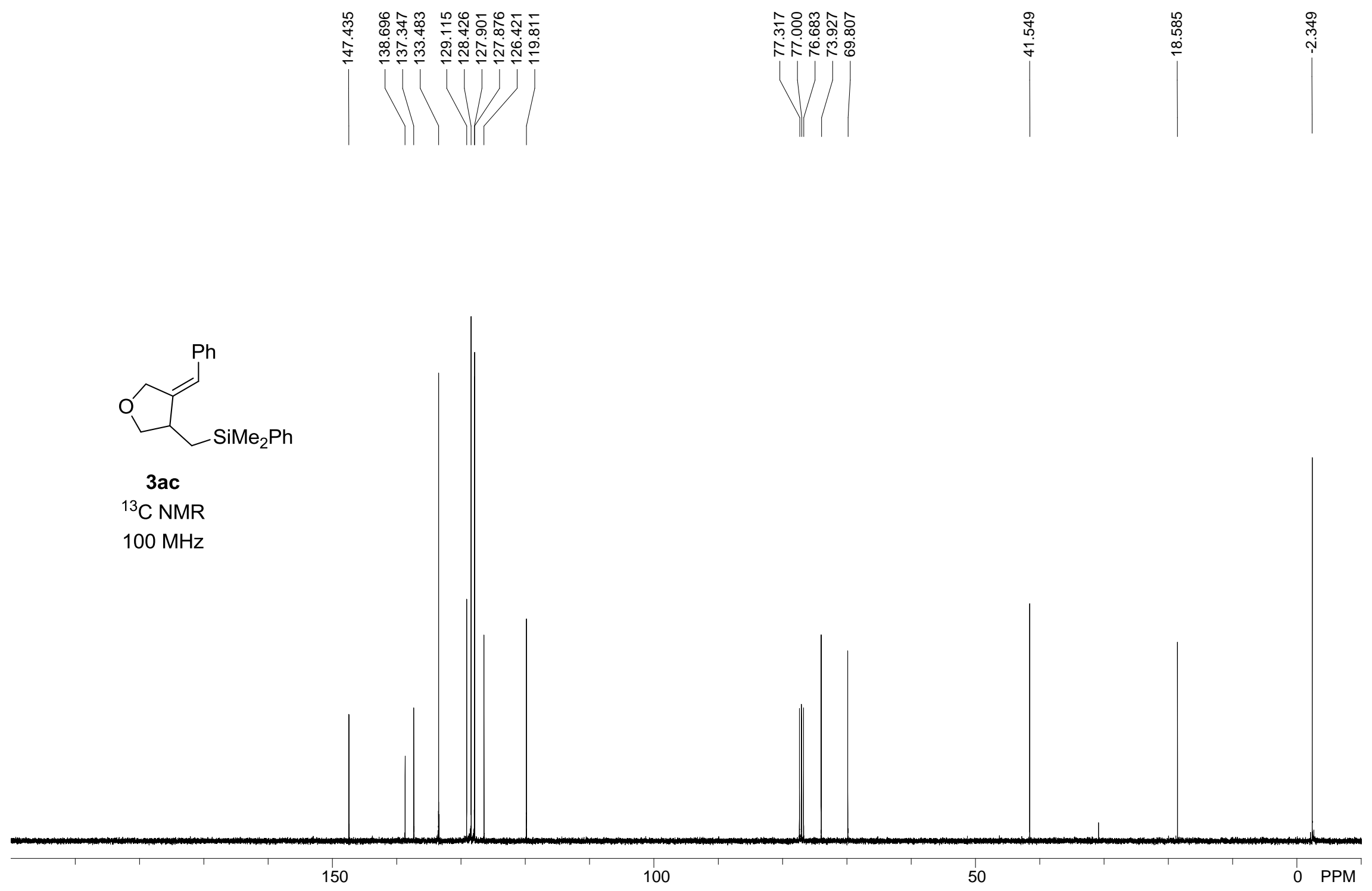

S50 


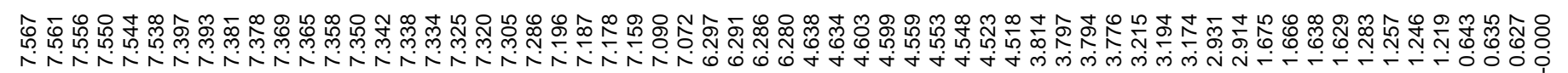

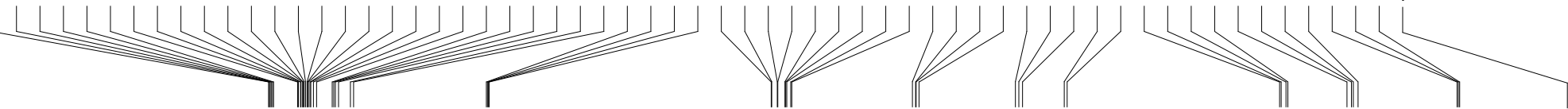

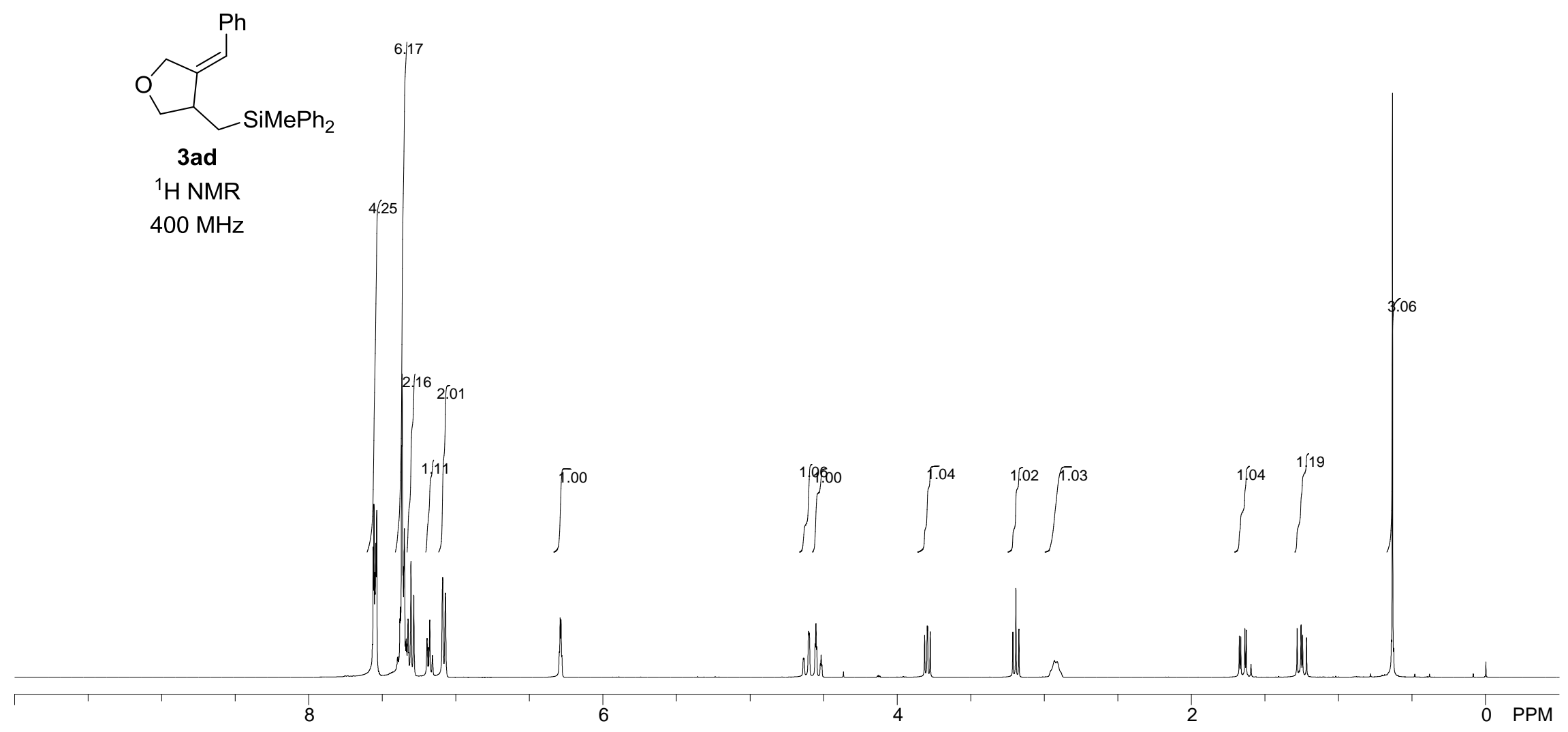



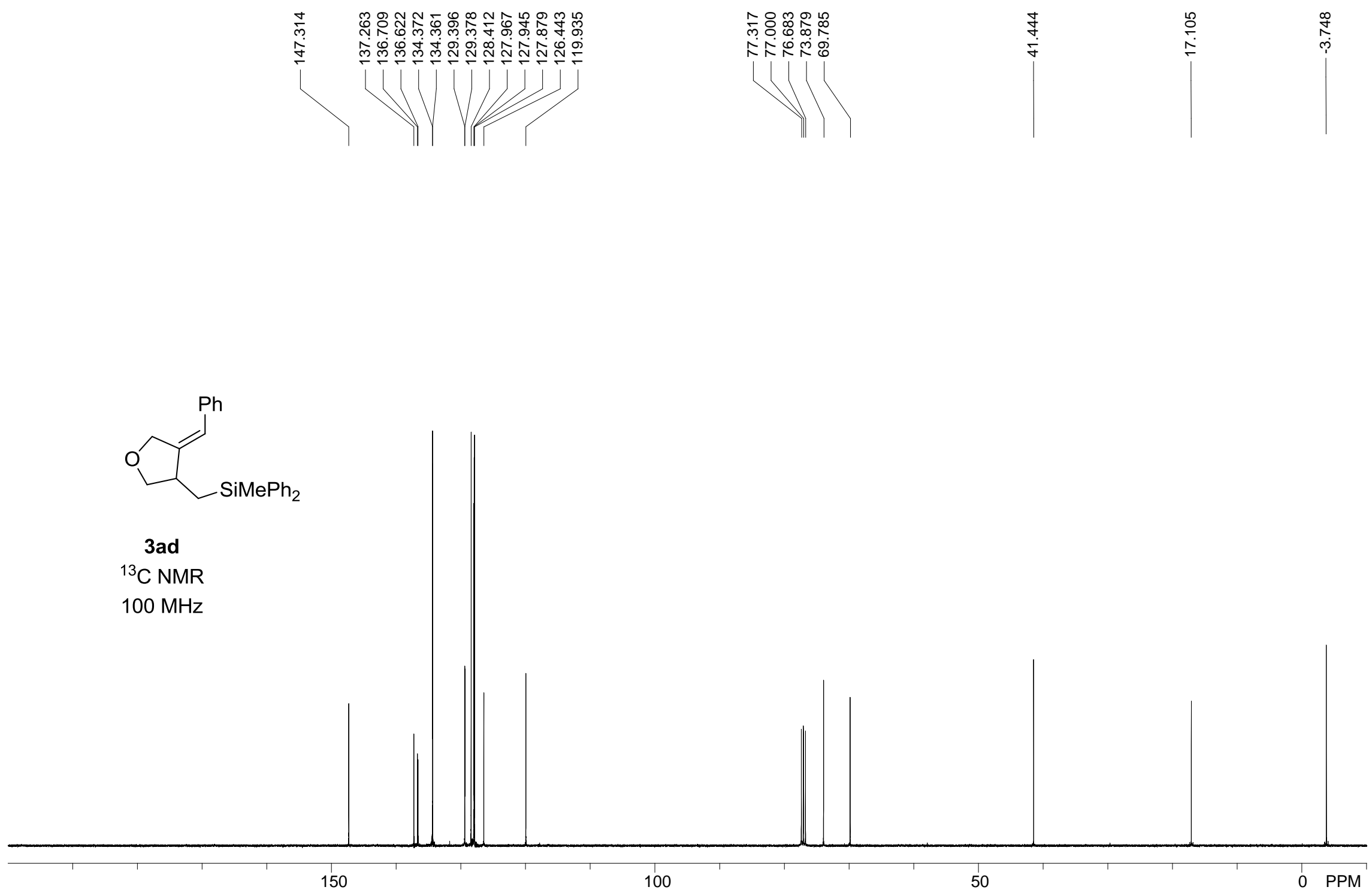

S52 


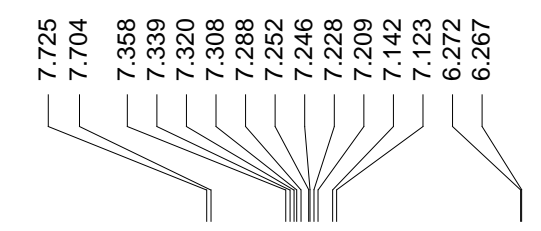

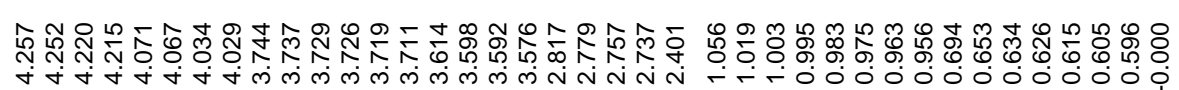

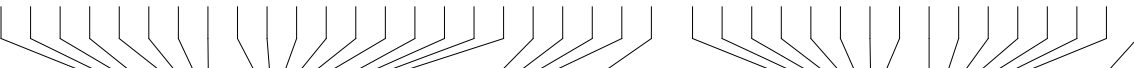
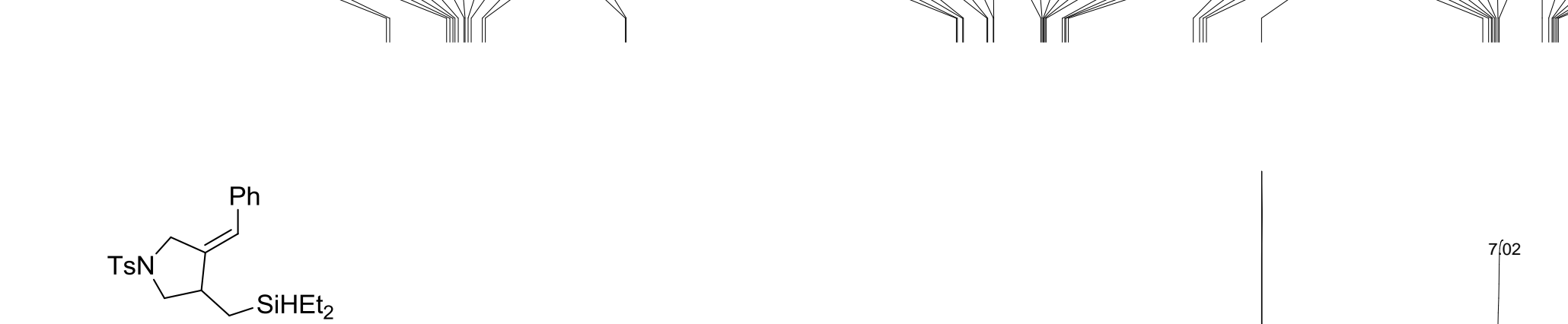

$3 \mathrm{cb}$

${ }^{1} \mathrm{H}$ NMR

$400 \mathrm{MHz}$

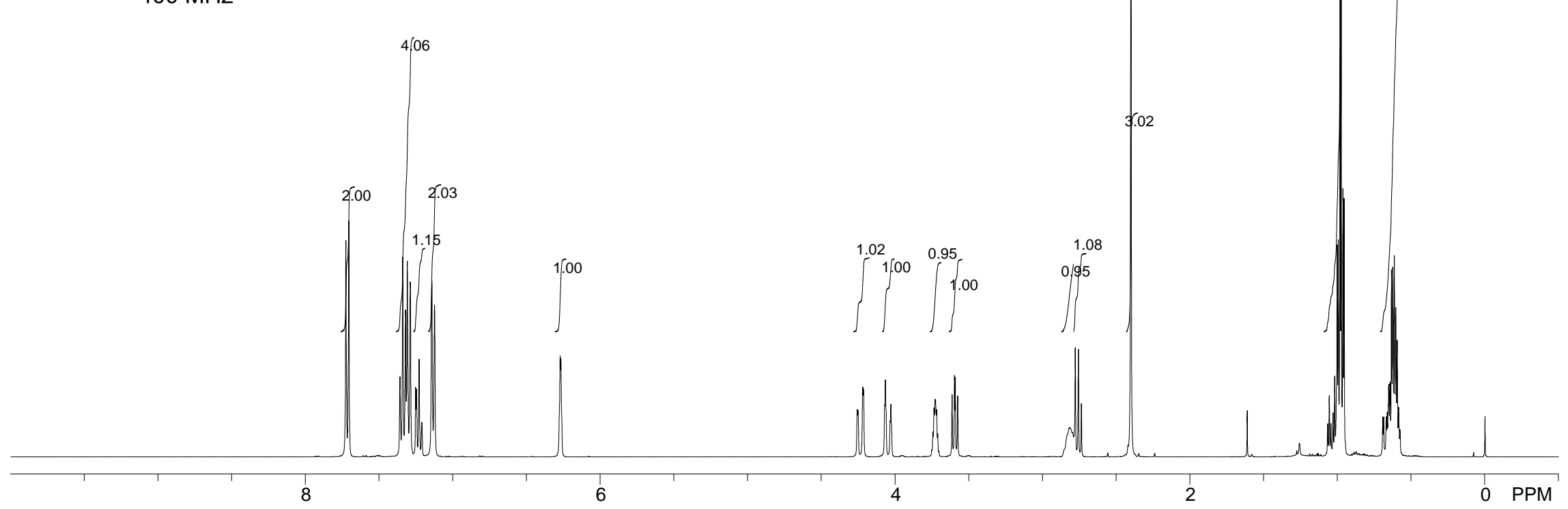




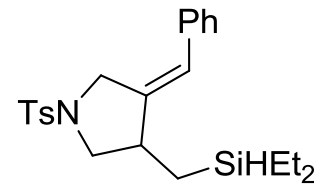

$3 \mathrm{cb}$

${ }^{13} \mathrm{C}$ NMR

$100 \mathrm{MHz}$

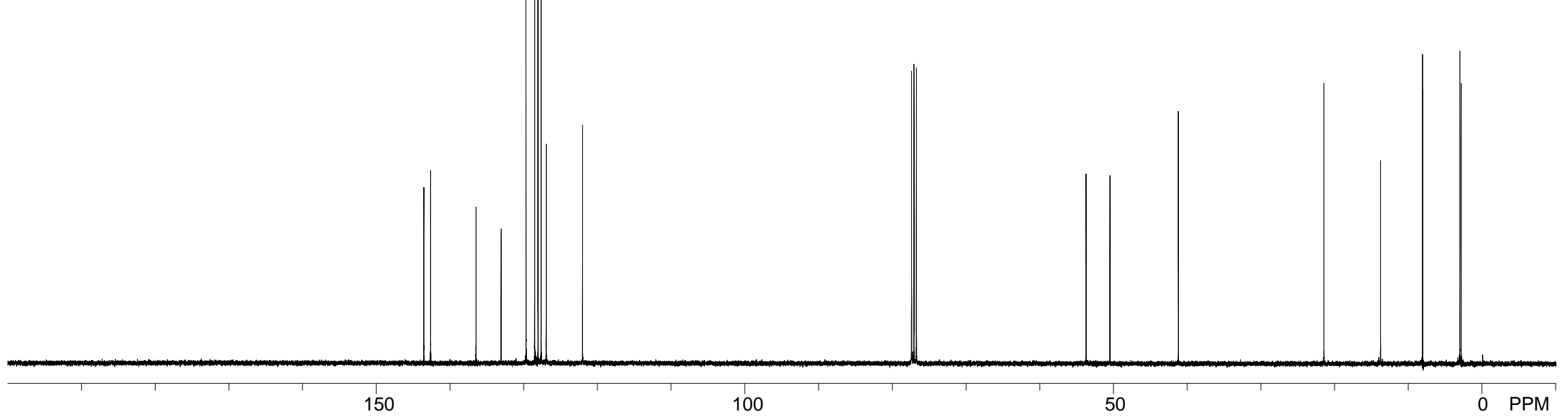




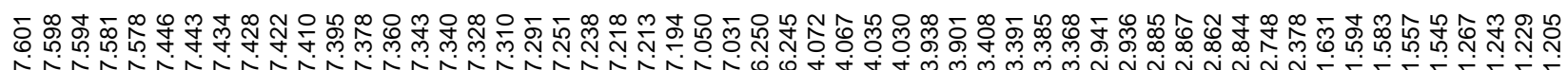
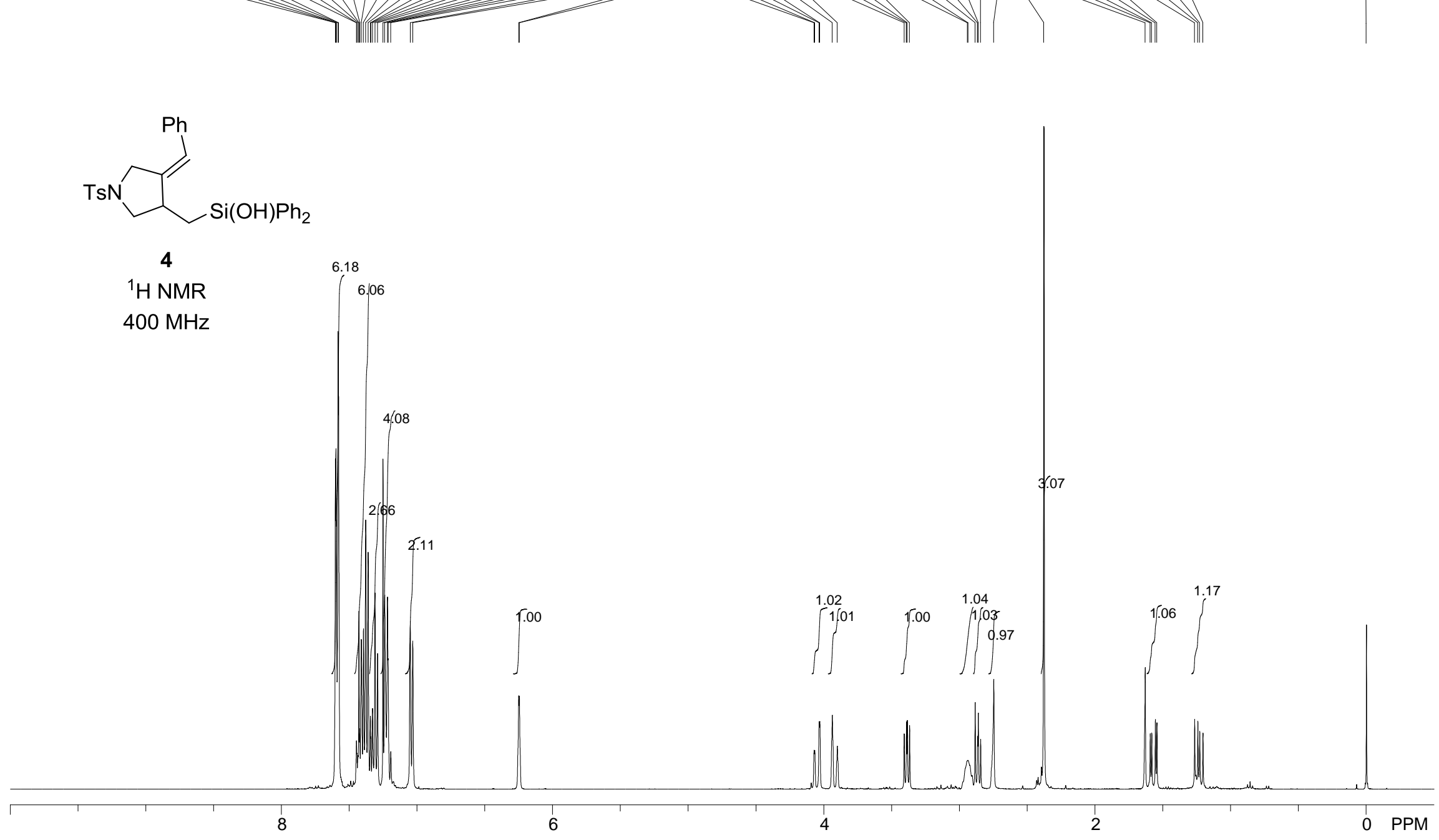


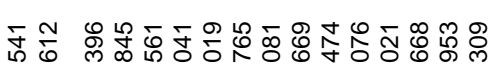

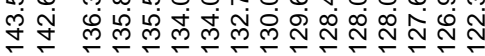

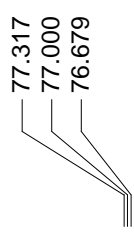

용ㅇㅇ

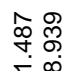

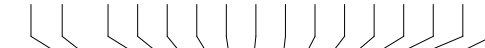

II IIII || III

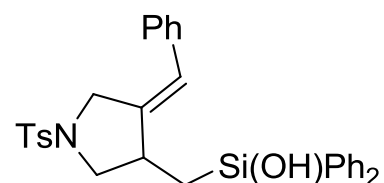

4

${ }^{13} \mathrm{C} \mathrm{NMR}$

$100 \mathrm{MHz}$

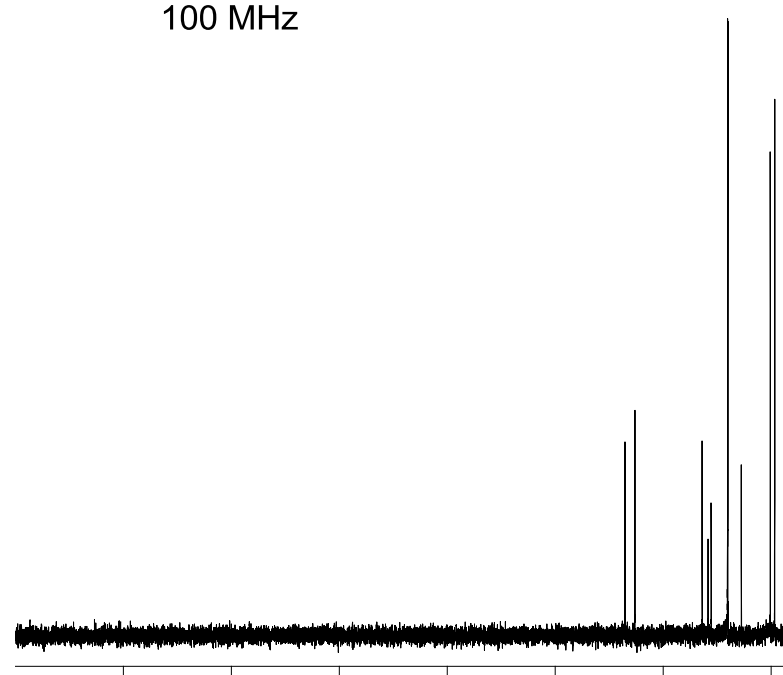




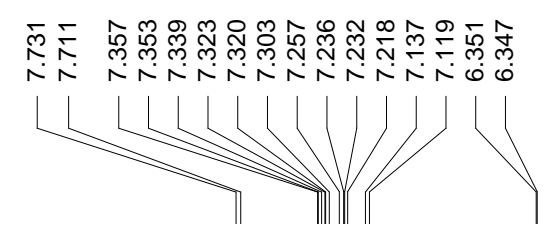

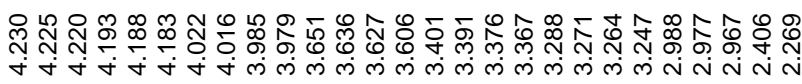

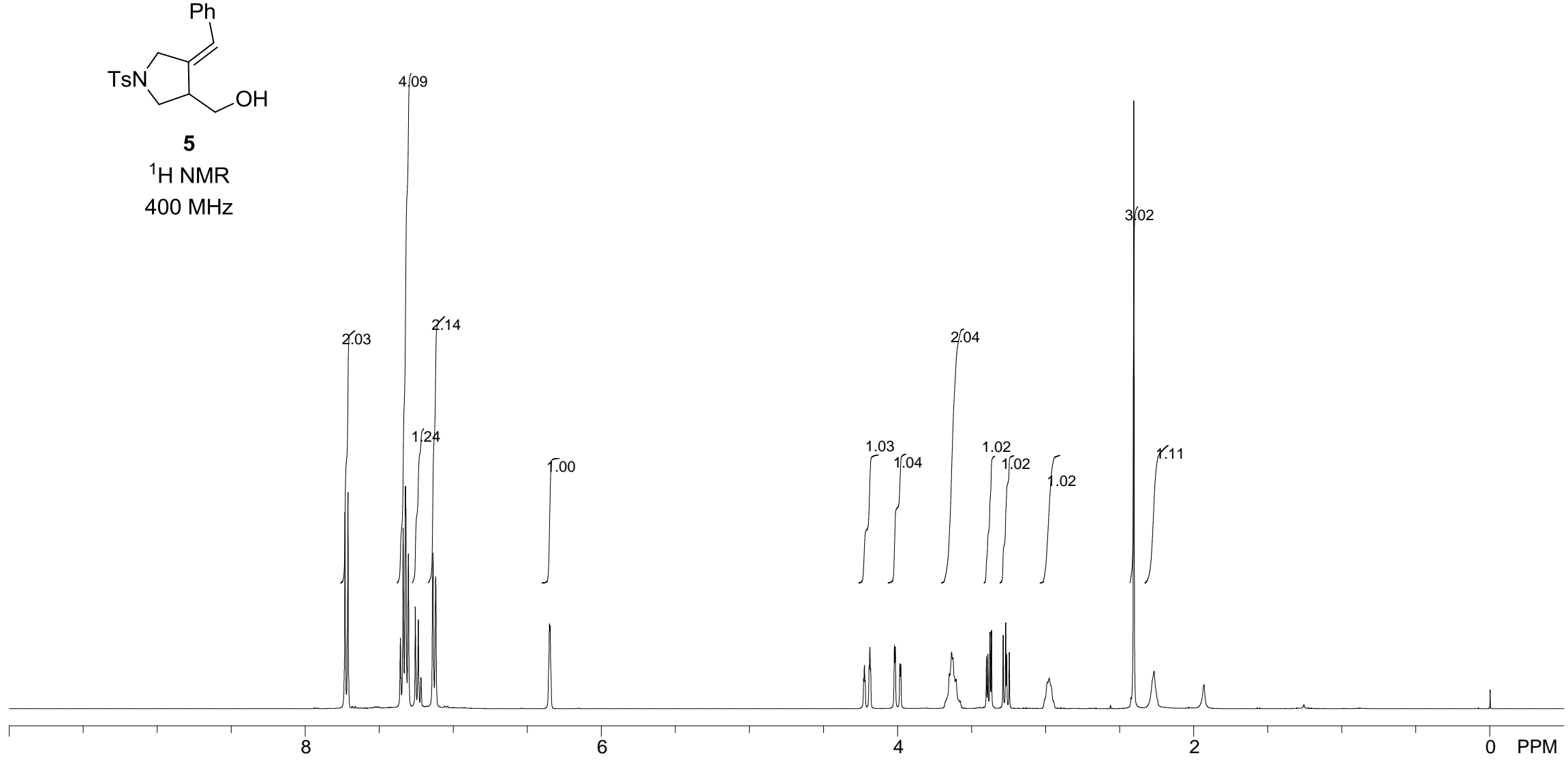




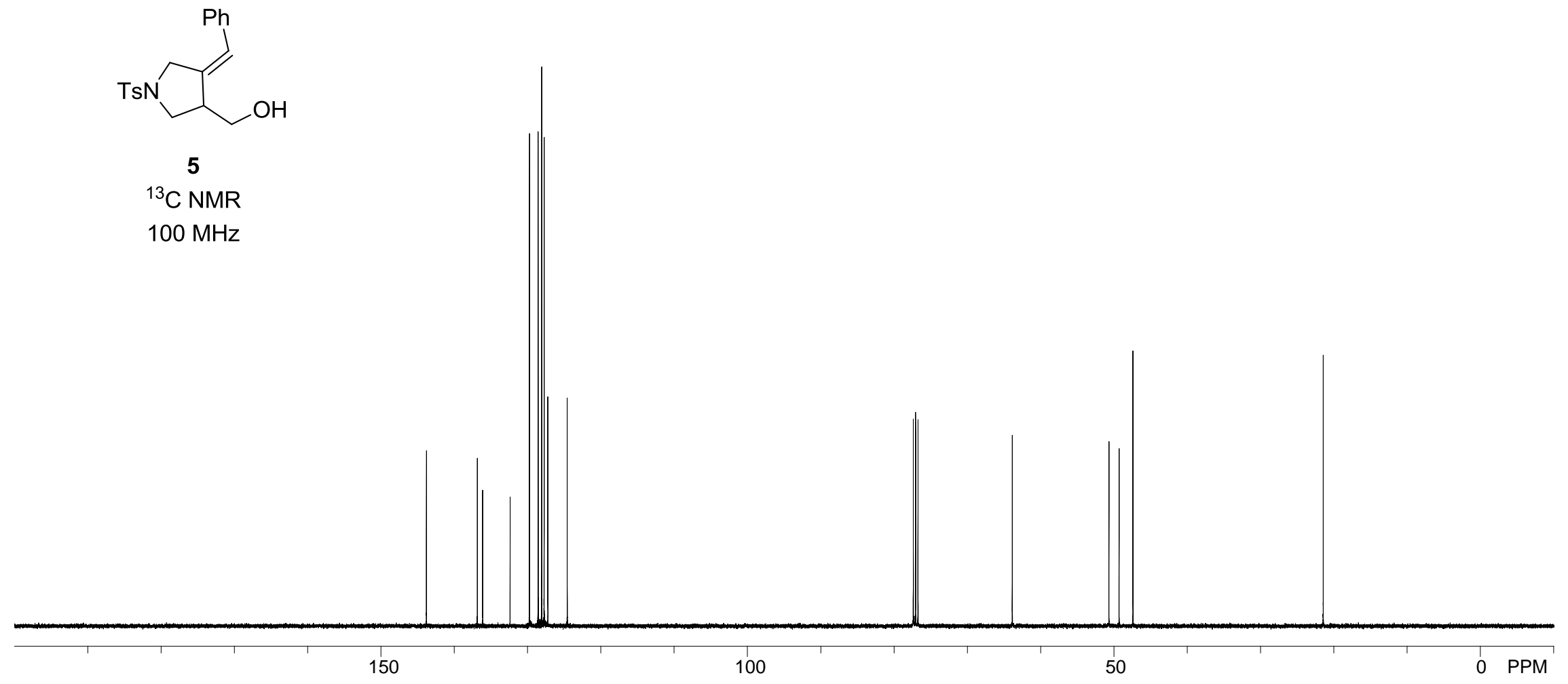




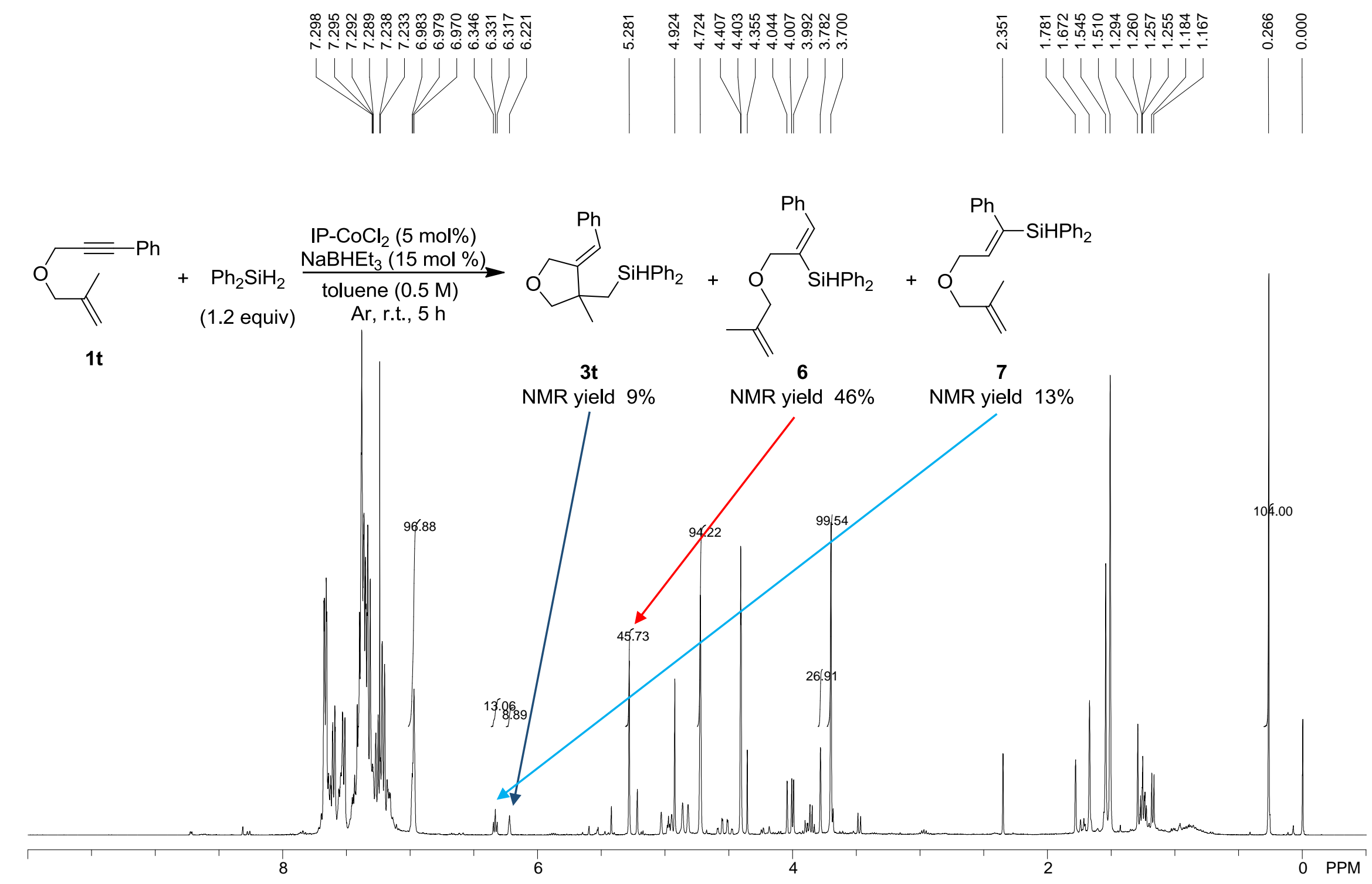




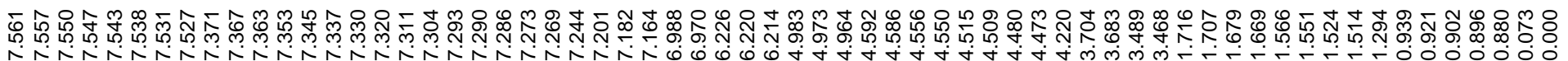

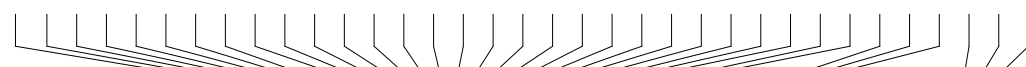

\ IIIIII
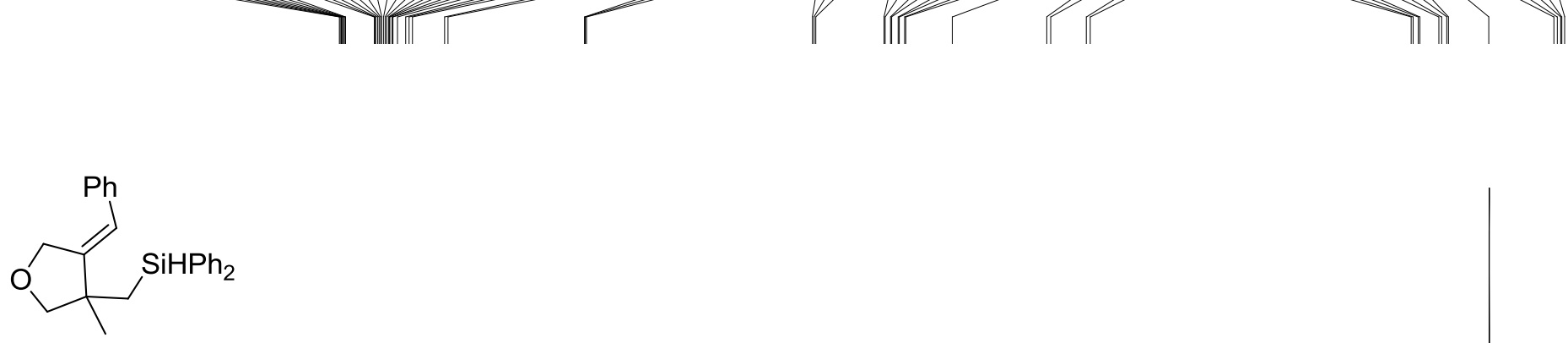

3t

8.27

${ }^{1} \mathrm{H} N M R$

$400 \mathrm{MHz}$

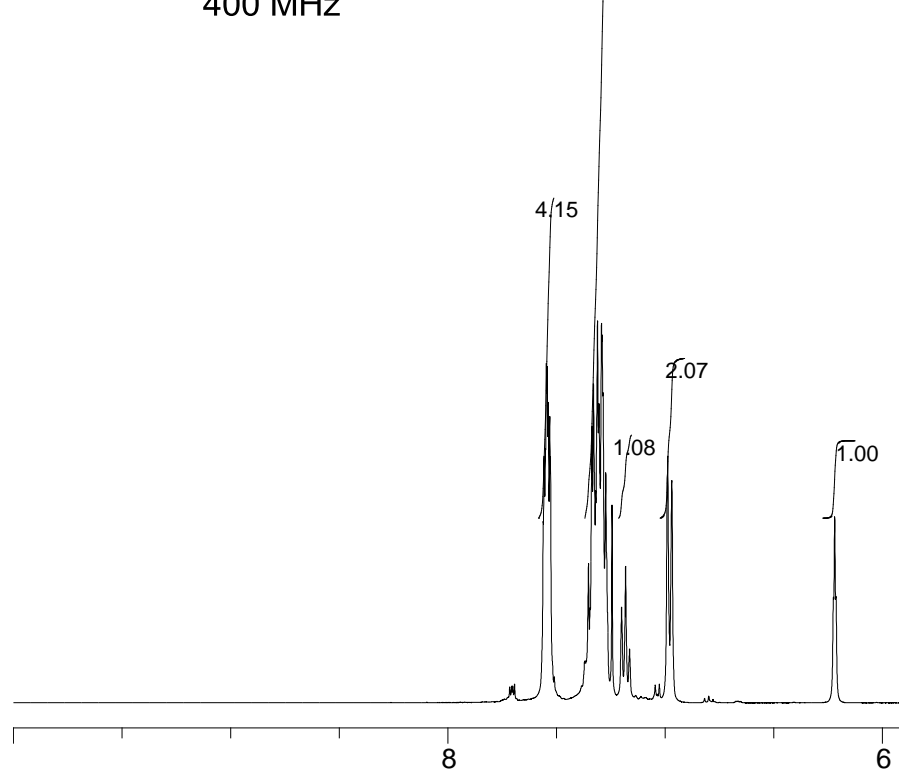

$00 \quad 0.96 \quad 1.04$

1.161 .06

3.28

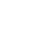




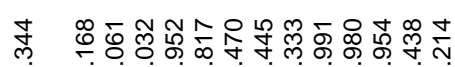

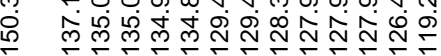

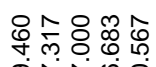

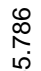

๙

的下品

(1)

Uu

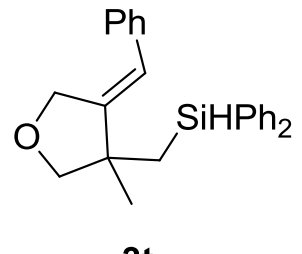

$3 t$

${ }^{13} \mathrm{C}$ NMR

$100 \mathrm{MHz}$

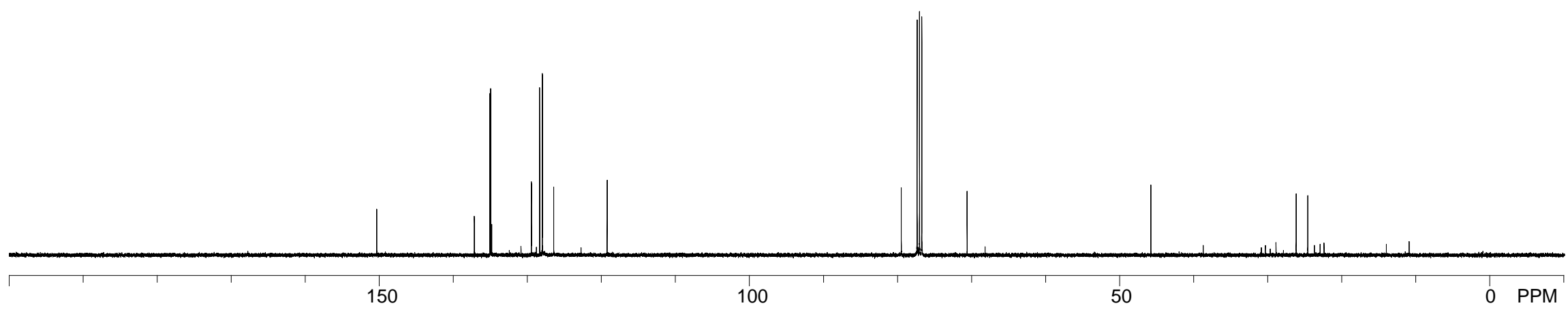




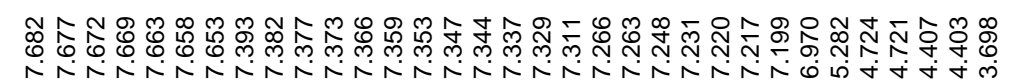

I IIIIII
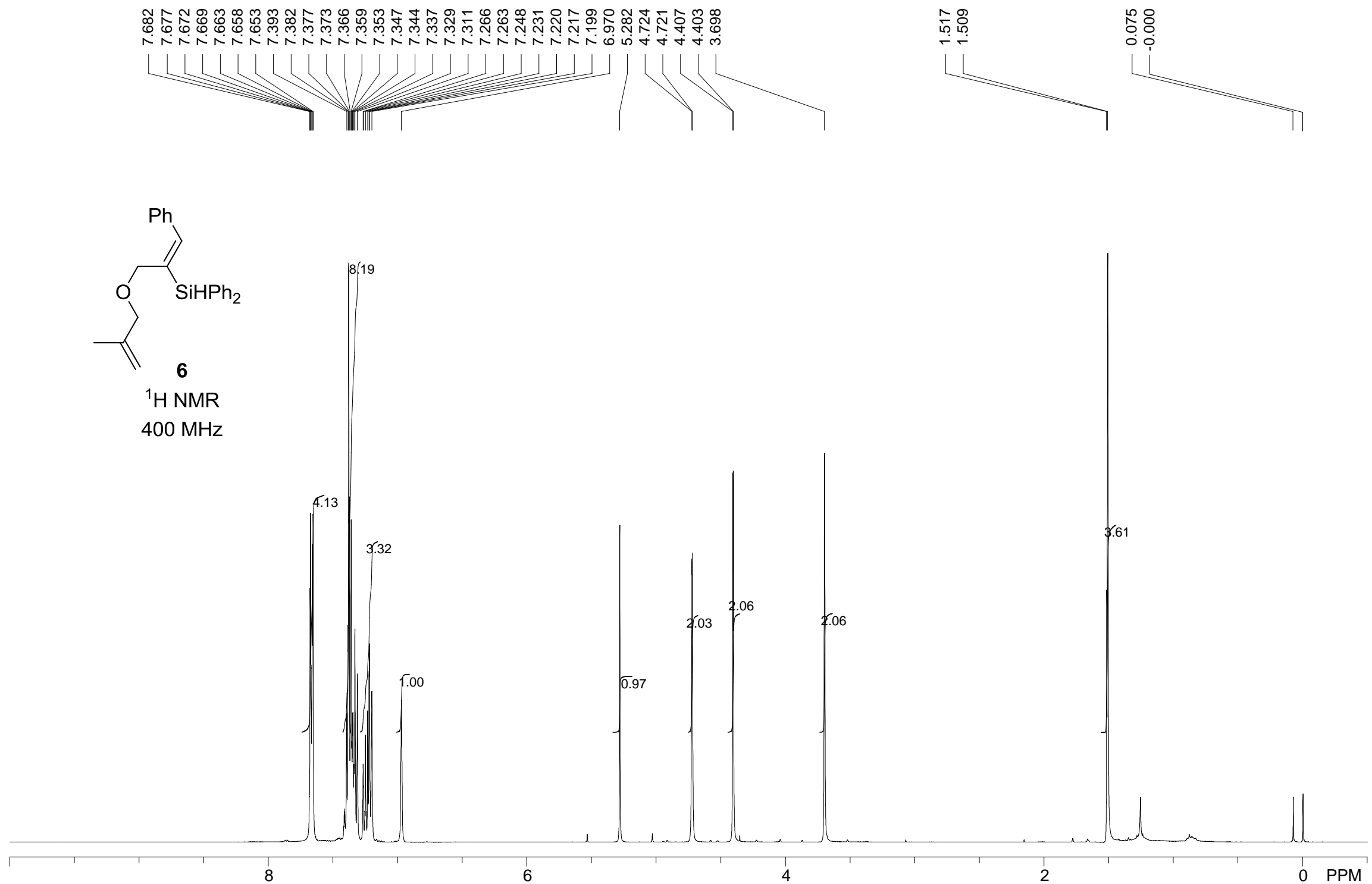


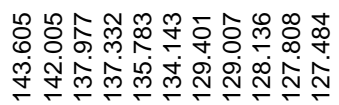
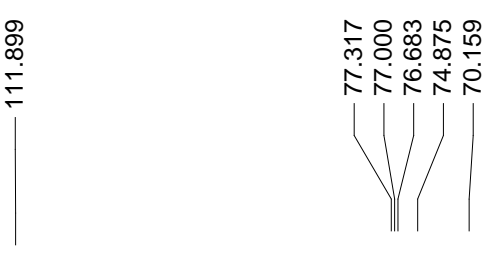

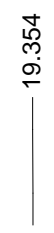

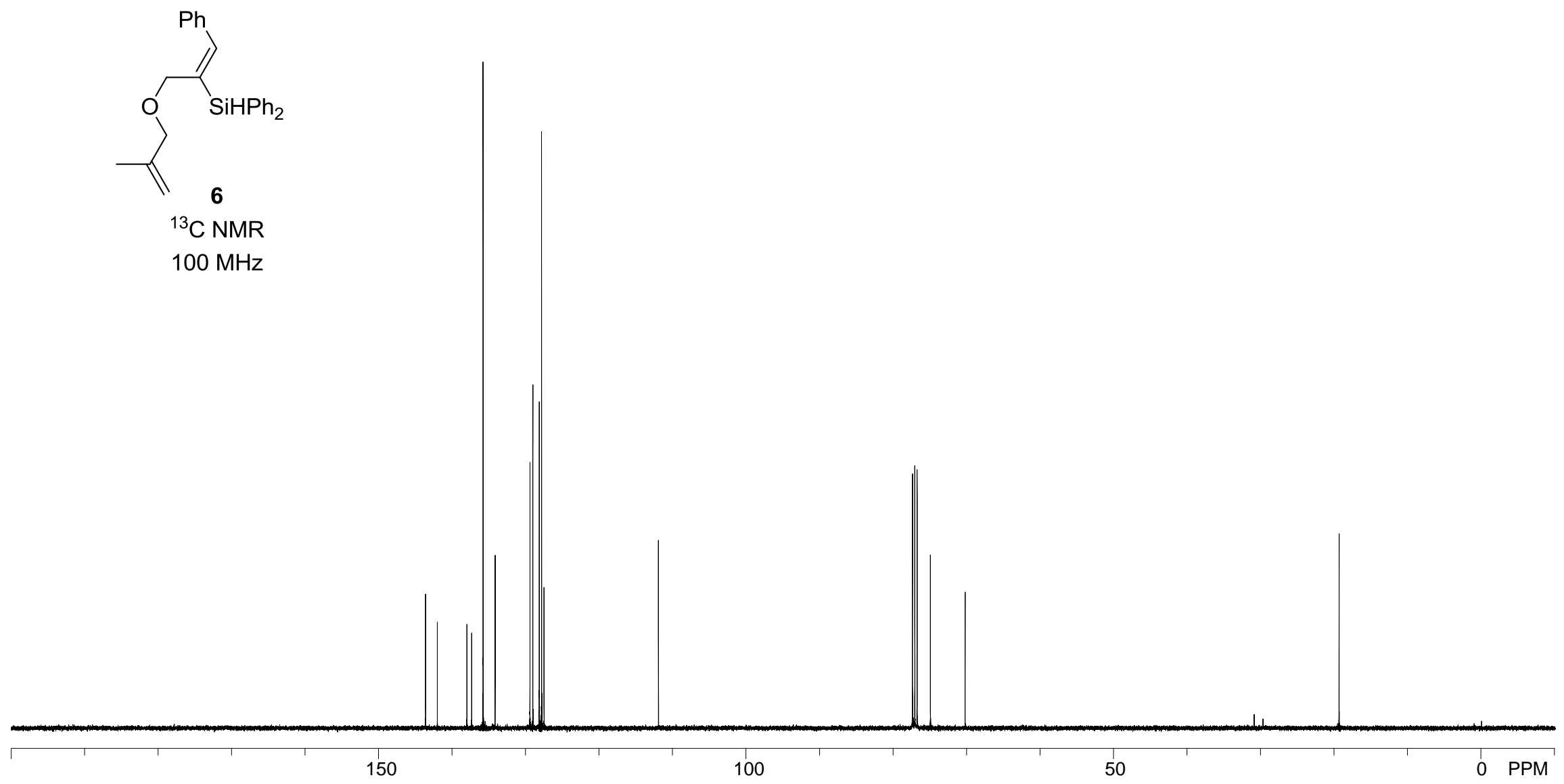

S63 


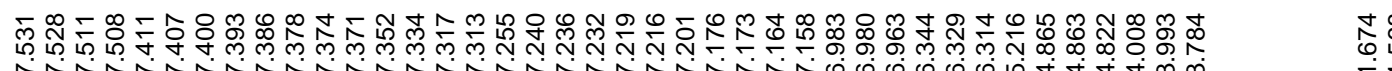

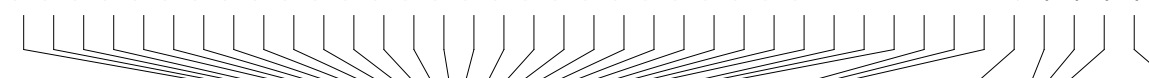

T IIII III

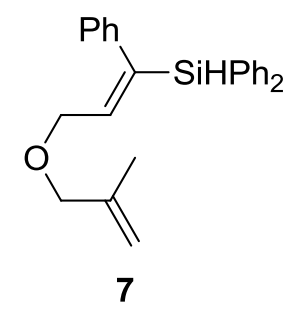

6.58

${ }^{1} \mathrm{H}$ NMR

$400 \mathrm{MHz}$

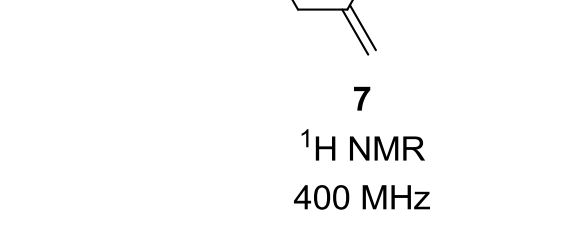

3.25

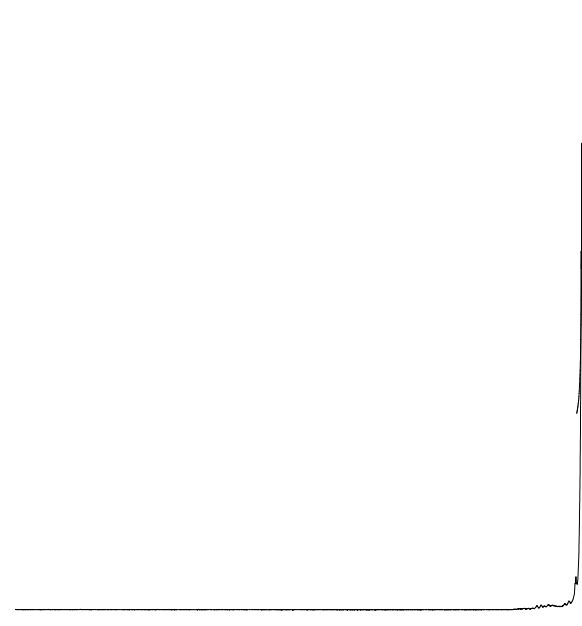

8

1.00

0.95

$2.17 \quad 2.03 .05$

M 

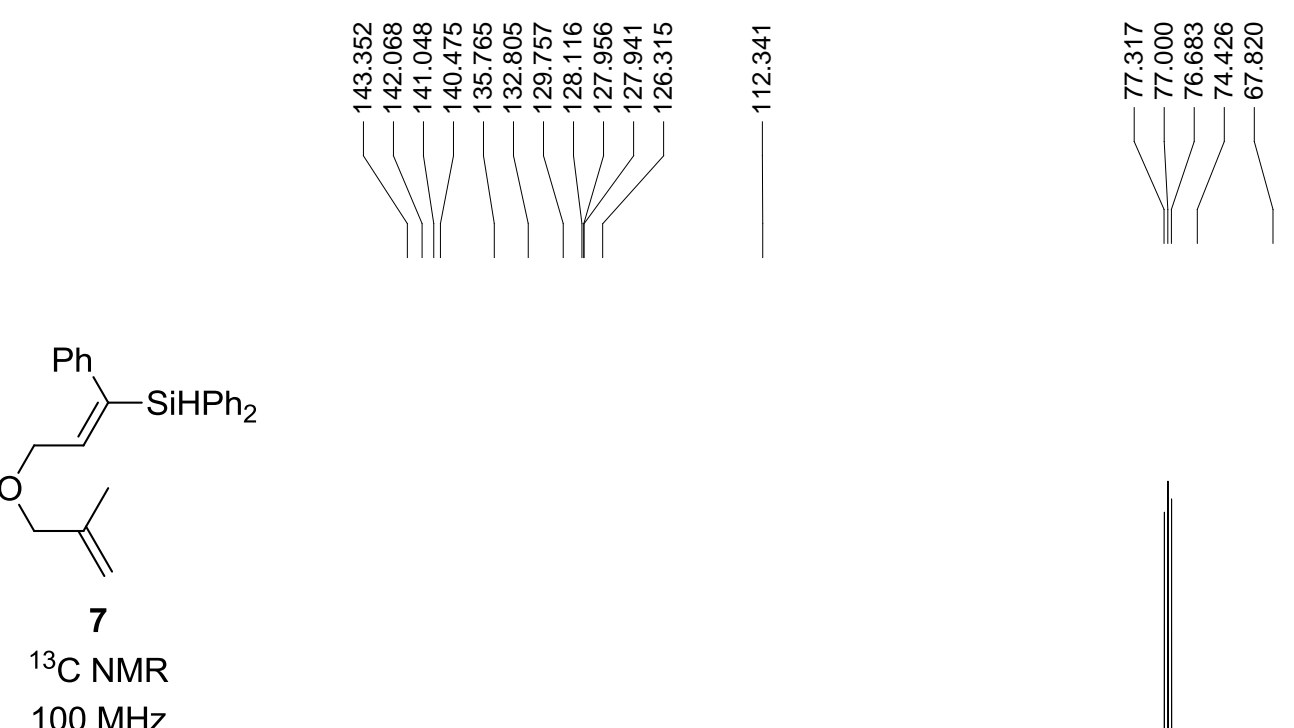

$100 \mathrm{MHz}$ 


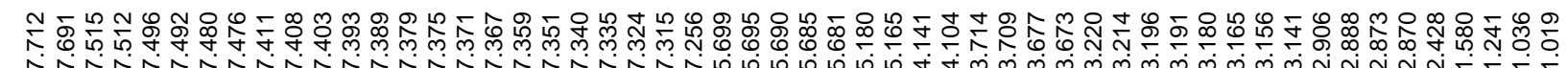
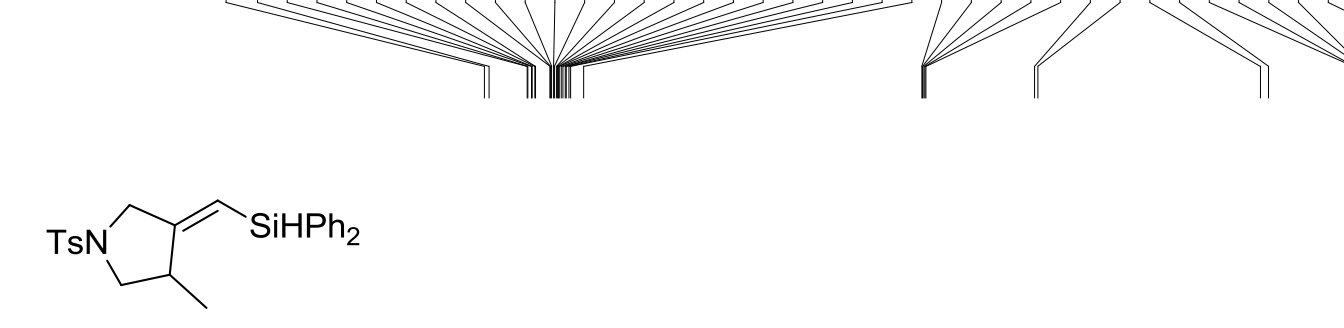

$3 \mathbf{u}$

${ }^{1} \mathrm{H}$ NMR

$400 \mathrm{~Hz}$

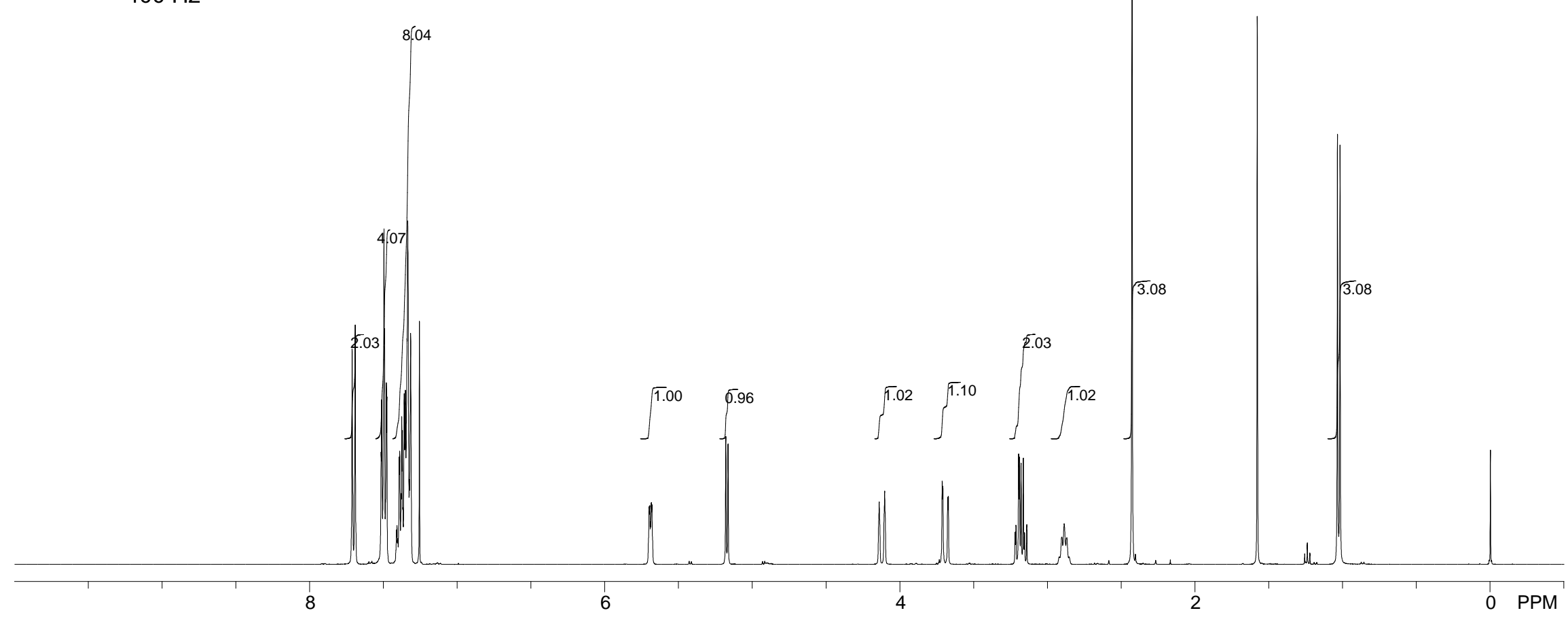




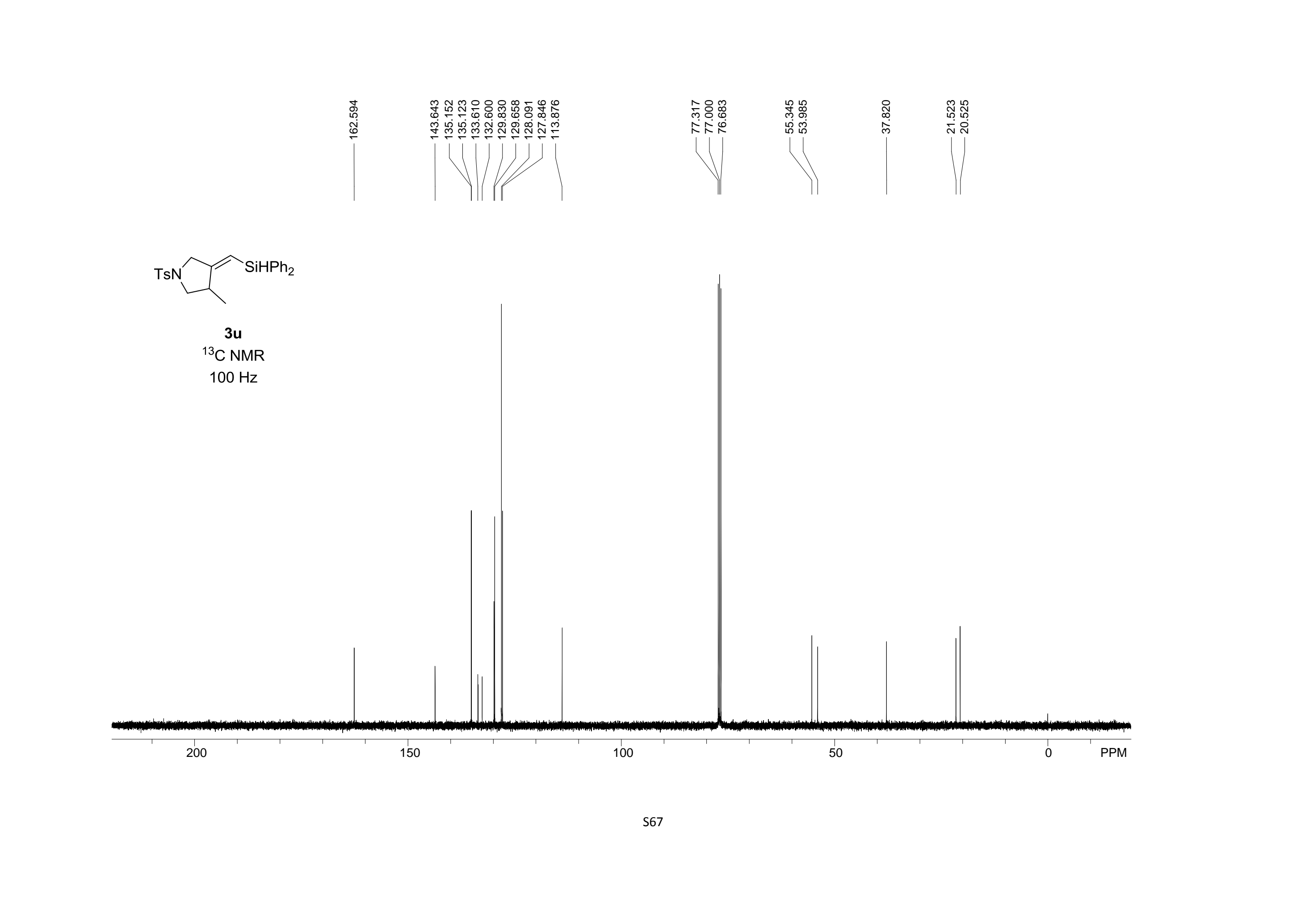




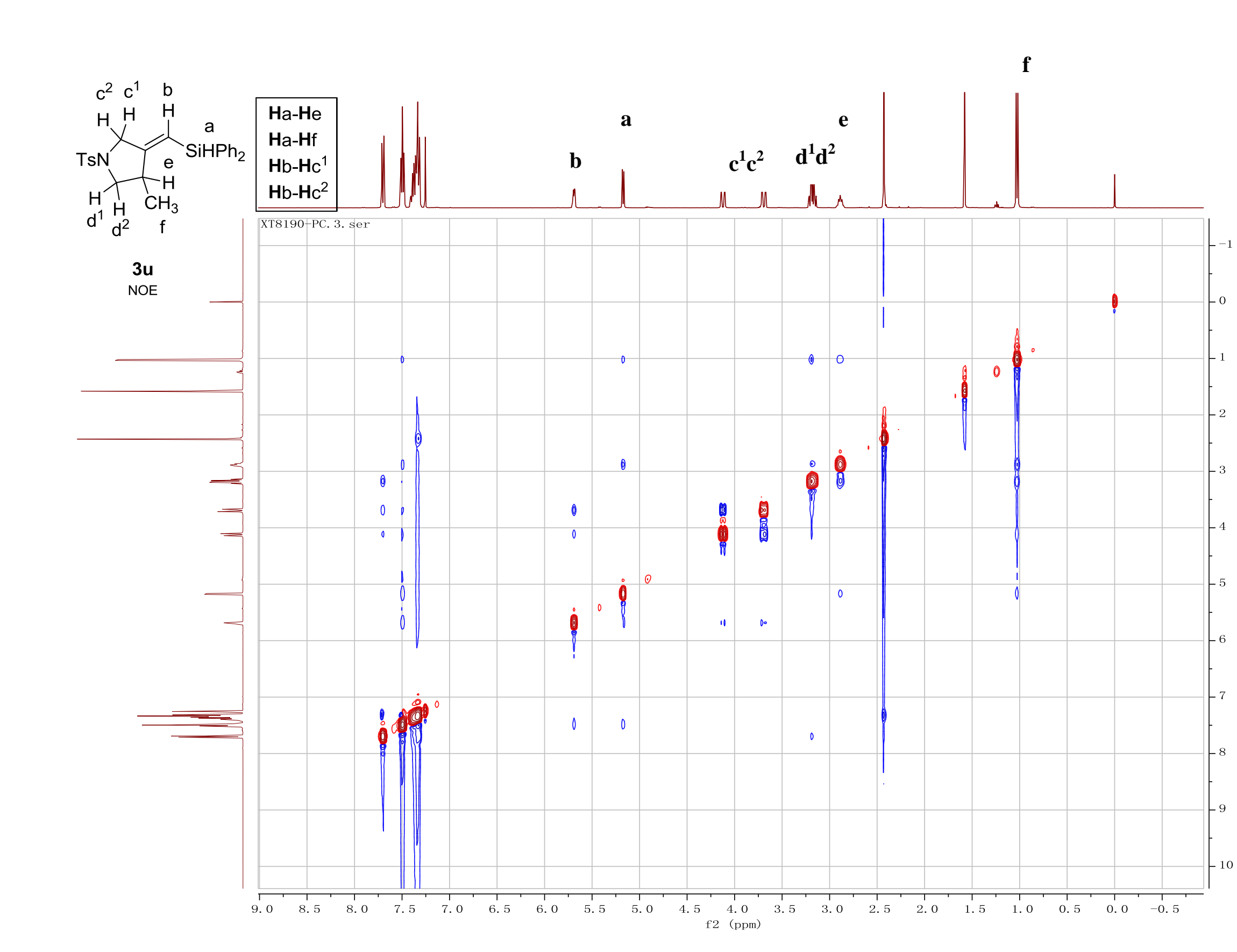




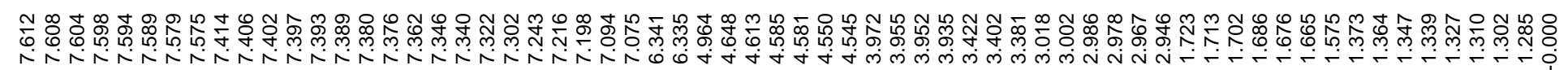

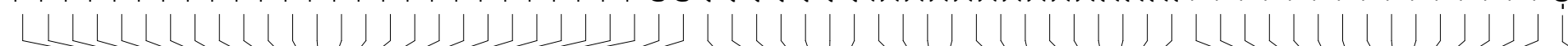

IIIIIII

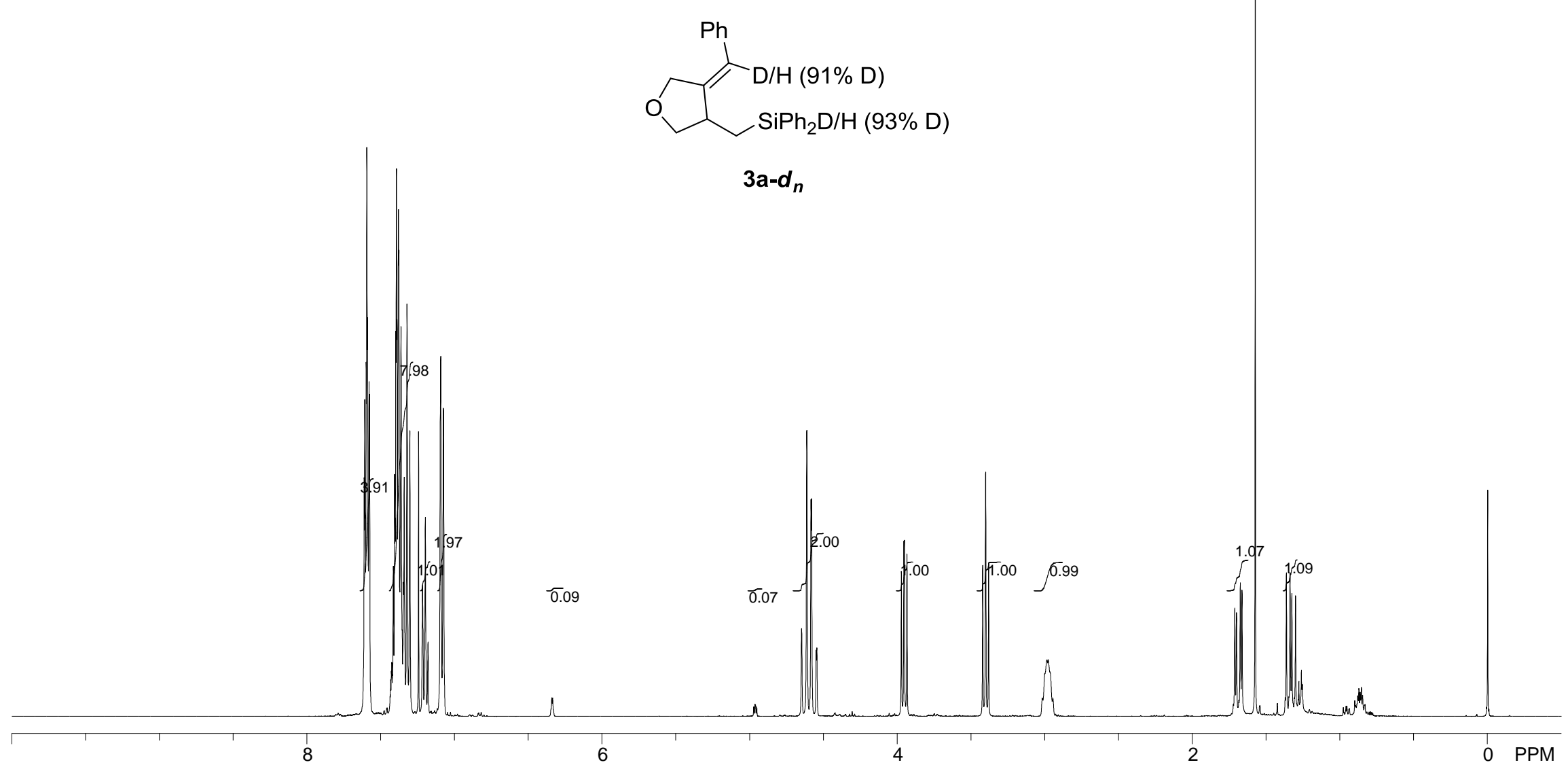

